Florida International University

FIU Digital Commons

FIU Electronic Theses and Dissertations

University Graduate School

$11-9-2018$

\title{
Rip Current Generation, Flow Characteristics and Implications for Beach Safety in South Florida
}

Stephen B. Leatherman

Florida International University, sleat003@fiu.edu

Follow this and additional works at: https://digitalcommons.fiu.edu/etd

Part of the Geomorphology Commons, and the Other Earth Sciences Commons

\section{Recommended Citation}

Leatherman, Stephen B., "Rip Current Generation, Flow Characteristics and Implications for Beach Safety in South Florida" (2018). FIU Electronic Theses and Dissertations. 3884.

https://digitalcommons.fiu.edu/etd/3884

This work is brought to you for free and open access by the University Graduate School at FIU Digital Commons. It has been accepted for inclusion in FIU Electronic Theses and Dissertations by an authorized administrator of FIU Digital Commons. For more information, please contact dcc@fiu.edu. 


\section{FLORIDA INTERNATIONAL UNIVERSITY}

Miami, Florida

\section{RIP CURRENT GENERATION, FLOW CHARACTERISTICS AND IMPLICATIONS \\ FOR BEACH SAFETY IN SOUTH FLORIDA}

A dissertation submitted in partial fulfilment of

the requirements for the degree of

DOCTOR OF PHILOSPHY

in

GEOSCIENCES

by

Stephen Beach Leatherman

2018 
To: Dean Michael R. Heithaus

College of Arts, Sciences and Education

This dissertation, written by Stephen Beach Leatherman, and entitled Rip Current Generation, Flow Characteristics and Implications for Beach Safety in South Florida, having been approved in respect to style and intellectual content, is referred to you for judgement.

We have read this dissertation and recommended that it be approved.

$\begin{array}{r}\text { Michael Sukop } \\ \hline \text { Shu-Ching Chen } \\ \hline \text { Dean Whitman, Co-Major Professor } \\ \hline \text { Keqi Zhang, Co-Major Professor }\end{array}$

Date of Defense: November 9, 2018

The dissertation of Stephen Beach Leatherman is approved.

Dean Michael R. Heithaus College of Arts, Sciences and Education

Andrés G. Gil Vice President for Research and Economic Development And Dean of the University Graduate School

Florida International University, 2018 
(C) Copyright 2018 by Stephen Beach Leatherman

All rights reserved. 


\section{ACKNOWLEDGMENTS}

This research was supported by a Florida International University Presidential Fellowship. Dr. Keqi Zhang and Dr. Dean Whitman, as my major professors, have provided guidance and support. Thanks to Dr. Stephen P. Leatherman, Dr. Klaus MeyerArendt, Dr. John Porter, Debora Leatherman and Andy Julca for field and laboratory assistance at various times during this study.

I would like to thank Chief Vincent Canosa of the Miami Beach lifeguards and Lt. Matthew Sparling of Haulover Park for their help in recording surf conditions. I would also like to thank Robert Molleda of the National Weather Service Miami Forecast Office and Scott Strippling, marine forecaster at the National Hurricane Center for their guidance. 


\title{
ABSTRACT OF THE DISSERTATION \\ RIP CURRENT GENERATION, FLOW CHARACTERISTICS AND \\ IMPLICATIONS FOR BEACH SAFETY IN SOUTH FLORIDA
}

by

\author{
Stephen Beach Leatherman \\ Florida International University, 2018 \\ Miami, Florida \\ Professor Keqi Zhang, Co-Major Professor \\ Professor Dean Whitman, Co-Major Professor
}

Rip currents are the most dangerous hazard at surf beaches. Rip currents in South Florida have previously not been studied. Beach profiles for three Florida beaches (Miami Beach, Lido Beach, Sarasota, and Pensacola Beach) and one Georgia beach (South Cumberland Island) were chosen for surveying because of their variable sand bar heights. Rip current hazard at each beach was assessed by lifeguard rip rescue and drowning statistics. A relationship was found between sand bar height, beach slope and rip current hazard.

Rip current measurements in South Florida, which involved utilizing GPS drifters, laser rangefinder and drone-imaged fluorescent tracer dye, showed that the speed ranged from $0.1-0.5 \mathrm{~m} / \mathrm{s}$, which is fairly slow compared to such measurements undertaken in California and Australia. The effect of rip currents on swimmers was analyzed based on the drag force acting on swimmers and the power they generate to overcome the currents when swimming against them. The drag force and power increase quadratically and 
cubically, respectively, with the increase of rip current and swimming speeds. Hence, even rip currents of low velocity can be dangerous and swimming against the current should be avoided if possible.

Strong rips in California have been shown to exhibit a circulatory pattern, which could bring a floater back to the safety of a shallow sand bar. Field measurements of rip currents in South Florida clearly defined the flow characteristics of a nearly straight-line current, sometimes deflected to the east-southeast. Therefore, the traditional approach of swimming left or right, parallel to the shore is the best escape strategy, but not against the longshore current if present. A logistic regression analysis was conducted to predict the occurrence of rip currents based on beach conditions. The logistic model showed that wave height, wave period and wind speed were statistically significant factors in rip generation. Rips were found to be most commonly generated by relatively small, nonthreatening waves (e.g., 0.6 to $0.9 \mathrm{~m}$ in height). These physical factors, along with social and safety considerations, pose a significant problem for coastal management. 
TABLE OF CONTENTS

CHAPTER

PAGE

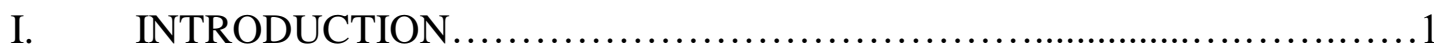

II. RIP CURRENTS IN SOUTH FLORIDA: A MAJOR WATER HAZARD AND MANAGEMENT CHALLENGE ...................................12

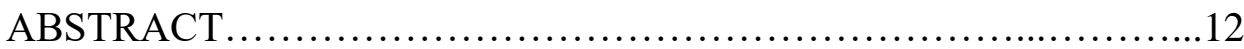

INTRODUCTION .................................................

BEACH CONDITIONS FOR RIP CURRENT DROWNING ...........15

PUBLIC SAFETY AND MANAGEMENT CHALLENGE.............16

CONCLUSIONS ..................................................18

III. RIP CURRENT HAZARD ON FLORIDA AND SOUTH GEORGIA

BEACHES ........................................................ 19

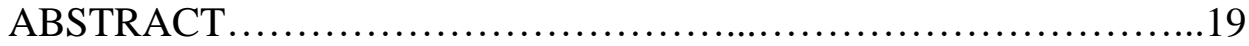

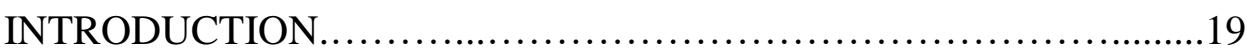

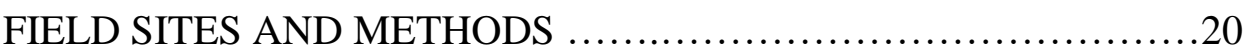

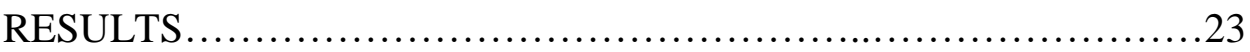

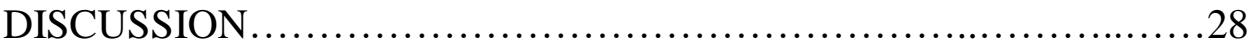

CONCLUSIONS ................................................ 30

IV. TECHNIQUES FOR MEASURING RIP CURRENTS ...................... 31

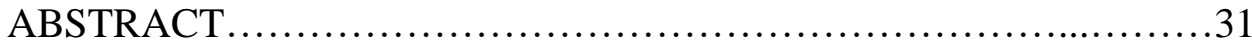

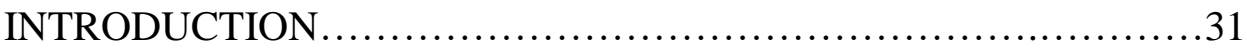

METHODS ....................................................... 33

Laser Rangefinder................................................

Drone Imaging of Tracer Dye................................... 35

Drone Particle Image Velocimetry...................................37

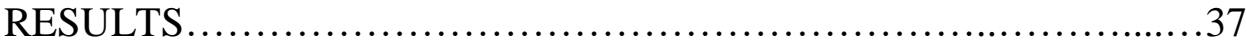

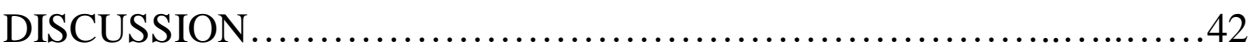

CONCLUSIONS ...............................................44

V. RIP CURRENT MEASUREMENTS AT THREE SOUTH FLORIDA

BEACHES .......................................................45

ABSTRACT ................................................... 45

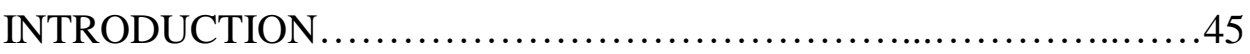

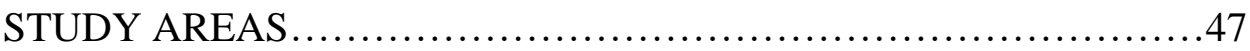

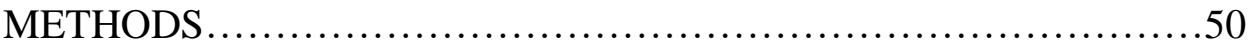

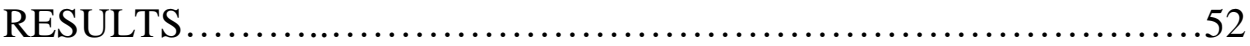

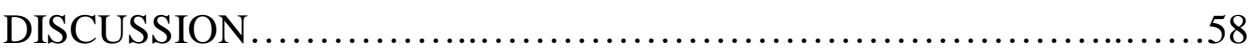

CONCLUSIONS .................................................61 
VI. RIP CURRENT FLOW CHARACTERISTICS AND HAZARDS FOR BEACHGOERS ......................................................62

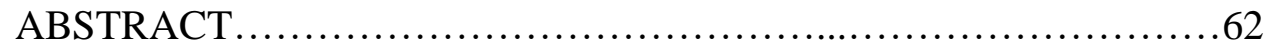

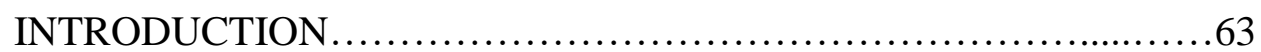

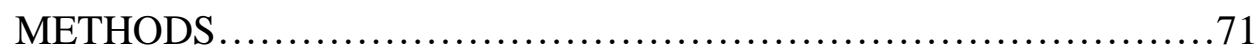

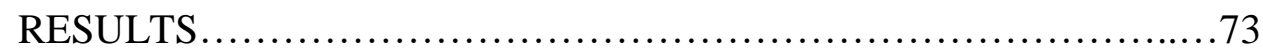

DISCUSSION ........................................................ 86

CONCLUSIONS ................................................. 90

VII. RIP CURRENT GENERATION AND MANAGEMENT IMPLICATIONS IN SOUTH FLORIDA .............................................. 92

ABSTRACT ............................................................. 92

INTRODUCTION ................................................ 92

RIP GENERATION ............................................... 94

RIP FORECASTING ............................................97

MANAGEMENT IMPLICATIONS ................................... 108

DISCUSSION .................................................

CONCLUSIONS ..............................................112

VIII. CONCLUSIONS ..............................................113

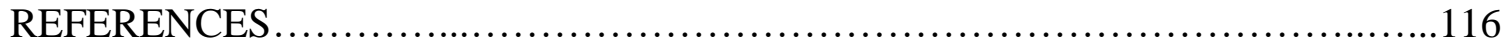

APPENDIX ............................................................. 126

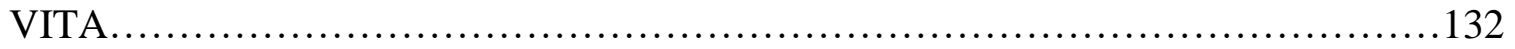




\section{LIST OF TABLES}

\section{TABLE}

PAGE

2-1. Field measurements of beach conditions during rip current events in South Florida

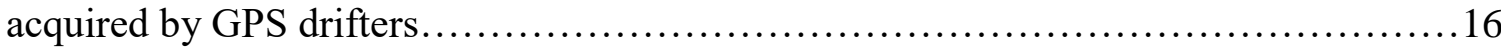

3-1. Visitation numbers and rip rescues by beach...............................27

4-1. Rip current speed measurements taken with the laser rangefinder on July 18, 2016

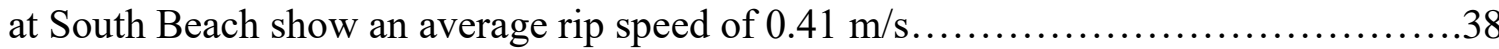

4-2. The laser rangefinder in conjunction with the compass allow for measuring a nonlinear rip path with an accuracy of $0.1 \mathrm{~m}$

5-1. Four GPS drifter deployments were undertaken at South Beach on March 23, 2016 , which had an average rip speed of $0.3 \mathrm{~m} / \mathrm{sec}$

5-2. Five GPS drifter deployments were carried out on April 10, 2016 at South Beach; average rip speed was $0.4 \mathrm{~m} / \mathrm{s}$

5-3. Three drifter deployments were undertaken on July 18, 2016 at South Beach......55

5-4. Three GPS drifter deployments at Haulover Park Jetty on April 6, 2016 indicated an average rip speed of $0.2 \mathrm{~m} / \mathrm{sec}$. The distance is measured in a northward direction along the breakwater, which is perpendicular to the jetty.

5-5. Five GPS drifter deployments at Haulover Park Jetty on June 20, 2016 indicated an average rip speed of $0.2 \mathrm{~m} / \mathrm{s}$. The distance is measured in a northward direction along the breakwater, which is perpendicular to the jetty.............................57

6-1. Parameters for the calculation of drag force $\left(f_{d}\right)$ and power $\left(P_{s}\right)$. The values of $\mathrm{e}_{\mathrm{p}}$ and $\mathrm{e}_{\mathrm{g}}$ were taken from Table 1 in Toussaint and Beek (1992).......................76

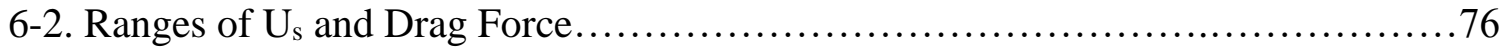

6-3. The rip hazard category based on increased power generated by an average swimmer of speed $1 \mathrm{~m} / \mathrm{s}$ to overcome the drag force by swimming against rip currents.

6-4. Rip current measurements at South Beach and rip hazard assessed for a $1 \mathrm{~m} / \mathrm{s}$ swimmer. Note that all measurements were taken at or near low tide... 
7-1 Deadliest beach areas in the United States (Paxton, 2014)....

7-2 Rip current presence at Miami Beach and Haulover Park Beach from lifeguard observations during January to June 30, 2016 are compared to the National Weather Service (NWS) high risk days during this time period.

7-3 Field deployments for rip presence by the research team (Leatherman, 2017) are compared to lifeguard observations and the National Weather Service rip forecast.......98

7-4. Rip current presence by location....................................98

7-5. Rip current presence by month....................................... 99

7-6. Rip current presence by wind speed.................................. 100

7-7. Rip current presence by wave height.................................. 100

7-8. The summary of missing data by variable for both locations......................... 102

7-9. The initial logistic regression results................................. 104

7-10. The reconstructed logistic regression model with the four optimal features.......105

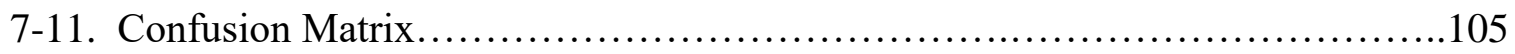

7-12. Classification Report.............................................. 106

7-13. Physical, safety and social factors that have important implications for management at Miami Beach............................................... 108 


\section{LIST OF FIGURES}

FIGURE

PAGE

1-1. Weather and marine deaths averaged from 1994 to 2003 from the National Weather Service. Rip currents are responsible for more deaths than floods, tornados, lightning, and hurricanes. (Retrieved from ripcurrents.com/watertracer, 2013)..........1

1-2. Bar-gap rip currents are diagrammatically illustrated. Adapted from Shepard (1936). 3

1-3. A powerful rip current in Malibu, California. The arrow represents the neck of the current, and a bather is circled. (Photo from Los Angeles County Coastal Monitoring Network, 2002).

1-4. Rip currents with a circulatory pattern are shown in California (Photo courtesy of

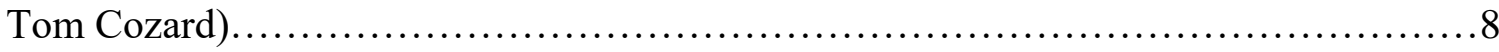

1-5. A very large rip current is shown at Huntington Beach, California; the pier is 580 meters in length (courtesy of Huntington Beach Lifeguards) ....................... 10

2-1. A “clear-water" rip current at Miami Beach, Florida as delineated by red fluorescent tracer dye.

2-2. Rip current drowning in continental United States from 1994 to 2012 (Paxton, 2014), not including the Great Lakes that average about 10 rip fatalities per year (www.Cleveland.com, June 16, 2016)....

3-1. South Cumberland Island, Georgia has a very flat beach profile and is characterized by low wave energy and a large tidal range.

3-2. Pensacola Beach, Florida, has a fairly steep foreshore beach profile and a cuspateshaped shoreline

3-3. Pensacola Beach has a large sand bar at $40 \mathrm{~m}$ with a sand bar height of $0.9 \mathrm{~m}$ relative to the channel depth (see vertical arrow) ....................................

3-4. Miami Beach has a medium-sized bar at $30 \mathrm{~m}$ with a height of $0.6 \mathrm{~m}$ relative to

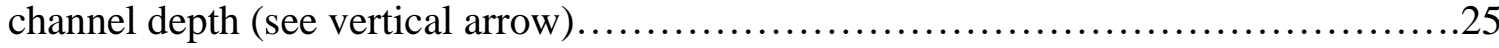

3-5. Lido Beach has a small bar located at $39 \mathrm{~m}$ with a height of $0.35 \mathrm{~m}$ relative to the

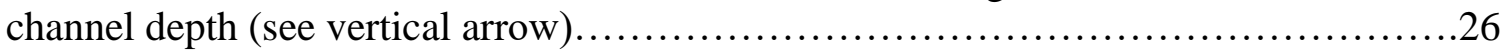

3-6. Cumberland Island has a very small bar at $105 \mathrm{~m}$ with a height of $0.25 \mathrm{~m}$ with no rip channel present (see arrow). 
4-1. The Nikon Prostaff 7 Laser Rangefinder and Steren Electronics compass are mounted on a photographic tripod to measure the speed and path of a rip current. The speed is measured by calculating the distance with the laser rangefinder of a floating object moving inside the rip current over time. The compass is used to determine the angle of the rip path in order to correct the distance measurements for a non-linear rip current path.

4-2. The DJI Phantom 3 Advanced Quadcopter is being prepared for take-off. This drone provides an aerial view of rip currents delineated by tracer dye, allowing for analysis of the rip path with implications for escape methods....

4-3. The Calculated Leg Distance (CLD) is determined using the law of cosines with the known sides of the triangle Laser Rangefinder Distance 1 (LFD1) and Laser Rangefinder Distance 2 (LFD2), and the known Referenced Angle (AR)...

4-4. A weak rip current is delineated by fluorescein tracer dye and imaged by a DJI Phantom 3 Advanced Quadcopter at South Beach on January 12, 2017. This South Florida rip current shows a relatively straight path.

4-5. Particle image velocimetry applied to drone video shows relative rip current velocity on the North Shore of Oahu, Hawaii. The red arrow vectors indicate the direction and magnitude of the current. A visible rip current that is flowing seaward is present on the right side of the image.

5-1. Location of three study areas in South Florida: A is Ocean Reef Park in Palm Beach County; B is Haulover Park and C is Miami Beach both in Miami-Dade County.

5-2. The breakwater at Haulover Inlet jetty is a popular spot for families to bathe....

5-3. The GPS drifter is constructed out of a PVC body with a Garmin E Trek H GPS attached on top.

5-4. Rip current paths as determined by GPS drifters on April 10, 2016 at $10^{\text {th }}$ Street in South Beach. The rip current was angled southeast because of the longshore current. The rip was not detected at the shoreline, but instead tens of meters offshore in waistdeep water....

5-5. The freeze-frame from the quadcopter video shows the rip current at Ocean Reef Park as delineated by fluorescent dye; the rip is angled east-southeast as controlled by the rock outcrop. 
6-1. A family prepares to enter the water at the location of a bar-gap rip current on the Outer Banks of North Carolina (Photo courtesy of David Elder). This "clear-water" rip is deceptively dangerous as the lack of breaking waves appears as an inviting place to swim.

6-2. Rip current deaths in the United States from 2014 to 2017 (Paxton, 2014).

6-3. A Florida panhandle rip current has an arcuate shape due to a strong longshore current (Photo courtesy of Choule Sonu, 1972).

6-4. Rip currents with a circulatory pattern are shown at Newport Beach, California (Photo courtesy of Tom Cozard)

6-5. The three study areas are shown: Ocean Reef Park, Haulover Park and Miami

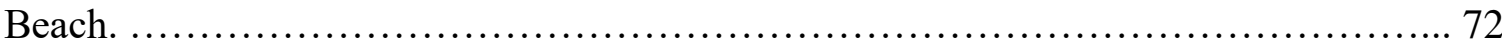

6-6. Diagram of the forces acting on a swimmer modified from the Physics of Swimming (https://www.real-world-physics-problems.com/physics-of-swimming.html).

6-7. (a) The relationship between head rip current speeds, swimming speeds and drag forces. (b) The relationship between head rip current speeds and drag forces with various swimming speeds. (c) The relationship between swimming speeds and drag forces with various head rip current speeds.

6-8. (a) The relationship between the head rip current speed, swimming speed and power. (b) The relationship between the head rip current speed and power with various swimming speeds. (c) The relationship between the swimming speed and power with various head rip current speeds.

6-9. The zones of low, intermediate, high, and extreme hazards based on rip current speeds. The relative power increment parameter $\mathrm{p}$ was calculated using Equation 10 .

6-10. A weak rip current at South Beach, Florida is marked with fluorescent dye.

6-11. A freeze-frame from the quadcopter video shows fluorescent dye moving around the jetty and toward the strong tidal current at Haulover Inlet on April 6, 2016. The arrows represent the rip current flow path....

6-12. A freeze-frame from the quadcopter video of fluorescent dye at Ocean Reef Park, Palm Beach County shows that the rip current is fairly linear and terminates at the surf zone on April 27, 2016 
6-13. The flip, float, and follow method of rip escape is now being shown on signage

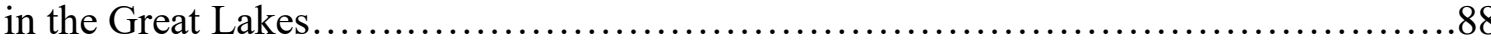

6-14. The traditional rip escape method of swimming parallel to the shore..............89

7-1. A Bermuda high pressure cell on April 10, 2016, off the mid-Atlantic coast resulted in a pressure difference of $4 \mathrm{mb}$ between the Florida Keys and Jacksonville, which generated a 15-20 knot East wind ............................................ 95

7-2. This nor'easter on October 30, 1991 off the mid-Atlantic coast generated large

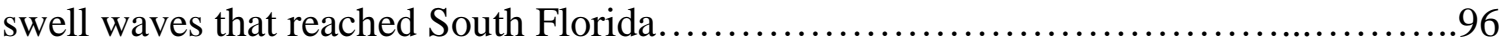

7-3. A heatmap of features shows wave height (height) corresponds well with rip presence (rip1)

7-4. The RFE cross-validation model shows the first four features are optimal. 104

7-5. The receiver operating characteristic shows that the reconstructed logistic regression model is located near the top left corner of the chart, which represents that the model is accurate for the true positive rate....................................... 107

7-6. Beachgoers at Haeundae Beach in Busan, South Korea are prohibited from entering the water at the location of a rip current. 


\section{INTRODUCTION}

Rip currents account for approximately 100 drownings in the United States annually and probably more than 500 globally (Brander and MacMahan, 2011). These seawardflowing currents are deceptively dangerous as they are often seen as calm water between breaking waves, offering an inviting place to swim. Rip currents receive far less attention than other coastal hazards because they do not result in economic losses to property and relatively few people are impacted at any one time or location. In fact, rip current drownings are rarely reported in the national news, and many people know little about their dangers (Fallon, 2017), yet they are responsible for more deaths annually on average than tornadoes, sharks, hurricanes and lightning strikes (Figure1-1).

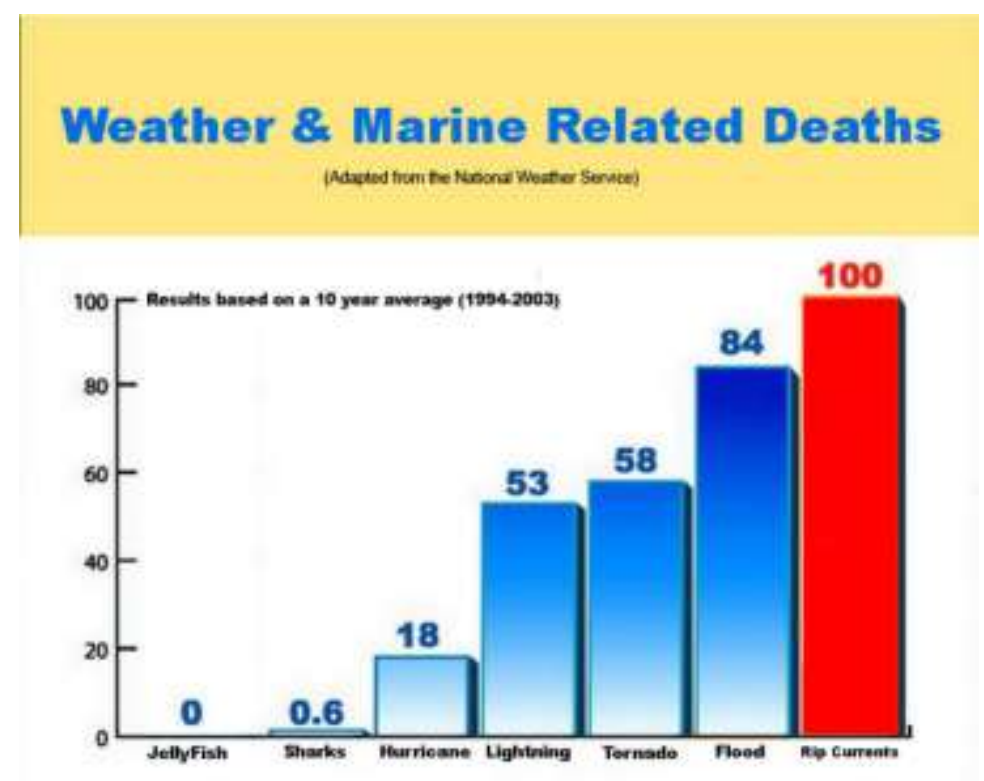

1-1. Weather and marine deaths averaged from 1994 to 2003 from the National Weather Service. Rip currents are responsible for more deaths than floods, tornados, lightning, and hurricanes. (Retrieved from ripcurrents.com/watertracer, 2013).

Beaches are the number one recreational destination for Americans, and there are more than two billion beach visits per year (Houston, 2013). The United States public is 
primarily educated about rip currents on site via beach hazard flags, where lifeguards post current beach conditions by using different colored flags to represent danger. Many visitors from inland areas lack experience and knowledge of the ocean, and international tourists may not be able to read beach warning signs or understand the hazard flag system. This lack of understanding of rip current hazards and techniques for escaping from rip currents contributes to the high annual death toll of rip currents.

Another way for beachgoers to learn about beach conditions and hazards is through local TV news, weather channels and the internet. The National Weather Service (NWS) provides rip current forecasts for regional areas. In Florida, these regions are Miami, Melbourne, Jacksonville, Tallahassee and Tampa. NWS forecasts are based on a predictive model of rip currents developed by Lushine (1991, 2011). This deterministic model accounts for wind speed and direction, wave height, and tide level. Lascody (1998) modified the original model to include swell waves generated by offshore storms which has been utilized by Schrader (2004) and Engle (2003) at Daytona Beach, Florida. These long-period waves are likely responsible for the strongest and most dangerous rip currents. The National Weather Service forecast is for low, moderate, or high risk of rip currents on a regional basis.

Rip currents have been an increasing topic for scientific study in the past two decades because of awareness of the danger to beachgoers. Experiments have been conducted in California (Smith and Largier, 1995; MacMahan et al., 2004; MacMahan et al., 2011), Denmark (Agaard et al., 1997), Australia (Brander and Short, 2000; Brander and Short, 2001; Callaghan et al., 2004), New Zealand (Brander, 1999), the Florida 
Panhandle (Sonu, 1972; Houser et al., 2013) and elsewhere. However, there have not been any previous rip current field studies in South Florida.

The driving force of rip currents is longshore variation in wave height (Haller et al., 2002; Dalrymple, 1975). This is typically caused by variations in the refraction and diffraction of waves due to sand bars. Bathymetric depressions will also cause wave refraction, resulting in waves with varying heights alongshore (Shepard and Inman, 1950). When waves break and swash is pushed up on the beach face, the backwash is concentrated in some areas. Topographic depressions or gaps in the sand bar can form when this concentrated backwash flows offshore. The resulting seaward-flowing current is called a bar-gap rip (Figure 1-2). In other cases, pre-existing bathymetric irregularity and rock formations serve to funnel the offshore-flowing current as a rip.

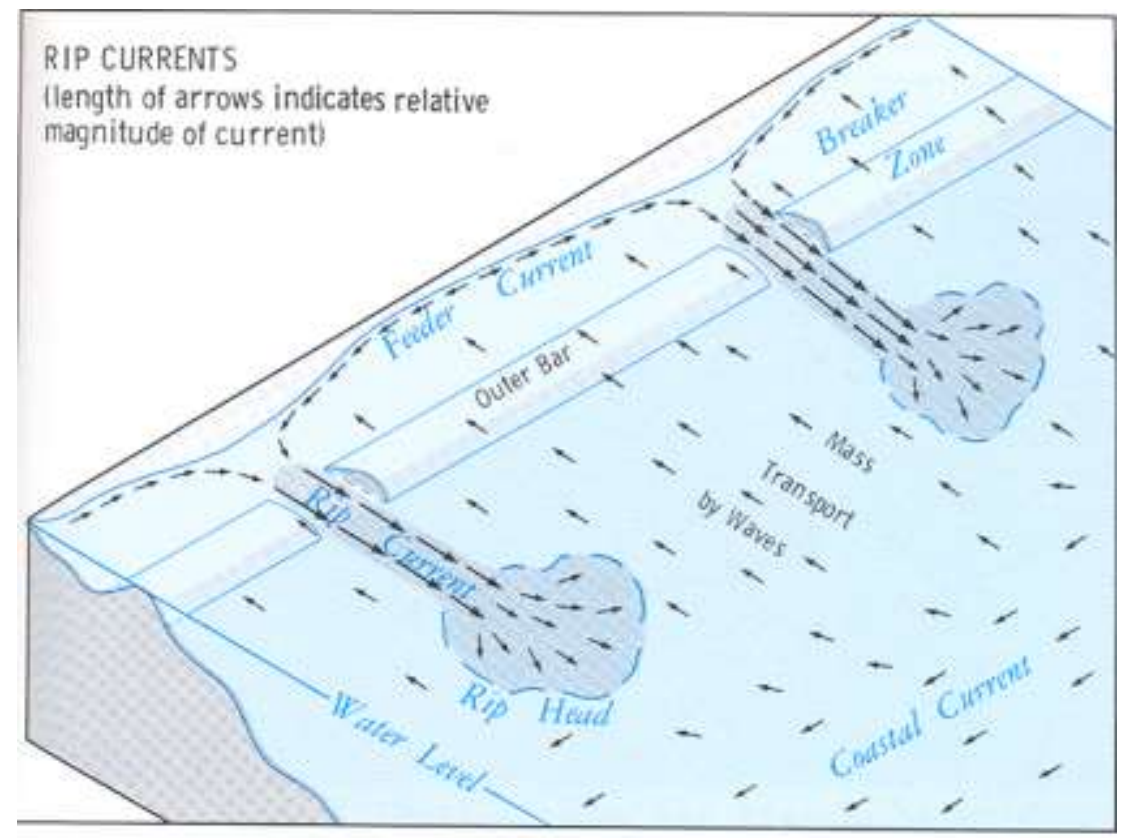

1-2. Bar-gap rip currents are diagrammatically illustrated. Adapted from Shepard (1936). 
Rip currents are typically characterized as mushroom-shaped in plan view (Figures 1-2 and1-3), but are not always visible to beachgoers. The strong offshoreflowing current in Malibu, California is visible because of suspended sediment. Feeder currents are sometimes found on either side of the rip near the shore and will flow into the current (Figure 1-2). The "neck" of the current is the concentrated backwash flowing offshore past the sand bar, and the "head" of the current is the dispersion of the water after traveling past the bar where the flow is not constricted. Rip mean velocity typically ranges from 0.3 to 0.8 meters per second with maximum velocities measured at 2 meters per second (Brander and McMahan, 2011; MacMahan et al., 2005).

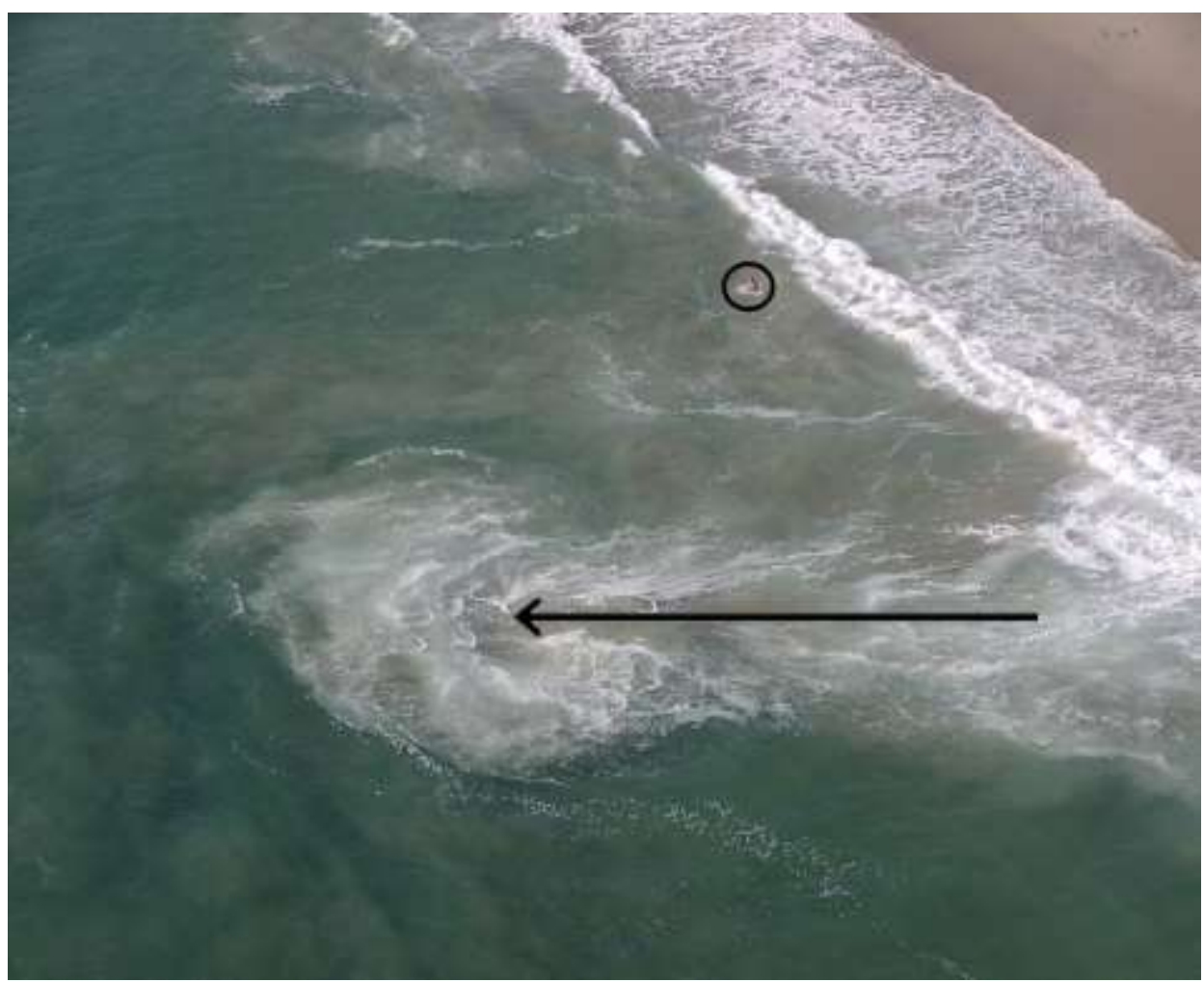

1-3. A powerful rip current in Malibu, California. The arrow represents the neck of the current, and a bather is circled. (Photo from Los Angeles County Coastal Monitoring Network, 2002). 
Wave height is the most important factor in the strength of rip currents as the energy of a wave is proportional to the wave height squared (Bowen, 1969). Higher waves increase rip current intensity (Dusek and Siem, 2013). Offshore storms will usually produce the strongest rip currents due to larger swell (Davis and Paxton, 2005). Long period, shore-normal waves produce the ideal conditions for generating rip currents. The long period of the waves will limit disturbance of the rip's seaward flow from on-coming waves. Wave breaker type can also affect rip currents--plunging as compared to spilling breakers create a stronger uprush and backwash and hence stronger rips. Spilling breakers are gradually dissipated and therefore usually generate weaker rips.

Beaches are typically classified as having low, moderate or high wave energy environments. The classifications for these environments vary greatly in the literature (Jackson et al., 2002). For the purposes of this research, low wave energy environments will be defined as beaches with significant wave heights of under 1m, moderate energy environments between $1-1.5 \mathrm{~m}$, and high energy environments as $1.5 \mathrm{~m}$ and higher.

This dissertation consists of multiple rip current studies conducted at several locations. The goal of this dissertation is to learn about the generation and characteristics of rip currents in South Florida and their impact on beach safety. The role of the sandbar on rip current presence and strength was studied on three geographically-dispersed beaches in Florida (Miami in Southeast Florida, Lido in Southwest Florida and Pensacola in the Florida Panhandle) and one in South Georgia (South Cumberland Island). These locations were chosen as the study areas due to their variability in bar heights. Rip current measurements were conducted at three South Florida beaches: Miami Beach, Haulover 
Park, and Ocean Reef Park. At two of these locations, Miami Beach and Haulover Park, lifeguards observations of beach conditions and rip current presence were recorded for a six month period to understand rip generation.

Chapter 2 examines the unique hazards of rip currents in South Florida through a case study of the deaths of two prominent rabbis. The first field measurements of rip currents in South Florida showed that these offshore-flowing currents are fairly weak as generated by moderate-sized waves during fair-weather conditions, but are still a major water hazard. Miami Beach is world famous, but unfortunately this area has a large number of drownings, partly because the rips here are nearly invisible. These ongoing tragedies were recently highlighted by the loss of two prominent rabbis that point to the misconceptions and lack of understanding of nearshore currents even by highly-educated people.

Chapter 3 examines the role of sand bar height on rip current presence and strength. Field observations have shown that rip currents are generally strongest during low tide (Sonu, 1972; Brander and Short, 2000; Aagaard et al., 1997; McCaroll et al., 2014). As the water level drops, sand bars become higher relative to the water level, restricting the wave backwash to flow seaward through a depression in the sand bar (Dean and Thieke, 2011). This chapter investigates the relationship between bar height, tidal level and rip presence and strength through wave tank experiments. In one set of experiments, bar height was constant while the water level was varied to simulate a changing tide. In another set, water level remained constant, and bar height was varied. In both cases, three wave energies were utilized to simulate low, moderate, and high 
wave conditions. The goal of the research in this chapter was to determine the role of bar height and tide level in rip current presence and strength.

In Chapter 4, techniques for measuring rip currents are discussed. There are a number of different techniques to measure the speed and offshore extent of rip currents, but the best ones generally require sophisticated equipment and a boat to retrieve GPScontrolled drifters. A new, simple and inexpensive method involves using a laser rangefinder at the beach to trace the current; measurements of speed will be the most accurate for rips moving in a straight path (e.g., not significantly deflected by a longshore current). The offshore terminus (e.g., seaward extent) of the rip current can also be determined for a distance of $100+$ meters. Another new technique is to aerial image fluorescein tracer dye in a rip current via a drone (e.g., quadcopter) and calculate the speed using a ground reference. Lastly, a new particle image velocimetry (PIV) technique is discussed that allows rip current velocity measurements from aerial drone video footage. This technique tracks motion through sequential frames from the drone video and outputs current vectors.

Chapter 5 shows the results of the first field measurements of rip currents in South Florida. Rip current characteristics, especially rip speed, path and offshore extent are essential in understanding the greatest hazard at surf beaches. Non-differential GPS surfzone drifters were used to determine rip characteristics in South Florida. GPS drifters were deployed at South Beach and Haulover Park, Florida during periods of rip current activity in order to characterize these offshore-flowing currents.

Chapter 6 quantifies rip current hazard, examines rip current flow characteristics and attempts to determine the best method for escaping rip currents in South Florida. The 
effect of rip currents on swimmers was analyzed based on the drag force acting on swimmers and the power they generate to overcome the currents when swimming against them. A rip current hazard rating was developed based on low, moderate, high and extreme rip current speed categories, with the goal of educating the public of the hazardous effect of rip currents on swimmers.

The most recent advisory to escape from rip current drowning is based on studies in California, where rip currents are often characterized by circulatory eddies. Therefore, it is reasoned that swimmers should float until the current brings them back to the sand bar (MacMahan et al, 2010; Figure 1-4).

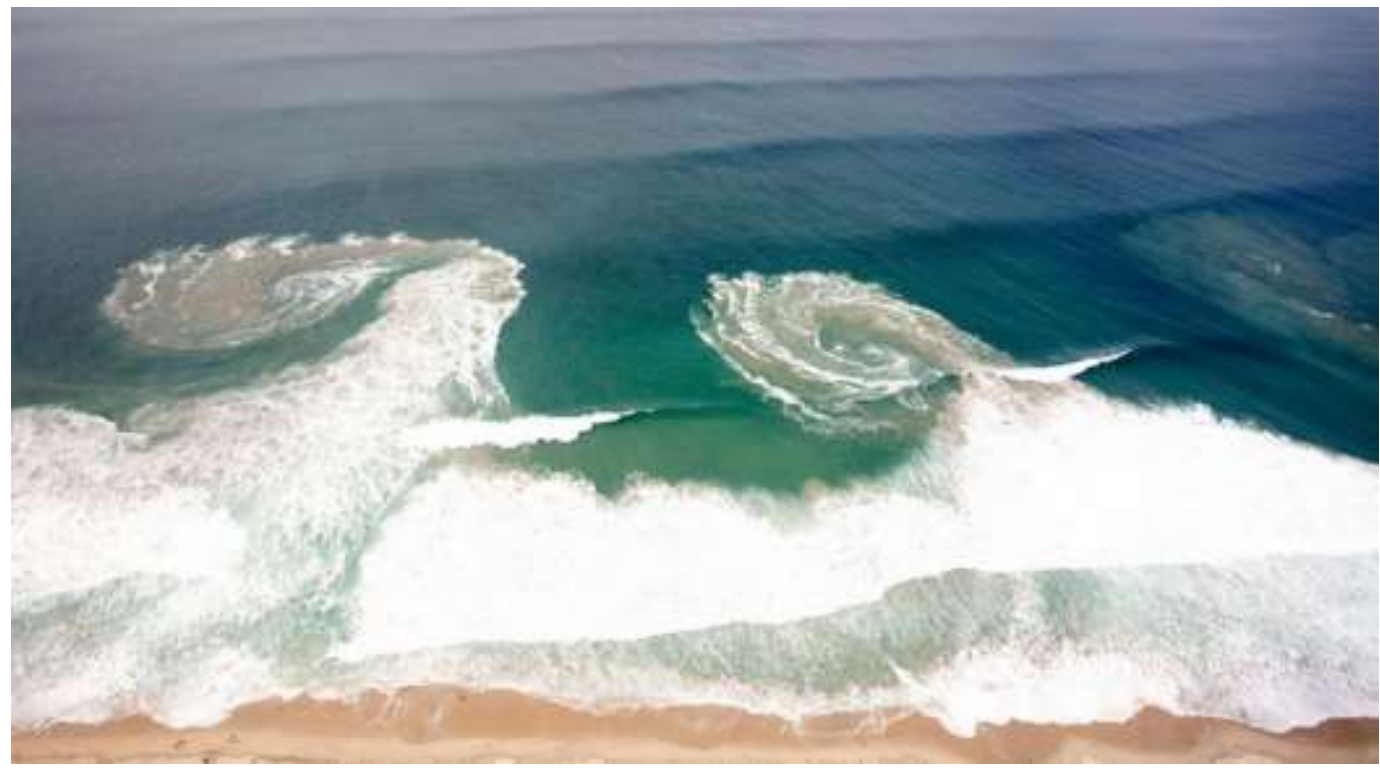

1-4. Rip currents with a circulatory pattern are shown in California (Photo courtesy of Tom Cozard).

California has relatively high, long-period waves that break as plungers on steep beaches. Higher waves create a much wider surf zone and stronger rip currents, and rips can extend hundreds of meters offshore (Figure 1-5). By contrast, many beaches along U.S. Atlantic and Gulf coasts have much lower energy waves with shorter periods and 
spilling or spilling/plunging breakers. For example, limited field observations suggest that rip currents in South Florida are weaker, have a shorter offshore extent, and probably do not circulate back to the bar. The popular swim parallel to the beach escape method is evaluated herein for South Florida. However, swimmers who choose to swim parallel to the beach may be swimming against a longshore current, which can pull them back into the rip current (McCarroll et al., 2014). Therefore, it is necessary to examine the characteristics of rip currents along U.S. Atlantic and Gulf coasts to develop an appropriate rip current escape guidance.

Dye tests were conducted in rip currents in South Florida to assess rip flow characteristics and escape strategies. Environmentally-safe fluorescein dye were released at the neck of a rip current. Aerial video and imagery from a remote-controlled quadcopter captured the circulation pattern and shape of the rip current as delineated by the fluorescent dye plume. 


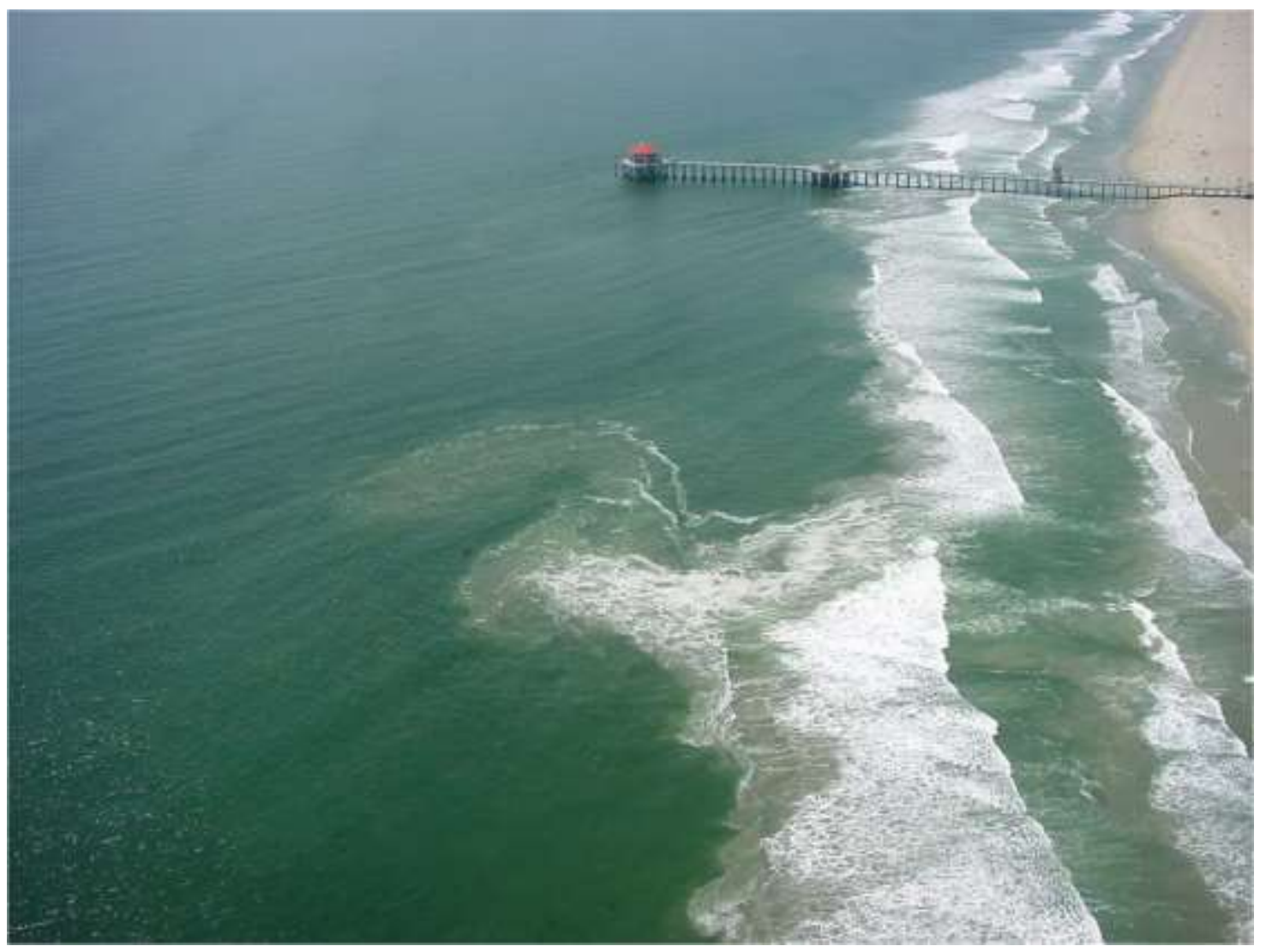

1-5. A very large rip current is shown at Huntington Beach, California; the pier is 580 meters in length (courtesy of Huntington Beach Lifeguards).

In Chapter 7, rip current generation is examined through lifeguard observations of rip current presence and beach conditions for a six-month period. Nearshore breaking waves are the drivers of rip currents. Alongshore variations of wave height caused by wave interaction, uneven bathymetry, or other factors can cause the channeling of wavegenerated backwash into an offshore-flowing current. It was important to study the wave characteristics of South Florida in order to learn more about the rips found here. NOAA has a large database of offshore wave buoys, but these data are not representative of nearshore wave characteristics (Paxton, 2014). Onshore wave breaking characteristics such as wave height, period and direction were measured at South Beach, Florida in 
concert with rip current measurements. Forecasting the occurrence of rip currents based on wave conditions is important to warn beach visitors of swimming risk. A logistic regression analysis was conducted to predict the beach conditions in which rip current were likely to occur. The goal of this chapter is to evaluate the conditions for generation of rip currents in order to better educate the public on avoiding rips. 


\title{
II. RIP CURRENTS IN SOUTH FLORIDA: A MAJOR WATER HAZARD AND MANAGEMENT CHALLENGE
}

\begin{abstract}
The first field measurements of rip currents in South Florida showed that these offshore-flowing currents are fairly weak as generated by moderate-sized waves during fair-weather conditions. Miami Beach is world famous, but unfortunately this area has a large number of drownings, partly because the rips here are nearly invisible. These ongoing tragedies were recently highlighted by the loss of two prominent rabbis that point to the misconceptions and lack of understanding of nearshore currents even by highly-educated people.
\end{abstract}

\section{INTRODUCTION}

Two high-profile rabbis from New York City drowned in a rip current at Haulover Park, just north of Miami Beach on May 17, 2016. These men were Orthodox Jews from Brooklyn that came to Haulover Park while on vacation. Upon arriving, they consulted with the lifeguards who informed them that rip currents were present and advised them to swim near a lifeguard tower. Due to their religion, the men were not able to show skin near women, and therefore chose an unpopulated area of the beach, which was unguarded. These two beachgoers unfortunately entered the water at the exact location of a rip current.

The rip current that drowned the two men was a "clear-water" rip--it contained little to no sediment and therefore was nearly invisible and hence very difficult to observe 
(Figure 2-1). The conditions on this day were idyllic - it was sunny and warm, and the waves were only of moderate size. What seemed like a perfect beach day ended in tragedy.

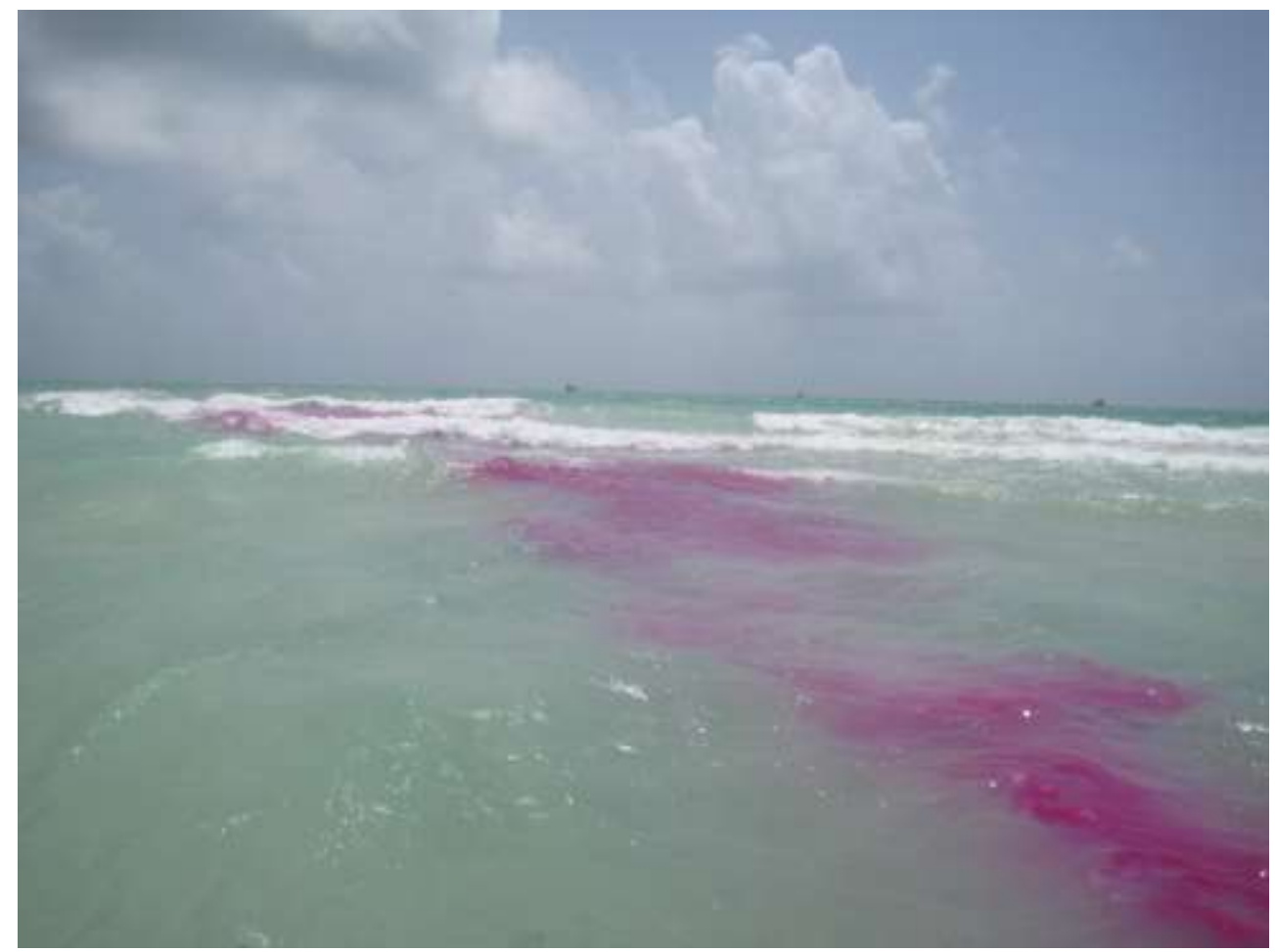

2-1. A "clear-water" rip current at Miami Beach, Florida as delineated by red fluorescent tracer dye.

This incident was a worldwide newsmaker--articles appeared in newspapers as far away as Australia (Dr. Robert Brander, personal communication, 2016). The front-page headline in the Miami Herald was titled "Two Rabbis Drown in Strong Rip Current." However, this is a misconception because the rip currents on this day were not strong albeit dangerous. The waves were not high--only 0.6-0.9 meters, which is certainly not enough to produce a strong rip current (Brander and Short, 2000). Strong rips are generally produced during stormy conditions, and most beachgoers do not enter the water 
during big wave days (e.g., exceeding 1.5 meters in height). Therefore, life-threatening rips can occur on sunny, fair-weather days with seemingly safe waves.

Florida is the rip drowning capital of the United States (Paxton, 2014; Figure 2-2). Ironically, Florida has a low to medium-low wave energy environment. So why does Florida have so many drownings? Florida boasts of 1,320 kilometers of high-quality, sandy beaches and good beach weather (e.g., Florida is called the "Sunshine State"). In addition, Florida is the third most populous state in the nation with nearly 20 million people and has the most visitors in the nation (more than 100 million per year; http://www.visitflorida.org/resources/research/). People visit Florida beaches from all over the world-- Canada, Europe, and especially Latin America for South Florida.

\section{Where Do People Drown?}

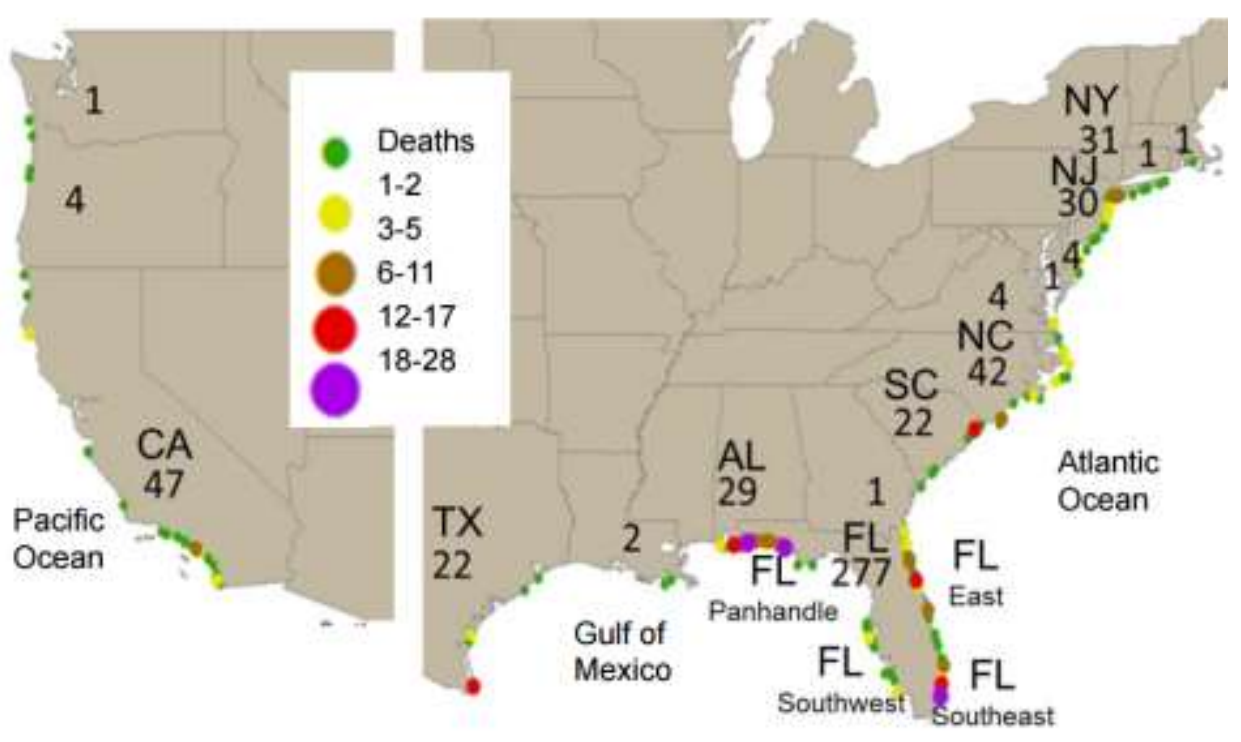

2-2. Rip current drowning in continental United States from 1994 to 2012 (Paxton, 2014), not including the Great Lakes that average about 10 rip fatalities per year (www.Cleveland.com, June 16, 2016) 


\section{BEACH CONDITIONS FOR RIP CURRENT DROWNING}

The rabbis entered the water exactly where a bar-gap rip current existed and during low tide on May 17, 2016. This was unfortunate on both counts; rip currents have been shown to be strongest at low tide (Brander and MacMahan, 2011; Leatherman et al., 2013). Bar-gap rips, which are the most common on surf beaches, form where the wave backwash is concentrated seaward through pre-existing channels or holes in the sand bar.

This particular day in May was "Chamber of Commerce weather," being sunny with a fresh onshore breeze. The air and water temperatures were both in the $80^{\circ}$ Fahrenheit range - a seemingly perfect day for bathing in the ocean although red flags were flying.

Haulover Park was chosen by the rabbis because it is a surf beach that is much less crowded than nearby Miami Beach. The waves on this day were less than one-meter high with spilling breakers, which are not threatening to beachgoers as compared to the dramatic plunging breakers that surfers seek. Most beachgoers avoid entering the water when waves approach 1.5-2 meters. It must be recognized that wave energy is proportional to the wave height squared so that a 2-meter wave is about ten times more powerful than a 0.6-meter wave. However, even weak rip currents can be deadly, and waves in the 0.6 to 0.9 -meter range are large enough to generate dangerous offshore currents that can take the lives of beachgoers who panic and drown.

The onshore wind on May 17, 2016 was only 10-15 kts according to observations by Lt. Matthew Sparling who is in charge of a well-regarded academy of lifeguards. Field measurements in South Florida by Leatherman (2017a) showed that relatively weak rip currents (e.g., approximately 0.3 meters per second) are often generated during the 
same conditions as experienced on the fateful day the two rabbis drowned (Table 2-1). By contrast, strong rip currents can exhibit speeds exceeding 2 meters per second as observed in California and Australia, which is faster than most Olympic swimmers.

2-1. Field measurements of beach conditions during rip current events in South Florida acquired by GPS drifters.

\begin{tabular}{|l|l|l|l|l|l|l|l|}
\hline $\begin{array}{l}\text { Date } \\
2016\end{array}$ & Location & $\begin{array}{l}\text { Tide } \\
\text { Level }\end{array}$ & $\begin{array}{l}\text { Wind } \\
\text { Speed }\end{array}$ & $\begin{array}{l}\text { Wind } \\
\text { Direction }\end{array}$ & $\begin{array}{l}\text { Wave } \\
\text { Height }\end{array}$ & $\begin{array}{l}\text { Flag } \\
\text { Color }\end{array}$ & $\begin{array}{l}\text { Rip } \\
\text { Speed }\end{array}$ \\
\hline $\begin{array}{l}\text { April } \\
6\end{array}$ & $\begin{array}{l}\text { Haulover } \\
\text { Park }\end{array}$ & Low & $15 \mathrm{kts}$ & $\mathrm{NE}$ & $\begin{array}{l}0.6- \\
0.9 \mathrm{~m}\end{array}$ & Red & $\begin{array}{l}0.2 \\
\mathrm{~m} / \mathrm{s}\end{array}$ \\
\hline June 20 & $\begin{array}{l}\text { Haulover } \\
\text { Park }\end{array}$ & Low & $\begin{array}{l}15-20 \\
\mathrm{kts}\end{array}$ & $\mathrm{NE}$ & $0.6-$ & Red & $\begin{array}{l}0.2 \\
\mathrm{~m} / \mathrm{s}\end{array}$ \\
\hline $\begin{array}{l}\text { March } \\
23\end{array}$ & $\begin{array}{l}\text { Miami } \\
\text { Beach }\end{array}$ & Low & $\begin{array}{l}15-20 \\
\mathrm{kts}\end{array}$ & ESE & $0.6 \mathrm{~m}$ & Red & 0.3 \\
\hline April 10 & Miami \\
Beach & Low & $15 \mathrm{kts}$ & $\mathrm{NE}$ & $0.6 \mathrm{~m}$ & $\mathrm{Red}$ & $\begin{array}{l}0.4 \\
\mathrm{~m} / \mathrm{s}\end{array}$ \\
\hline
\end{tabular}

\section{PUBLIC SAFETY AND MANAGEMENT CHALLENGE}

Rip current drownings do not generally garner national attention, but they are responsible for more deaths than other marine-related hazards, killing approximately 100 people annually in the United States. The greatest fear of beachgoers is sharks, which account for less than one death per year (Brander et al., 2013). So why is it that rip currents are so deadly, yet the public is not that afraid of them? The public knows very little about rip currents, and they are difficult to spot, especially the "clear water" rips of South Florida (Figure 2-1). While a shark kills in a terrifying display with blood in the 
water, rip currents result in relatively "quiet deaths" contrary to the Hollywood portrayal of victims frantically thrashing around in the water (http://pulse.seattlechildrens.org/doctor-explains-the-truth-about-drowning-its-a-silentkiller/).

There are methods to lower your risk of being caught in a rip current. The following is recommended by the author as a surf safety check list:

- Check for warning signs and flags (double red flags mean the beach is closed and a red flag indicates no swimming allowed)

- Swim near a lifeguard

- Scan the water from a high point to look for signs of a rip current:

- Areas of less breaking wave activity where the rip is forcing its way seaward through the surf zone; beachgoers often seek more quiescent water thinking it is safer, which is counterintuitive.

○ Change in water color from the surrounding water or choppy water; bargap rips, which are the most common type of rip currents, flow through holes or channels in the nearshore bar wherein the deeper water will appear slightly darker colored when viewed through polarized sunglasses that greatly reduce reflection off the water surface.

- Floating objects moving seaward (e.g., seaweed caught in a rip is a good indicator)

- Study the waves, especially the wave approach angle:

○ Straight on-shore waves (e.g., arriving perpendicular to the shore) result in a higher risk of rips. 
- Waves approaching at an angle can create a sweep or longshore current. When present, swim with the longshore current to escape the rip, not against it.

\section{CONCLUSIONS}

Rip currents are the friend of surfers who use them to take a free ride offshore, but the foe of bathers who do not recognize these offshore-flowing, clear-water currents. Rip current drowning is preventable, but beachgoers need to heed all warnings (e.g., signage and red flags), learn to read the surf and know how to swim. All surf beaches are subject to rip current drowning and beachgoers should swim near a lifeguard. The public is generally aware of water flow in rivers and streams, but have little understanding of oceanic currents, especially nearshore rip currents which are wave-generated. 


\title{
III. RIP CURRENT HAZARD ON FLORIDA AND SOUTH GEORGIA BEACHES
}

\begin{abstract}
Rip currents are wave-generated, seaward-flowing currents at surf beaches. Beach profiles for three Florida beaches (Miami Beach, Lido Beach, Sarasota, and Pensacola Beach) and one Georgia beach (South Cumberland Island) were chosen for surveying because of their variable sand bar heights. Rip current hazard at each beach was assessed by lifeguard rip rescue and drowning statistics. A relationship was found between sand bar height and rip current hazard wherein higher bars are associated with more rip drownings.
\end{abstract}

\section{INTRODUCTION}

Rip currents account for approximately 100 drownings in the United States annually and probably more than 500 globally (Brander and MacMahan, 2011). These seaward-flowing currents are deceptively dangerous as they are often seen as calm water between breaking waves, offering an inviting place to swim. Rip currents receive far less attention than other coastal hazards because they do not result in economic losses to property and relatively few people are impacted at any one time or location. In fact, rip current drownings are rarely reported in the national news, and many people know little about their dangers.

Beaches are the number one recreational destination for Americans, and there are more than two billion beach visits per year (Houston, 2013). Many visitors from inland 
areas lack experience and knowledge of the ocean, and international tourists may not be able to read beach warning signs or understand the hazard flag system. This lack of public knowledge contributes to the high annual death toll of rip currents.

A hole (or gap) in a sand bar acts as a relief valve for the water built up landward of the bar, funneling the water seaward in the form of a rip current. Rip currents are generally stronger at low tide, based on field studies (Brander and Short, 2001). Wave tank experiments have also shown that sand bar height has a great effect on rip current presence and strength (Leatherman et al., 2013). In the field, sand bar heights have been observed to vary greatly even in the same geographic region. The role of sand bar height on rip current hazard was examined through field profile studies to confirm these laboratory findings.

\section{FIELD SITES AND METHODS}

Three geographically-dispersed beaches in Florida (Miami in Southeast Florida, Lido in Southwest Florida and Pensacola in the Florida Panhandle) and one in South Georgia (South Cumberland Island) were chosen as the study areas due to their variability in bar heights (Leatherman, 2015). South Cumberland Island is a remote beach on a barrier island off South Georgia. This beach (Figure 3-1) has a very gentle foreshore beach slope $\left(1^{\circ}\right)$, low wave energy, and no recorded rip current deaths (Dean, 2010). Cumberland Island National Seashore is only accessible by boat, and there are no lifeguards present. This beach has no coastal structures and has never had a beach nourishment project. 


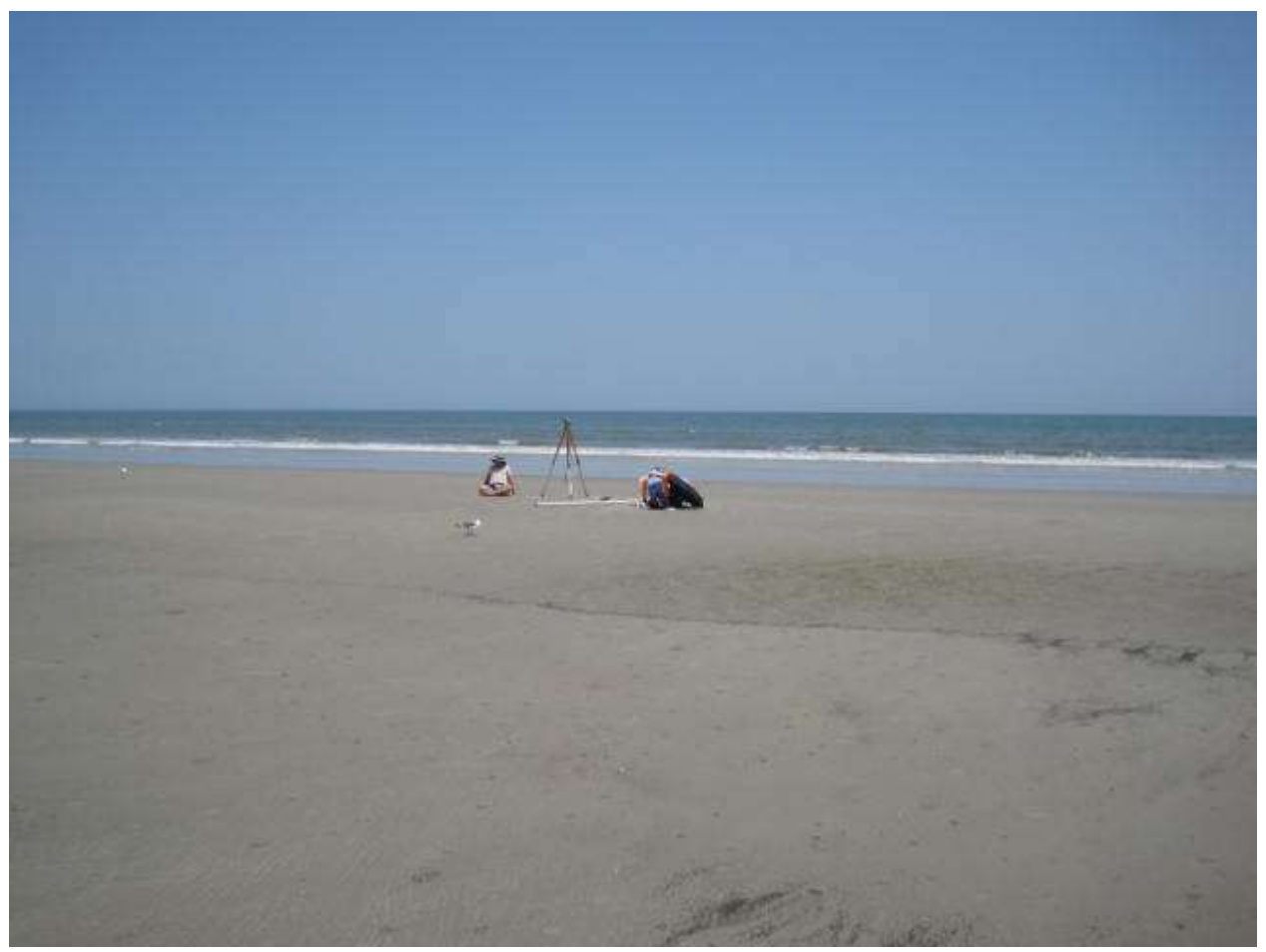

3-1. South Cumberland Island, Georgia has a very flat beach profile and is characterized by low wave energy and a large tidal range

Lido Beach is located on a barrier island in Sarasota, Florida. This beach is a very popular tourist destination. Lido Beach is characterized by a gentle foreshore beach slope $\left(2^{\circ}\right)$ and low wave energy. Since this beach is located on the Gulf Coast, it does not typically experience waves as large as those on the Florida Atlantic coast. Lido Beach has lifeguards, and there are some rip current rescues. Lido Beach has no coastal structures and has had several small beach nourishment projects.

Miami Beach is the most popular beach in Florida with more than eight million visitors annually (Houston, 2013). This beach is characterized by a moderately-sloping foreshore beach $\left(5^{\circ}\right)$ and moderate wave energy. The field surveys were conducted at South Beach, which has no coastal structures and has had a large nourishment project in the late 1970 s to early 1980 s, but none since this time. 
Pensacola Beach is located in the Florida panhandle. This beach (Figure 3-2) is characterized by a steep-sloping foreshore beach $\left(17^{\circ}\right)$ and high wave energy (by Gulf Coast standards). Rip currents are morphologically controlled by transverse ridges which refract the incident waves to create alongshore variations in wave height - the driving force behind these rips. This configuration sets up a rhythmic transverse bar and rip state, with rip currents present between the ridges (Barrett and Houser, 2012). Pensacola Beach has no coastal structures, and has had two beach nourishment projects.

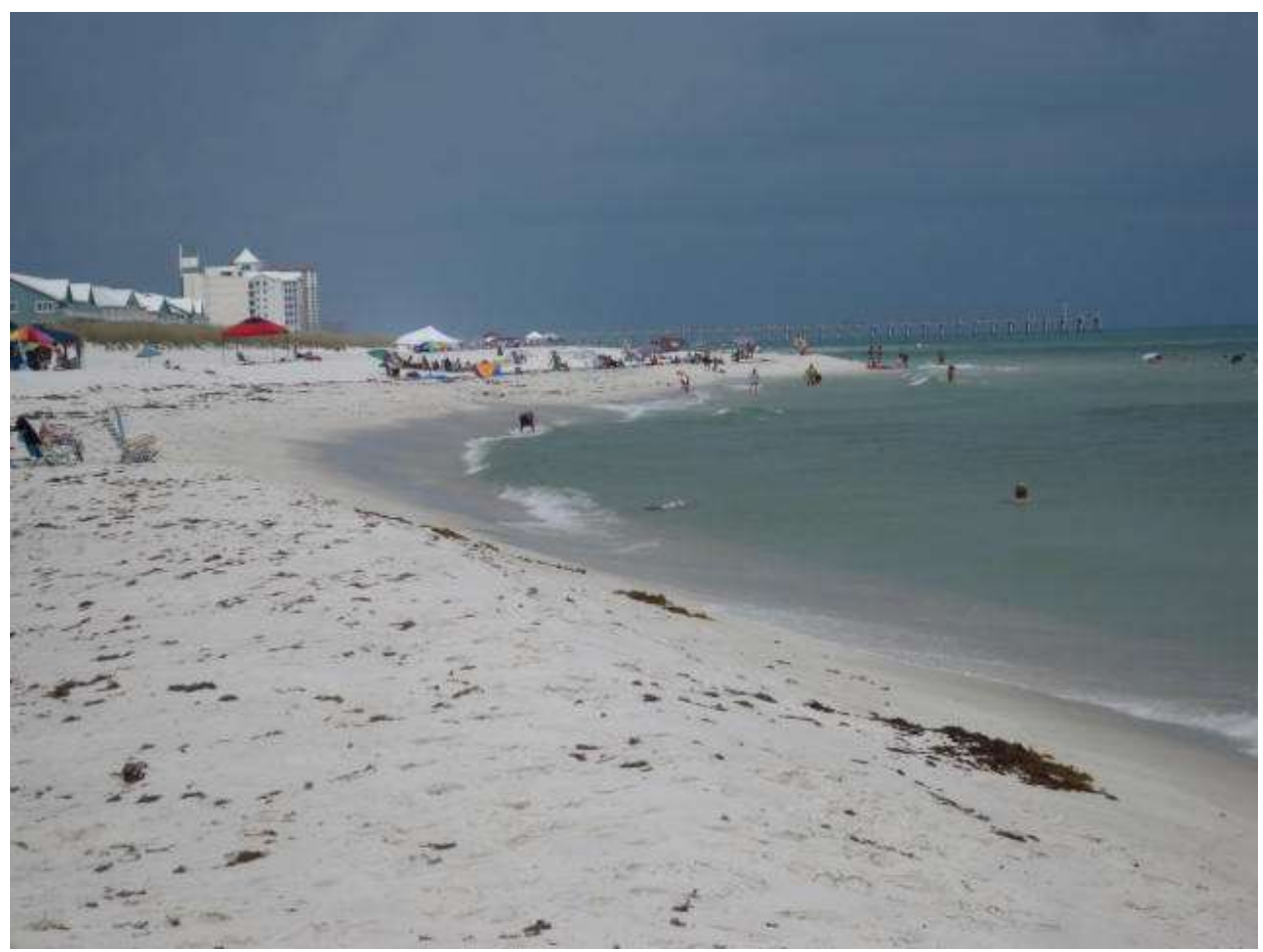

3-2. Pensacola Beach, Florida, has a fairly steep foreshore beach profile and a cuspate-shaped shoreline.

Three beach profiles were surveyed at each area using transit and rod. The goal of the field surveys was to capture the height of the sand bars as well as the depth of the rip current channels where present. This was undertaken by conducting one survey line in the rip channel and two survey lines on the adjacent sand bars. These surveys enabled 
the determination of channel depths relative to adjacent bar heights in order to ascertain sand bar heights at the four study areas.

\section{RESULTS}

Rip current hazards were primarily assessed by utilizing United States Lifesaving Association (USLA) lifeguard rescue statistics. These statistics are available online and show the number of rescues from rip currents at each beach where USLA lifeguards are present (United States Lifesaving Association, 2013). According to the USLA, $80 \%$ of all lifeguard rescues are caused by rip currents. Table 3-1 shows the visitation numbers and rip rescues for each beach. Lido Beach experienced an average of 53 rip rescues with an average of 4,309,939 visitors. Miami Beach experienced 234 rip current rescues and had an attendance of 13,268,841 visitors.

Pensacola Beach Convention and Visitors Bureau reported that annual beach attendance in 2009 for Pensacola Beach was 3,843,766 (Pensacola Beach Visitation Numbers, 2009; Table 3-1). Pensacola Beach's lifeguards are not part of the United States Lifesaving Association. Between 2004 and 2009, 759 swimmers were rescued at Pensacola Beach according to Houser et al. (2011). This averages out to 152 rescues per year during that time period. If $80 \%$ of the rescues are from rip currents, the number of rip rescues per year averages 122 (Table 3-1).

The beach at South Cumberland Island has no recorded rip current rescues or deaths and has an annual attendance of only 45,000 visitors per year (Table 3-1). Cumberland Island National Seashore is only accessible by boat and has a limit of 300 visitors per day, which explains the low visitation numbers. 
The rip current hazard is determined by the number of rip current rescues per million visitors (Table 3-1). Another source of data for assessing rip current hazard is the National Climatic Data Center (2012) storm data that indicates 21 rip drownings at Pensacola Beach, eight at Miami Beach, and none at Lido Beach or Cumberland Island (Table 3-1).

Beach profile surveys showed that Pensacola Beach has the largest sand bar height relative to rip channel depth at $0.9 \mathrm{~m}$ (Figure3-3), followed by Miami Beach at 0.6 m (Figure3-4), and Lido Beach at $0.35 \mathrm{~m}$ (Figure 3-5). At South Cumberland Island the bar height at $0.25 \mathrm{~m}$ was measured relative to the runnel because no rip channel was present (Figure 3-6; Table 3-1). Therefore, the height of the sand bar was based on a projected profile. Time-series beach profile data retrieved from the Florida Department of Environmental Protection (2014) show that bar heights match the data displayed in Table 3-1. These other data showed bar heights of $0.9 \mathrm{~m}$ at Pensacola Beach, $0.5 \mathrm{~m}$ at Miami Beach, and no discernable nearshore bar at Lido Beach because of very widelyspaced profile intervals. Profile data for South Cumberland Island recorded a subtle bar feature at $0.25 \mathrm{~m}$ (Dean, 2010) which matched the data shown in Figure 3-6. 


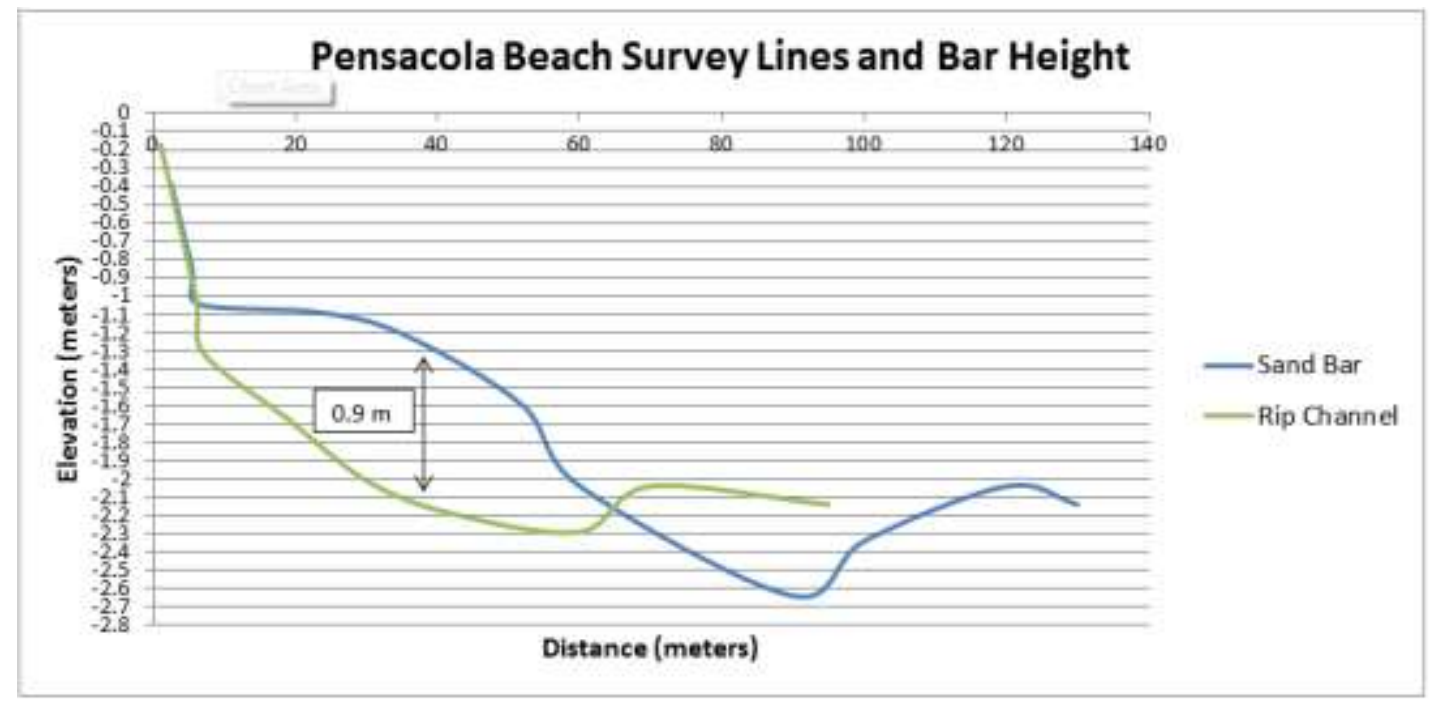

3-3. Pensacola Beach has a large sand bar at $40 \mathrm{~m}$ with a sand bar height of $0.9 \mathrm{~m}$ relative to channel depth (see vertical arrow).

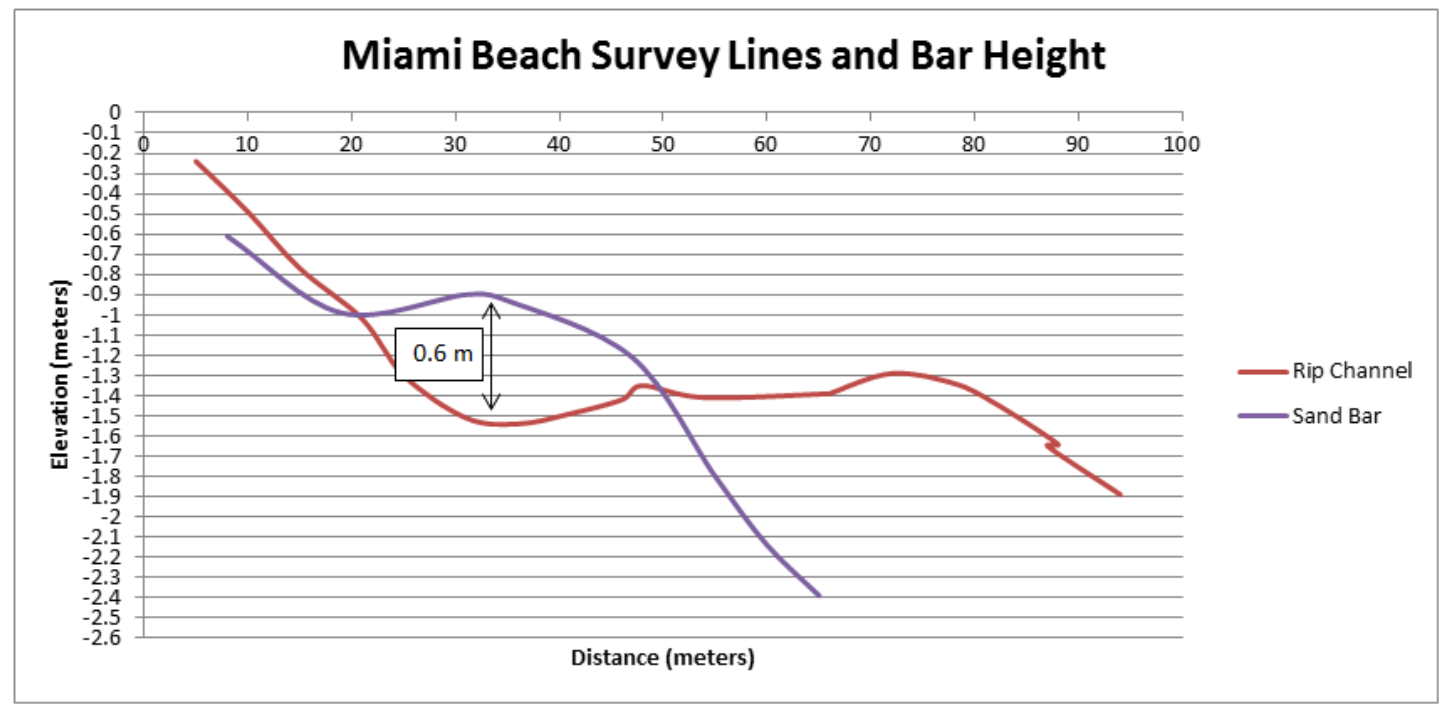

3-4. Miami Beach has medium-sized bar at $30 \mathrm{~m}$ with a height if $0.6 \mathrm{~m}$ relative to channel depth (see vertical arrow). 


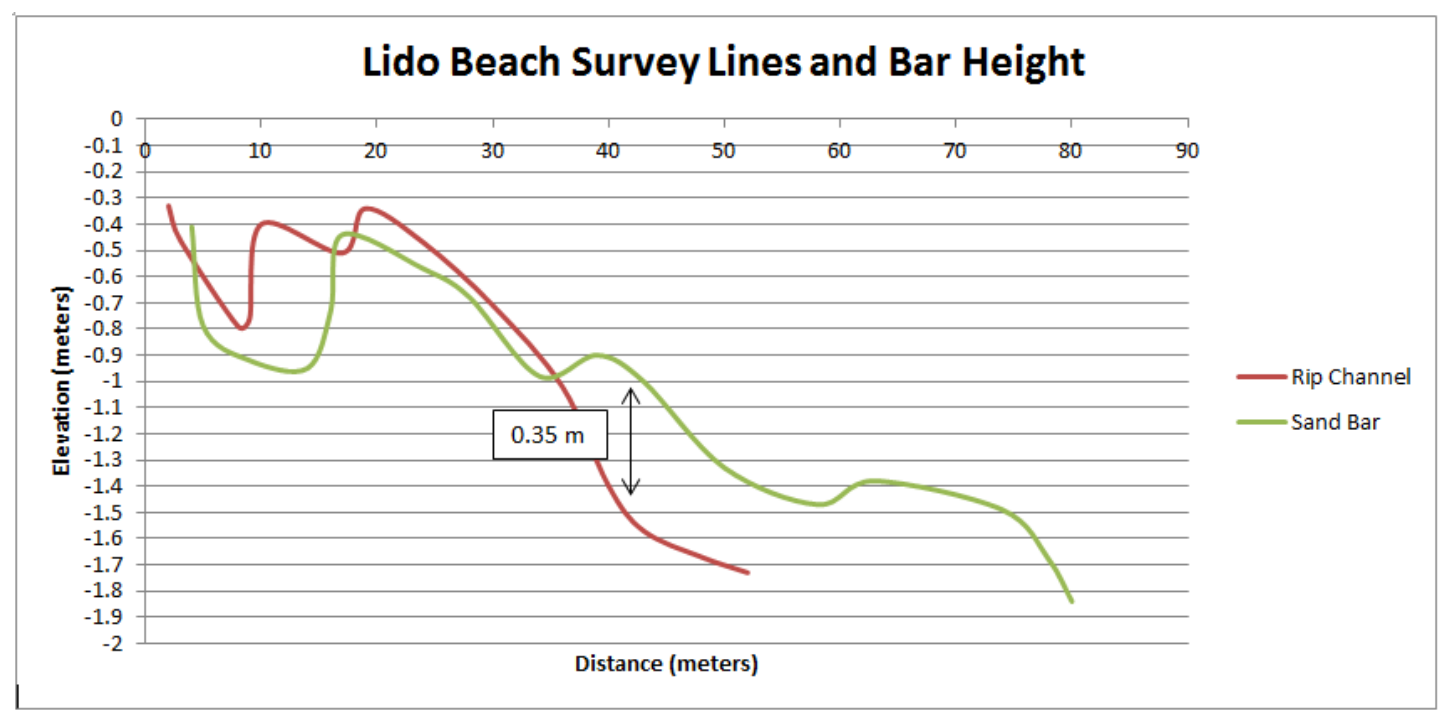

3-5. Lido Beach has a small bar located at $39 \mathrm{~m}$ with a height of $0.35 \mathrm{~m}$ relative to the channel depth (see vertical arrow).

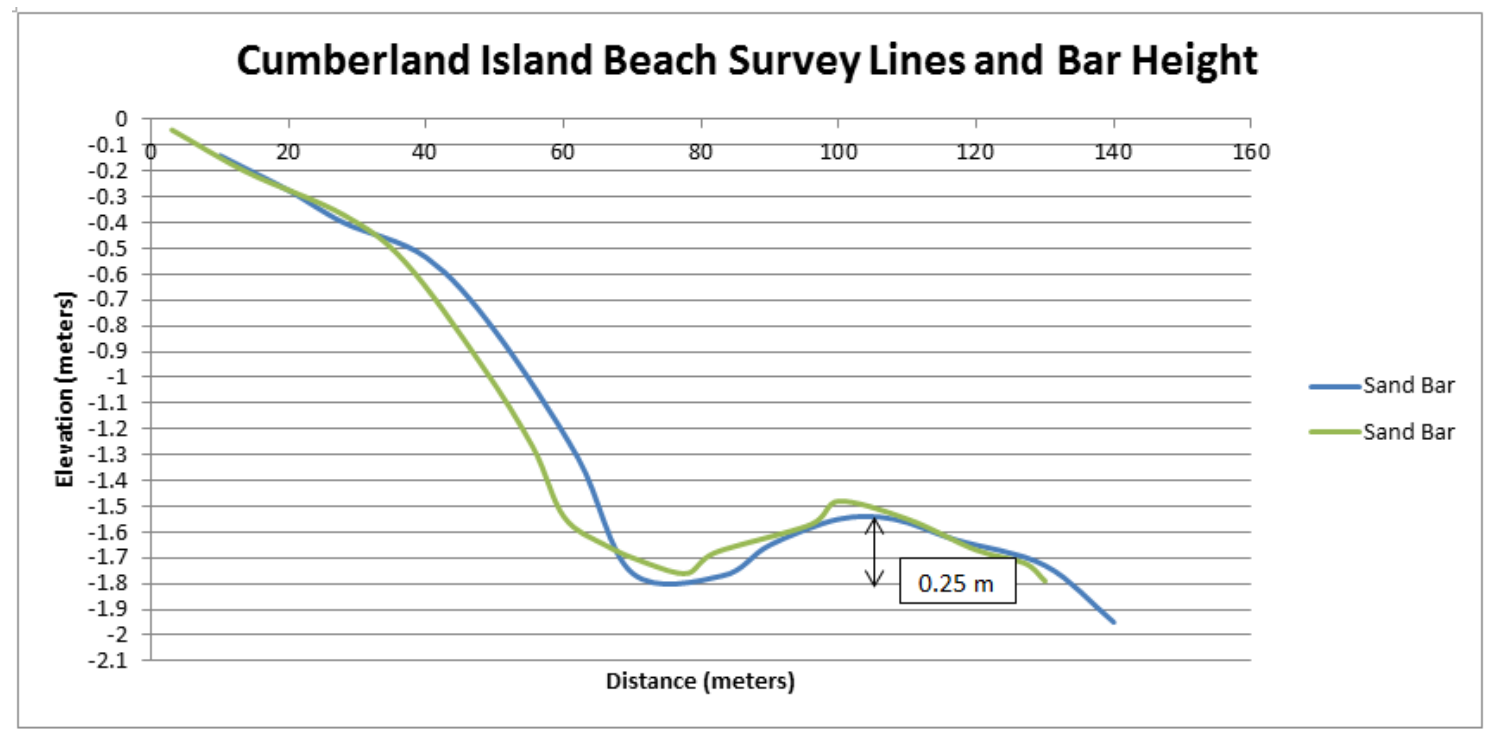

3-6. Cumberland Island has a very small bar at $105 \mathrm{~m}$ with a height of $0.25 \mathrm{~m}$ with no rip channel present (see arrow). 
3-1. Visitation numbers and rip rescues by beach.

\begin{tabular}{|c|c|c|c|c|c|c|c|c|}
\hline Location & Annual Attendance & $\begin{array}{l}\text { Rip } \\
\text { Rescues }\end{array}$ & $\begin{array}{l}\text { Rip rescues } \\
\text { per million } \\
\text { visitors } \\
\text { annually }\end{array}$ & $\begin{array}{l}\text { Total deaths due } \\
\text { to rip currents } \\
\text { from } 2000 \text { to } \\
2012\end{array}$ & $\begin{array}{l}\text { Sand bar } \\
\text { height relative } \\
\text { to channel (m) }\end{array}$ & $\begin{array}{l}\text { Wave } \\
\text { Climate }\end{array}$ & $\begin{array}{l}\text { Beach } \\
\text { slope } \\
\text { (degrees) }\end{array}$ & $\begin{array}{l}\text { Mean } \\
\text { grain } \\
\text { size } \\
(\mathrm{mm})\end{array}$ \\
\hline $\begin{array}{l}\text { Pensacola } \\
\text { Beach }\end{array}$ & $\begin{array}{l}3,843,766 \text { (averaged } \\
\text { from 2004-2009) }\end{array}$ & 122 & 32 & 21 & 0.9 & High & 17 & 0.38 \\
\hline $\begin{array}{l}\text { Miami } \\
\text { Beach }\end{array}$ & $13,268,841(2011)$ & 234 & 18 & 8 & 0.6 & Medium & 5 & 0.44 \\
\hline Lido Beach & $\begin{array}{l}4,309,939 \text { (averaged } \\
\text { from years } 2004, \\
2005,2007,2008, \\
\text { and 2009) }\end{array}$ & 53 & 12 & 0 & 0.35 & Low & 2 & 0.33 \\
\hline $\begin{array}{l}\text { South } \\
\text { Cumberland } \\
\text { Island }\end{array}$ & 45,000 & 0 & 0 & 0 & 0.25 & Low & 1 & 0.14 \\
\hline
\end{tabular}




\section{DISCUSSION}

South Cumberland Island is located in the Georgia bight, which has the widest continental shelf on the U.S. Atlantic coast, extending approximately $600 \mathrm{~km}$ offshore. Offshore waves lose energy propagating over the shallow continental shelf due to bottom friction. This results in significantly lower wave heights at Cumberland Island relative to nearby Jacksonville Beach, Florida. This south Georgia beach also has very fine sand with a mean grain size of $0.14 \mathrm{~mm}$, and the lowest sand bar height of all the study areas (Table 3-1). The rip rescue statistics show that South Cumberland Island has not experienced any rip current rescues or drownings.

Miami Beach has the narrowest continental shelf of all the study areas, only extending a few km offshore. This would normally allow large ocean waves to propagate close to shore without being broken, but Miami Beach is shielded from large ocean waves by the Bahamas, which explains the moderate wave activity compared to higher wave energy northward at Palm Beach, Florida. Miami Beach has the largest grain size of all study areas at $0.44 \mathrm{~mm}$, and the second steepest foreshore beach slope $\left(5^{\circ}\right)$. The rip rescue statistics show that Miami Beach experiences the second most rip rescues and deaths, which agrees qualitatively with the laboratory data regarding rip current presence and strength relative to bar height (Leatherman et al., 2013).

Pensacola Beach has fine-grained sand $(0.38 \mathrm{~mm})$ and a steep foreshore beach slope $\left(17^{\circ}\right)$. This steep slope is indicative of higher wave energy at Pensacola Beach relative to the other study areas. Higher wave energy beaches are typically characterized by coarser-grained sediment, but only fine-grained sand is available to Pensacola Beach 
from panhandle source areas. The rip rescue statistics show that Pensacola Beach has the highest number of rescues and deaths (Table 3-1).

Pensacola Beach and Lido Beach are both located in the Gulf of Mexico, which characteristically has smaller waves than the Atlantic Ocean. Both areas have a wide continental shelf, but it is much narrower at Pensacola Beach in the Florida panhandle. Pensacola Beach also experiences higher waves during storm events. Tropical storms formed in the Caribbean generally track northward, resulting in larger swell-type waves traveling to the panhandle beaches. Similarly, frontal systems rarely extend far enough south to create large waves at Lido Beach, which are more common at Pensacola Beach.

Lido Beach was found to have the second smallest grain size at $0.33 \mathrm{~mm}$, and the second shallowest foreshore beach slope $\left(2^{\circ}\right)$. The fine-grain sand and gently-sloping beach at Lido are indicative of the low wave energy at this beach. These findings agree with the rip rescue statistics which show Lido Beach having the second lowest number of rip rescues (Table 3-1). This beach was experiencing onshore movement of the recovery bar at the time of field surveying, and a ridge and runnel system is evident in the profile data at the five to ten meter marks (Figure 3-5).

There is a clear relationship between sand bar height and presence of rip currents based on the field profile surveys and rescue data (Table 3-1). Additionally, the National Climatic Data Center (NCDC) data show that the number of deaths due to rip currents is highest in Pensacola Beach, followed by Miami Beach. While the NCDC dataset is not complete, it has been proven accurate enough to be used in rip current fatality comparisons (Genisi and Ashley, 2010). This study could be improved by recording the number and strength of rip currents present at each study area. However, these data are 
not presently available due to the large area for observation (e.g., Florida has more than $1,300 \mathrm{~km}$ of sandy beaches) and the difficulty of identifying and measuring rip currents which are transient in nature. It is well established that lifeguard data are very reliable, and that more than $80 \%$ of all lifeguard rescues on surf beaches are the result of rip currents. Therefore, it is reasonable to use lifeguard rip current rescue statistics as a means of determining rip current hazard at the study areas.

\section{CONCLUSIONS}

Sand bar heights have been shown to vary geographically as related to sand size, beach slope and wave energy. Pensacola Beach in the Florida Panhandle has the largest bar height at $0.9 \mathrm{~m}$ and this area is known as the drowning capital of Florida. Miami Beach in southeast Florida has a bar height of $0.6 \mathrm{~m}$ and the second highest number of drownings in the state. Lido Beach in southwest Florida has a bar height of only $0.35 \mathrm{~m}$ and is characterized by very few drownings with most attributed to tidal currents at Big Sarasota Pass Inlet. The beach at South Cumberland Island is located a few km north of Florida and has a subtle bar with a height of $0.25 \mathrm{~m}$, and there has never been a documented rip current drowning. Time-series beach profile data from the Florida Department of Environmental Protection (2014) and Dean (2010) match these bar height measurements closely. The wave tank data also show a clear relationship between bar height and rip current presence and strength (Leatherman et al., 2013). All of these data indicate that bar height is an important factor in determining rip current hazards on surf beaches. Currently, the National Weather Service rip current forecast does not include local geographic information, which could make their forecasts more accurate. 


\title{
IV. TECHNIQUES FOR MEASURING RIP CURRENTS
}

\begin{abstract}
There are a number of different techniques to measure the speed and offshore extent of rip currents, but the best ones generally require sophisticated equipment and a boat to retrieve GPS-controlled drifters. A new, simple and inexpensive method involves using a laser rangefinder at the beach to trace the current; measurements of speed will be the most accurate for rips moving in a straight path (e.g., not significantly deflected by a longshore current). The offshore terminus (e.g., seaward extent) of the rip current can also be determined for a distance of $100+$ meters. Another new technique is to aerial image fluorescein tracer dye in a rip current via a drone (e.g., quadcopter) and calculate the speed using a ground reference. Lastly, a new particle image velocimetry (PIV) technique is discussed that allows rip current velocity measurements from aerial drone video footage. This technique tracks motion through sequential frames from the drone video and outputs current vectors using a MATLAB program.
\end{abstract}

\section{INTRODUCTION}

Rip currents, which are narrow areas of seaward-flowing water, are the greatest hazard at surf beaches worldwide. Researchers have employed a variety of methodologies to identify rip currents. The most common approach has been direct observation by the naked eye. The tell-tale signs include a tongue of sediment-laden water moving offshore, seaward movement of floating objects, unusual wave choppiness, foamy water in the outer edges of the rip head, gap in the breaking waves, and darker 
water that indicates the presence of a rip channel. Polarizing sunglasses are often used to eliminate the water glare, allowing for better observation of differential water coloration. Floating objects such as sticks, oranges and coconuts can be thrown in the water to detect longshore, rip and tidal currents. Tracer dyes have been used to better delineate rips, especially when the tell-tale signs are not present or obvious.

Sonu (1972) used water-filled polyethylene balls that were adjusted to be neutrally buoyant to detect rip currents. Comparison with dye releases indicated that the movement of the freely-drifting balls represented the mean flow. Nearly-filled plastic jugs of water can be used to locate rips and provide an indication of Lagrangian trajectories (Inman et al., 1980). They can be retrieved by attaching a floating neoprene line so as not to cause littering. This low-cost method, which is still used extensively in developing countries, can also provide an estimate of rip speed.

Video cameras have long been used to measure waves and currents at beaches (Sonu, 1972). Beach cams placed atop buildings, high poles or tethered balloons with telephoto lenses aimed at the surf zone have been extensively utilized. Holman and Stanley (2007) employed an Argus camera system at the Corps of Engineers Field Research Facility at Duck, North Carolina to obtain time-lapsed photography. Google Earth and Bing satellite images sometimes show rip channels based on differential water coloration or rips in action as denoted by offshore-flowing sediment plumes.

In recent years, more sophisticated instrumentation has been deployed at ripprone beaches. In-situ measuring devices include tripod-mounted current meters and pressure sensors. The problem with this Eulerian method of rip measurement is that it involves instrumentation placement - there are concerns that the current meter might not 
remain in the mean flow area of the rip. There are also logistical problems and safety constraints of installation in a dangerous location (Brander and Short, 2000).

Rip float experiments (e.g., using human drogues) have been conducted in Australia, wherein a person floating freely in the rip current is tracked by theodolites (Short and Hogan, 1994) or more recently GPS technology. Lagrangian methods of measuring rip currents have recently become popular. These methods such as GPScontrolled drogues have the advantage of less set-up time, safer deployment, more mobility and can capture the path of the rip current. GPS-controlled drogues have been extensively used by MacMahan et al. (2006) to measure rip current velocity at beaches in California, France and Australia. Generally, five or more GPS-instrumented drogues are released in a rip current and tracked in real-time by observers on the beach using laptop computers. Real-time differential GPS drifters have an accuracy less than 1 meter after carrier phase post-processing (Schmidt et al., 2003). Non-differential GPS units, which are an order of magnitude less expensive, are now being used to study rip currents with much success (Sabet and Barani, 2011).

\section{METHODS}

A new technique to measure rip speed is to use a laser rangefinder to calculate the distance from an observer to a floating object in the rip current over time. A compass used in conjunction with the laser rangefinder is used to determine the angle of the rip current path in order to correct the distance measurements for non-linear rip currents. A second technique to measure rip currents is to aerially image the rip path using a drone 
(e.g., a quadcopter) equipped with a video camera and fluorescein tracer dye to delineate the rip.

\section{Laser Rangefinder}

Laser rangefinders are extensively used in the construction industry because of their small size, low cost and high accuracy for measuring distances. Laser rangefinders cannot image water as there is no return, but this hand-held device can bounce a laser off any object and determine the laser travel time instantly and hence the distance to the object. There are many options available when choosing a laser rangefinder; prices range from approximately $\$ 100$ to $\$ 300$. The optimal laser rangefinder would have a built-in compass, which exists for the Uineye Laser Rangefinder, but this unit is no longer available for purchase.

A Nikon Prostaff 7 laser rangefinder and a Steren Electronics compass mounted on inexpensive photographic tripods were used to determine the position and path of floating objects in currents (Figure 4-1). The Prostaff 7 model, which costs $\$ 300$, has an accuracy of $0.1 \mathrm{~m}$ up to a distance of $540 \mathrm{~m}$ according to the manufacturer. This model does not have the means to attach to a tripod so an adhesive camera mount was attached to the bottom. The Steren Electronics compass is a low-cost device (\$100) which was used to measure the horizontal angle for non-linear flow paths in combination with a laser rangefinder. 


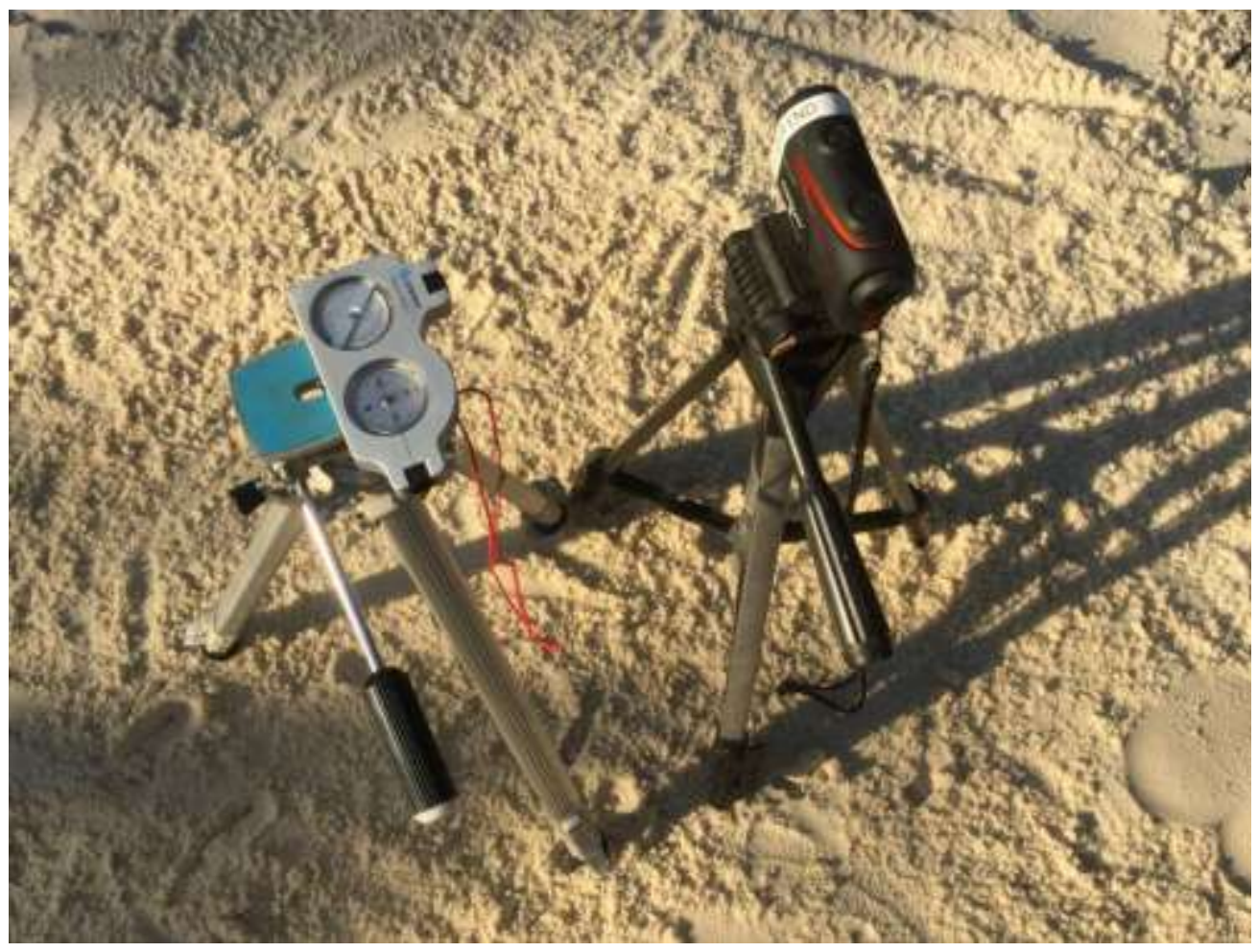

4-1. The Nikon Prostaff 7 Laser Rangefinder and Steren Electronics compass are mounted on a photographic tripod to measure the speed and path of a rip current. The speed is measured by calculating the distance with the laser rangefinder of a floating object moving inside the rip current over time. The compass is used to determine the angle of the rip path in order to correct the distance measurements for a non-linear rip current path.

Drone Imaging of Tracer Dye

Tracer dyes have long been utilized by scientists and medical doctors for water movement indicators and blood flow markers in the human body, respectively. Coastal scientists use several dyes for water tracer studies, especially fluorescein, potassium permanganate, and rhodamine, but fluorescein dye is the only one that has been shown by the U.S. Environmental Protection Agency to be safe in the marine environment. Fluorescein dye is non-toxic, biodegradable, and NSF approved as safe in drinking water (see Material Safety Data Sheet for fluorescein, disodium salt; www.hazard.com/msds). This liquid fluorescein tracer dye costs $\$ 80$ per gallon for the lowest grade--higher grades 
are not necessary for this application. Larger quantities can be obtained at lower unit cost from manufacturers.

Quadcopters, which are a type of drone, are now being used for field surveying in many areas. They are especially useful for studying rip currents adjacent to shoreperpendicular, coastal engineering structures (e.g., groins and jetties) and in high-energy wave environments where large breaking waves cause dangerous conditions. A DJI Phantom 3 Advanced quadcopter (which costs about \$1000; Figure 4-2) equipped with a high definition, gimbal-stabilized video camera was used to trace a plume of fluorescein tracer dye carried seaward by the rip current.

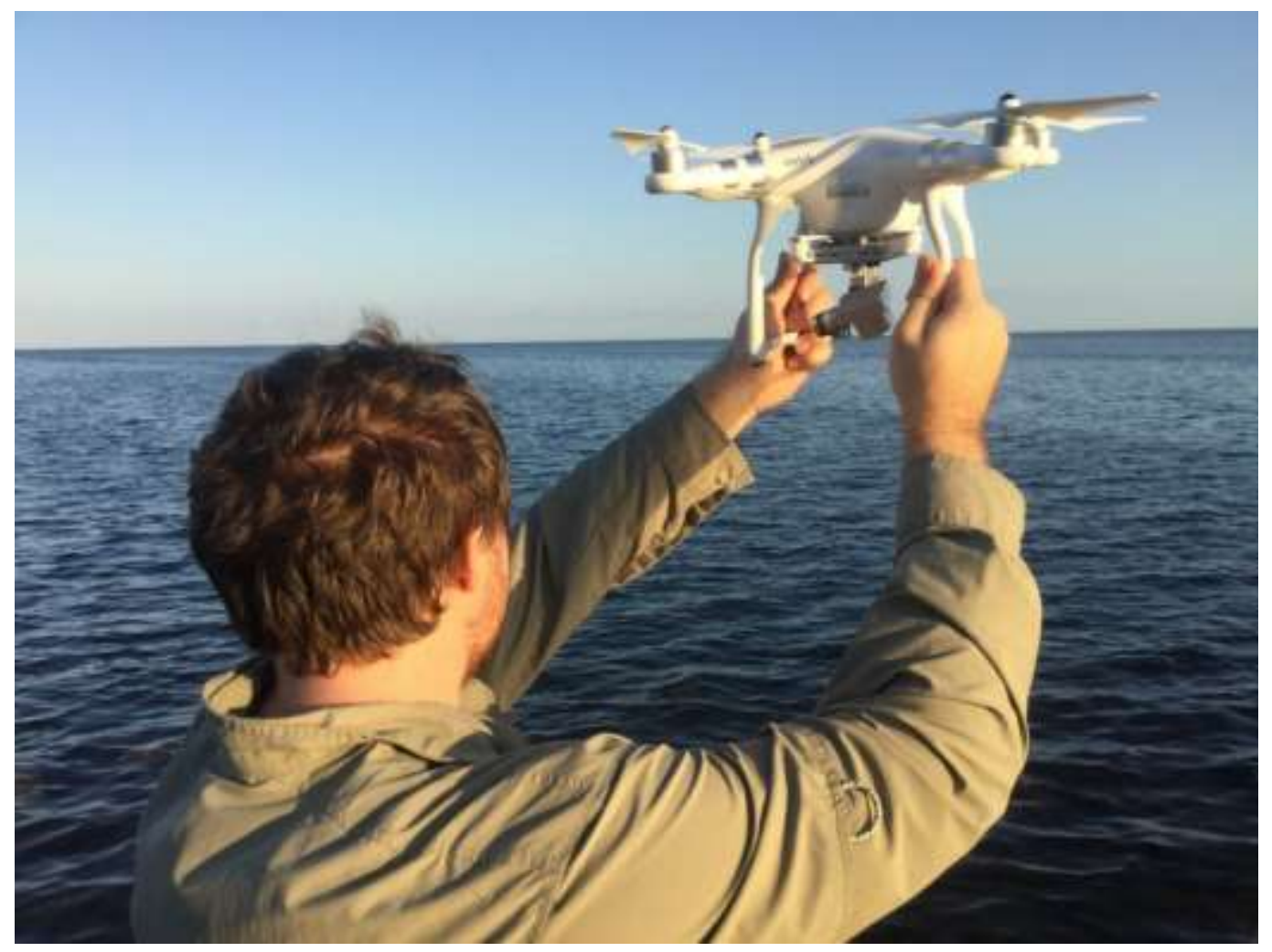

Figure 4-2. The DJI Phantom 3 Advanced Quadcopter is being prepared for takeoff. This drone provides an aerial view of rip currents delineated by tracer dye, allowing for analysis of the rip path with implications for escape methods. 


\section{Drone Particle Image Velocimetry}

Particle Image Velocimetry (PIV) using cameras has been utilized in the past to obtain swash flow velocity. This technique samples multiple sequential images and identifies spatial offsets, which are used in conjunction with the sampling interval to derive velocity vectors (Holland et al, 2001). This PIV technique is traditonally conducted using land-based cameras, and pre-processing methods are utlizied to georectify oblique imagery to a planar surface. This PIV technique can be utilized on the high-resolution and stablizied video footage available from low-cost consumer drones.

\section{RESULTS}

Rip current measurements were conducted on July 18, 2016 at South Beach in Miami, Florida using the laser rangefinder (Leatherman and Leatherman, 2017). An assistant floating in the rip current was used as a target for the laser rangefinder. The rip current moved in a relatively straight path as delineated by the fluorescein tracer dye. The rangefinder measurements showed an average rip speed of $0.4 \mathrm{~m} / \mathrm{s}$ over three deployments (a.k.a. "runs", Table 4-1), which corresponded well with simultaneouslyobtained GPS drogue measurements (Leatherman, 2017a). 
4-1. Rip current speed measurements taken with the laser rangefinder on July 18, 2016 at South Beach show an average rip speed of $0.41 \mathrm{~m} / \mathrm{s}$.

Run 1

\begin{tabular}{|l|l|l|}
\hline Seconds & $\begin{array}{l}\text { Distance } \\
(\mathrm{m})\end{array}$ & Speed $(\mathrm{m} / \mathrm{s})$ \\
\hline 0 & 61.0 & \\
\hline 21 & 69.0 & 0.38 \\
\hline 8 & 71.5 & 0.31 \\
\hline 10 & 77.5 & 0.60 \\
\hline 11 & 82.0 & 0.41 \\
\hline 37 & 94.5 & 0.34 \\
\hline
\end{tabular}

Run 2

\begin{tabular}{|l|l|l|}
\hline Seconds & $\begin{array}{l}\text { Distance } \\
(\mathrm{m})\end{array}$ & Speed $(\mathrm{m} / \mathrm{s})$ \\
\hline 0 & 68 & \\
\hline 18 & 73 & 0.28 \\
\hline 9 & 75 & 0.22 \\
\hline 9 & 78 & 0.33 \\
\hline 7 & 81 & 0.43 \\
\hline 5 & 84 & 0.60 \\
\hline 13 & 90 & 0.46 \\
\hline 11 & 92 & 0.18 \\
\hline 21 & 101 & 0.43 \\
\hline
\end{tabular}

Run 3

\begin{tabular}{|l|l|l|}
\hline Seconds & $\begin{array}{l}\text { Distance } \\
(\mathrm{m})\end{array}$ & Speed $(\mathrm{m} / \mathrm{s})$ \\
\hline 0 & 60 & \\
\hline 34 & 73 & 0.38 \\
\hline 9 & 78 & 0.56 \\
\hline 10 & 84 & 0.60 \\
\hline 10 & 91 & 0.70 \\
\hline 6 & 93 & 0.33 \\
\hline 6 & 97 & 0.67 \\
\hline 7 & 99 & 0.29 \\
\hline 6 & 100 & 0.17 \\
\hline 11 & 108 & 0.73 \\
\hline 15 & 111 & 0.20 \\
\hline
\end{tabular}

The Steren Electronics compass can be used to more accurately determine the rip path distance and therefore the speed in cases where the rip current is deflected by the longshore current. A "dry run" test was performed to determine the accuracy of using the compass in conjunction with the laser rangefinder for an arcing rip current. A 32-meter tape measure was laid out in a curved path representing the path of a rip current, and 12 markers, representing measurements points, were placed along the path at varying distances. The laser rangefinder was used to measure the distance to each marker and a 
compass to determine the angle between adjacent markers. Using the law of cosines, the distance between each marker was calculated and compared to the true tape measure distance to determine accuracy.

The law of cosines is as follows:

$$
a^{2}=b^{2}+c^{2}-2 b c \cos A
$$

Where $\mathrm{a}, \mathrm{b}$ and $\mathrm{c}$ are the length of the legs of a triangle and $\mathrm{A}, \mathrm{B}$, and $\mathrm{C}$ are the corresponding angles of a triangle. In the laser rangefinder calculations, a represents the Calculated Leg Distance (CLD), b represents the Laser Rangefinder Distance 1 (LFD1), c represents Laser Rangefinder Distance 2 (LFD2), and A is the Referenced Angle ( $\left.A_{R}\right)$, as shown in Figure 4-3. The results showed that the laser rangefinder in conjunction with the compass was accurate to about 0.1m (Table 4-2). 


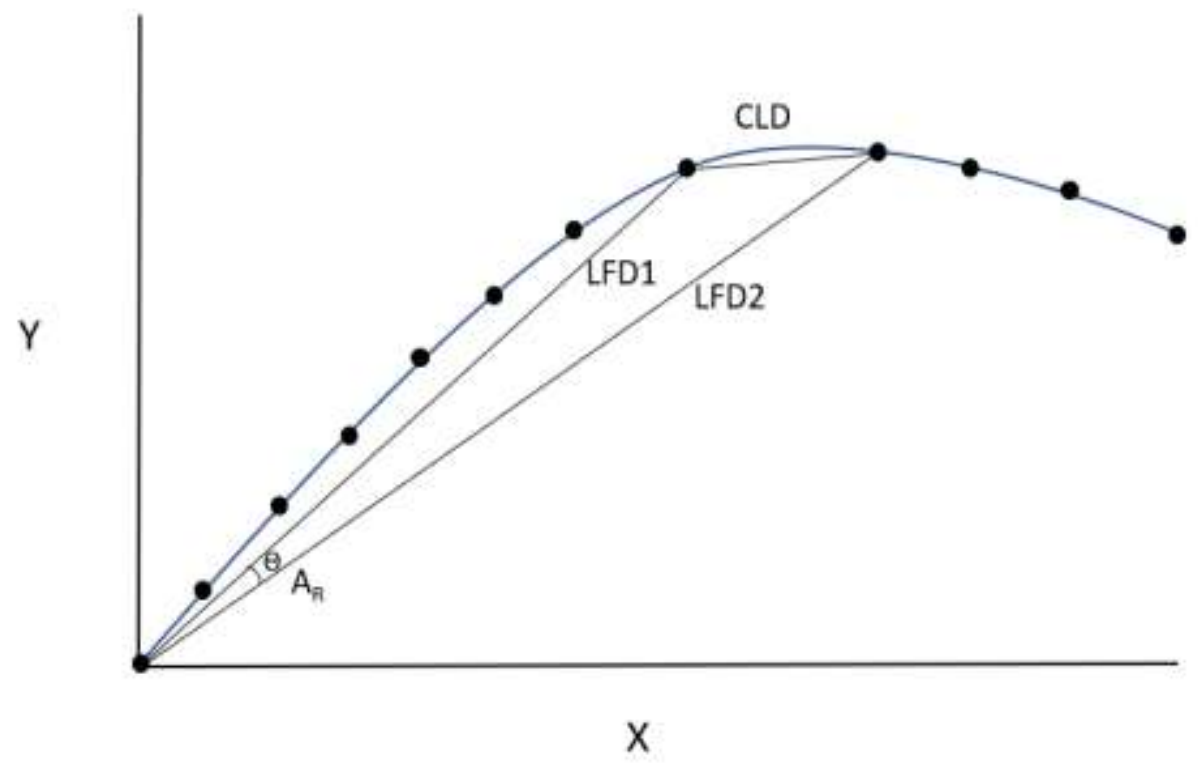

Figure 4-3. The Calculated Leg Distance (CLD) is determined using the law of cosines with the known sides of the triangle Laser Rangefinder Distance 1 (LFD1) and Laser Rangefinder Distance 2 (LFD2), and the known Referenced Angle $\left(A_{R}\right)$.

4-2. The laser rangefinder in conjunction with the compass allow for measuring a non-linear rip path with an accuracy of $0.1 \mathrm{~m}$.

\begin{tabular}{|l|l|l|l|l|l|l|l|}
\hline Point & $\begin{array}{l}\text { Compass } \\
\text { Angle } \\
\text { Reading } \\
\text { (degrees) }\end{array}$ & $\begin{array}{l}\text { Referenced } \\
\text { Angle } \\
\text { (degrees) }\end{array}$ & $\begin{array}{l}\text { Angle } \\
\text { (radians) }\end{array}$ & $\begin{array}{l}\text { Laser } \\
\text { Rangefinder } \\
\text { Distance } \\
\text { (meters) }\end{array}$ & $\begin{array}{l}\text { Calculated } \\
\text { Leg } \\
\text { Distance } \\
\text { (meters) }\end{array}$ & $\begin{array}{l}\text { Calculated } \\
\text { Rip Path } \\
\text { Distance } \\
\text { (meters) }\end{array}$ & $\begin{array}{l}\text { Actual } \\
\text { Tape } \\
\text { Distance } \\
\text { (meters) }\end{array}$ \\
\hline 1 & 334 & 0 & 0 & 4.9 & 4.90 & 4.90 & 5.0 \\
\hline 2 & 334 & 0 & 0 & 8.0 & 3.10 & 8.00 & 8.0 \\
\hline 3 & 334 & 0 & 0 & 11.1 & 3.10 & 11.1 & 11 \\
\hline 4 & 335 & 1.0 & 0.017 & 12.9 & 1.81 & 12.91 & 13 \\
\hline 5 & 335 & 0 & 0.000 & 14.9 & 2.00 & 14.91 & 15 \\
\hline 6 & 339 & 4.0 & 0.070 & 17.9 & 3.21 & 18.12 & 18 \\
\hline 7 & 343.5 & 4.5 & 0.079 & 20.3 & 2.83 & 20.95 & 21 \\
\hline 8 & 344.5 & 1.0 & 0.017 & 21.2 & 0.97 & 21.92 & 22 \\
\hline 9 & 348.5 & 4.0 & 0.070 & 23.8 & 3.04 & 24.96 & 25 \\
\hline 10 & 353 & 4.5 & 0.079 & 26.1 & 3.02 & 27.98 & 28 \\
\hline 11 & 355 & 2.0 & 0.035 & 28 & 2.12 & 30.10 & 30 \\
\hline 12 & 357 & 2.0 & 0.035 & 29.7 & 1.98 & 32.07 & 32 \\
\hline
\end{tabular}


The drone was used to image the tracer dye at South Beach on January 12, 2017 (Figure 4-4). This weak rip was generated by a 15 knot East wind and 0.6 meter spilling breakers. The drone provides an aerial view of the rip in motion as delineated by the dye. Drones are especially useful where drifters are difficult to deploy.

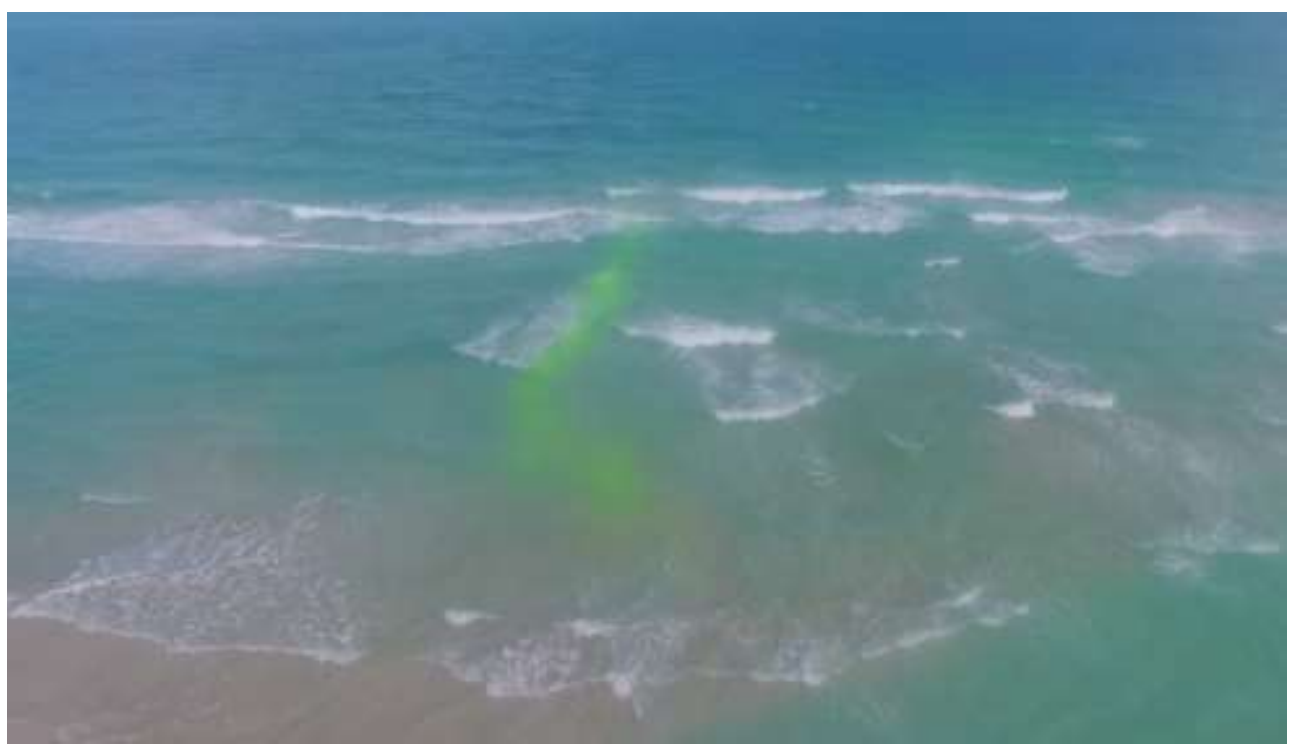

4-4. A weak rip current is delineated by fluorescein tracer dye and imaged by a DJI Phantom 3 Advanced Quadcopter at South Beach on January 12, 2017. This South Florida rip current shows a relatively straight path.

Drone video footage of rip currents on the North Shore of Oahu, Hawaii was collected for a ten day period in March 2018. The videos were analyzed using a proprietary matlab program that utilizes particle image velocimetry (PIV) to determine rip velocity. The foam in the images is useful for tracking particle motion. This program is the property of Dr. John Porter in Honolulu, Hawaii. Figure 4-5 shows the vector map of Ehukai-Pupukea Beach on the North Shore of Oahu, Hawaii with the red arrows indicating relative current flow velocity; a visible rip current is evident on the right side of the image. Each arrow was derived from 60 image pairs over a one-minute time- 
period. PIV-acquired velocities can be verified by GPS drifter measurements undertaken simultaneously with the drone-acquired video.

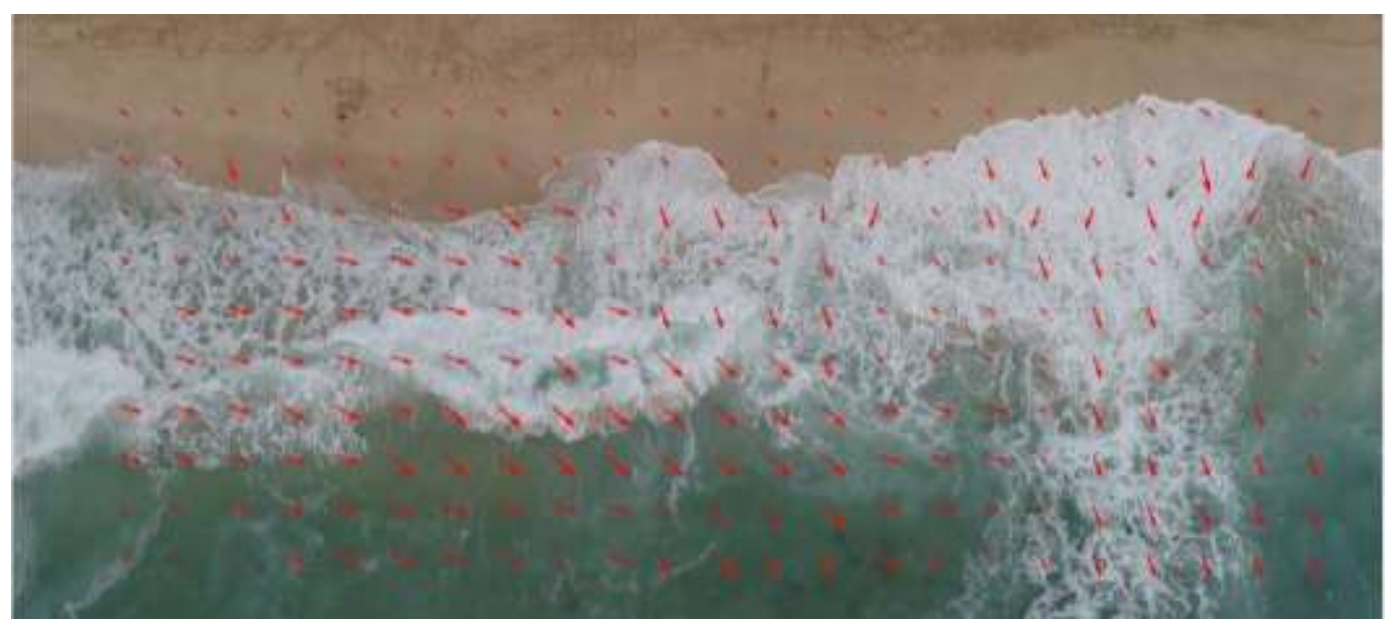

4-5. Particle image velocimetry applied to drone video shows relative rip current velocity on the North Shore of Oahu, Hawaii. The red arrow vectors indicate the direction and magnitude of the current. A visible rip current that is flowing seaward is present on the right side of the image.

\section{DISCUSSION}

The laser rangefinder can image coconuts or any floating objects, has the advantage of being much less expensive than GPS drifters and does not risk instrument loss. Differential GPS instrumentation can cost $\$ 5000$ per drifter (Johnson et al., 2003), and considerable time is required to process the data. Instrument retrieval requires a boat so that the total cost for a deployment can be expensive and time consuming.

The laser rangefinder is hand-held so the operator can be affected by the wind. A fairly steady onshore wind of 15-20 kts was not a problem, but the 30-40 kts wind on another occasion caused problems in holding the rangefinder steady in order to consistently hit the target. A tripod to steady the rangefinder solved this problem.

There can be difficulty hitting a small target such as a coconut at long distances with a laser rangefinder so a larger target like a human drogue can be employed. Tracer 
dye was also used to assure that the person is keeping adrift with the current. South Florida rip currents rarely extend more than 100 meters offshore so there was no problem in employing this technique (Leatherman, 2017). For mega-rips as documented in Australia and California (Brander and MacMahan, 2011), flow measurements along the full extent of the rip may not be possible.

The drone and tracer dye technique has the advantage of the aerial perspective to delineate the full path of the rip current. Videos of rips in action are very useful to study flow characteristics and to visualize currents for public recognition in order to promote beach safety. Speed measurements can be determined by timing the tracer dye as it moves in the rip current relative to ground references. Freeze frames from the drone video can be distorted, but this measurement error can be minimized by positioning the drone directly above the field of view.

Drone operation and placement of fluorescent tracer dye in the water must be cleared with lifeguards and local officials at recreational beaches. Large crowds at Miami Beach greatly restricted drone usage for safety concerns so that only a very weak rip current was imaged (Figure 4-4) on a cold, blustery day when few people were at the beach.

Drone PIV is a low-cost and safe method to measure rip current velocity. A major advantage of using drones instead of land-based cameras for PIV calculations is that drones can capture video straight down. This aerial view permits equal measurements in the front of waves as in the back of waves, which allows for cancellation of the wave motion during statistical analysis. Land-based camera systems capture only the front of the waves, which can introduce wave motion into the current 
measurements. The major limitations of this method are wind conditions. Strong, gusty winds are common during rip current occurrences, and field tests indicate that winds greater than 20-25 kts are not suitable for drone flight.

High winds at the beach can interfere with drone takeoffs and landings. In these situations, the preferred takeoff method is to have an assistant hold the drone above his head while the drone operator rapidly accelerates the drone upwards (Figure 4-2). When landing the drone in high wind speed conditions, quick landing and recovery of the drone is necessary so that sand entering the motors and camera is minimal. A launch pad may be useful.

\section{CONCLUSIONS}

The new methods of using a laser rangefinder with compass, aerial drone video with tracer dye and drone particle image velocimetry provide cost-effective techniques of measuring rip currents. This instrumentation is mobile, can be rapidly deployed and requires a crew of only two people to operate. These new methods separately or in concert can greatly increase our understanding of rip current flow characteristics, especially in dangerous and inaccessible areas. 


\title{
V. RIP CURRENT MEASUREMENTS AT THREE SOUTH FLORIDA BEACHES
}

\begin{abstract}
Rip current measurements in South Florida were undertaken at three locations: Miami Beach, Haulover Park and Riviera Beach. Rip speeds, measured by GPS drifters and fluorescein tracer dye as imaged by a quadcopter, ranged from $0.1-0.5 \mathrm{~m} / \mathrm{s}$ in response to low energy incident waves, which are common for this area. The purpose of this research is to provide a better understanding of the physical aspects of rip currents in a highly-populated area that is also the destination for millions of visitors each year; this information will help lower the loss of life which is presently quite high. The behavior of rips in South Florida was not known because there has been no previous field research conducted in this area. Rip currents, while weak, are hazardous because the wave conditions during these events do not seem threatening to beachgoers.
\end{abstract}

\section{INTRODUCTION}

Rip currents are narrow, seaward-flowing currents that represent the greatest hazard to beachgoers globally. Rip current research was first initiated by Shepard (1936) with application to cross-shore transport and sediment budget calculations. Rip current research has become an increasing topic for scientific study in the past two decades, mainly focusing on beach safety (Leatherman and Fletemeyer, 2011). Extensive field experiments have been conducted in California (MacMahan, et al., 2005; MacMahan et al., 2011), Australia (Brander and Short, 2000; Brander and Short, 2001), New Zealand 
(Brander, 1999), and elsewhere. However, there have not previously been any rip field studies in South Florida.

These "rivers in the sea" generally extend from the shoreline to the breakers and sometimes beyond. The principle driving force is longshore variation in wave height, which is affected by many factors (Haller et al., 2002; Houser et al., 2013; Wright and Short, 1984). Current velocities within rip channels in low energy environments have been found to be on the order of 0.8 to $1.2 \mathrm{~m} / \mathrm{s}$ (Aagaard et al., 1997; Brander, 1999; Sherman et al., 1993; Smith and Largier, 1995), which is higher than measured at these three South Florida beaches.

The objective of this research is to explore the behavior of rip currents in South Florida, which was previously unknown. The overall goal is to promote beach safety. A major problem is that the beaches in South Florida appear safe because they typically have fairly small waves and the so-called "tell-tale" signs of a rip current are not apparent to beachgoers. Another problem is that there is a large number of international visitors who frequent world-famous Miami Beach and have little to no knowledge of these offshore-flowing currents. The result is that Miami Beach experiences the third most rip current drownings in the nation (Paxton and Collins, 2014).

A variety of methodologies have been used to study rip currents. The most common method is direct observation with the naked eye. Visual characteristics of rip currents often include a tongue of sediment flowing offshore, a gap in the breaking waves, darker water indicating a rip channel, and foamy water around the edges of the rip head. However, many times rip currents do not show these "tell-tale" signs and can be difficult to detect by direct observation. Sonu (1972) was one of the first scientists to 
describe the flow characteristics of rip currents. He deployed neutral-density balls and used dye to trace rips at Sea Grove, Florida in the Gulf of Mexico. More advanced technology such as in-situ current meters and pressure sensors are now being used to measure rip velocity. These Eularian methods provide accurate measurements, but there are concerns that in-situ sensors may not capture the mean flow area of the rip (Brander and Short, 2000).

GPS drogues have been used extensively to measure rip currents in California (MacMahan et al., 2011) and elsewhere. These drogues typically consist of a floating platform weighted to be neutrally-buoyant with a GPS unit attached on the top. These real-time, differential GPS units are available commercially for around $\$ 5000$ per unit (Johnson et al., 2003), and therefore the cost of using this technology for rip current studies can be prohibitive to many researchers. Non-differential GPS units, which are an order of magnitude less expensive, are now being used to study rip currents with much success (Sabet and Barani, 2011).

\section{STUDY AREAS}

Rip current measurements in South Florida were conducted at three different coastal settings: South Beach at Miami Beach, Haulover Park, and Ocean Reef Park in Riviera Beach (Figure 5-1). The continental shelf off Miami is narrow, only extending a few kilometers offshore. This would normally allow swell waves to propagate close to shore without being broken, but Miami Beach and Haulover Park are shielded from large oceanic waves by The Bahamas and the extensive offshore shoals as displayed on the Google Earth image (Figure 5-1). Farther northward in Palm Beach County, wave 
energy is higher, and Ocean Reef Park has rock outcroppings on the beach shoreface. All of these beaches have lifeguards to protect swimmers from large waves and rip currents.

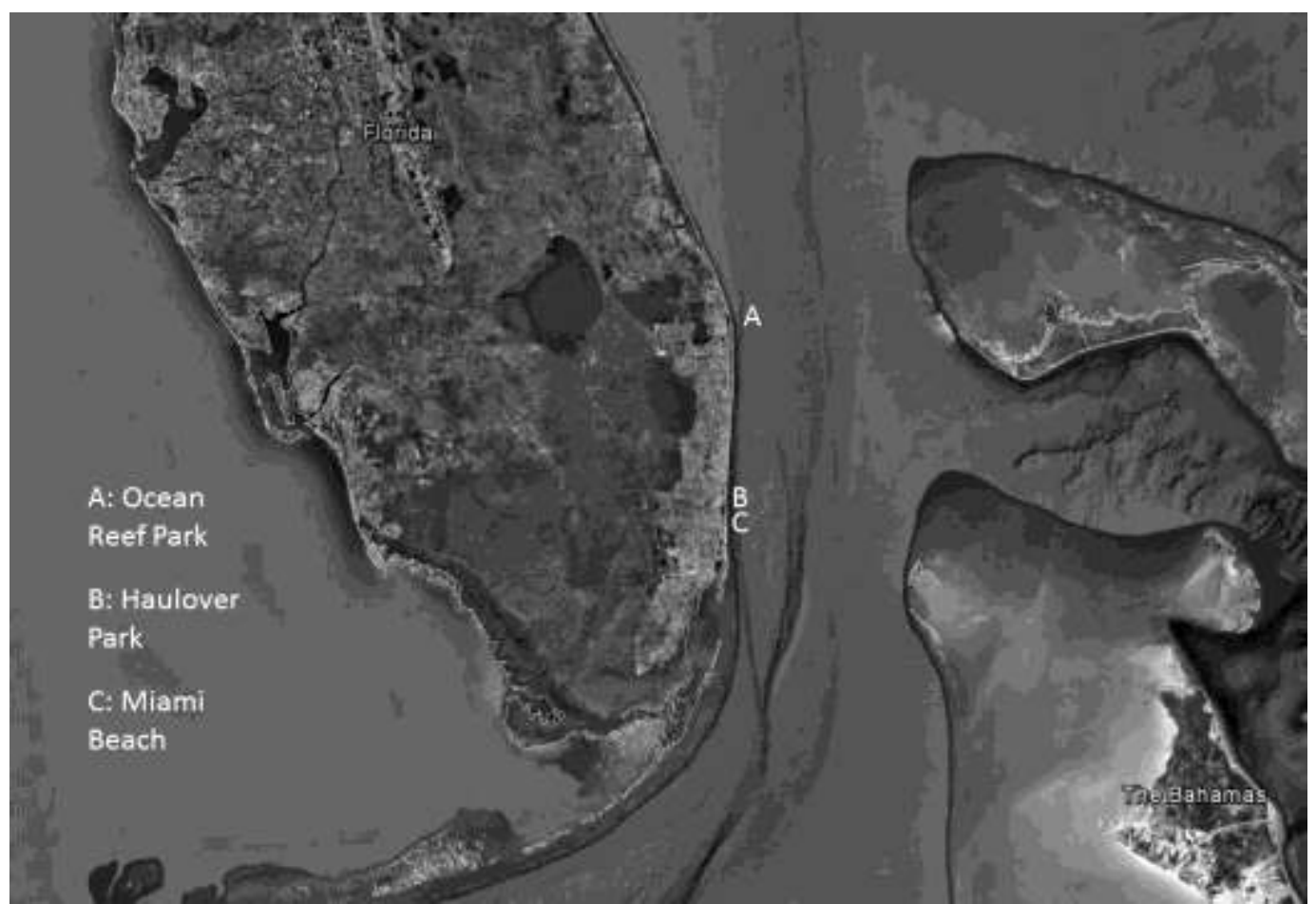

5-1. Location of three study areas in South Florida: A is Ocean Reef Park in Palm Beach County; B is Haulover Park and C is Miami Beach both in Miami-Dade County.

Bar-gap rip currents were studied at South Beach, which is the south end of Miami Beach. South Beach is the most popular beach in Florida with more than eight million visitors annually (Houston, 2013). This beach is characterized by a moderatelysloping beach foreshore $\left(5^{\circ}\right)$ and moderately low wave energy (Leatherman, 2015). Miami Beach was chosen to study bar-gap rips because they commonly occur and cause the most drownings in Southeast Florida (Paxton, 2014).

Structurally-controlled rip currents were studied at Haulover Park, which is located just north of Miami Beach. Haulover Park is the largest available surf beach park in Miami-Dade County. The jetty area attracts many visitors because it is the major 
beach access point with nearby parking. Picnic tables and grills, shaded by Australian pine trees, are also available for public usage in this area. The jetty at Haulover Park is a unique structure that has a beach-parallel spur at the end, which provides a barrier against the waves and creates calmer water near the rocks, making it an inviting place for families (Figure 5-2). This combination of good access and what appears to be safe water can result in a dangerous situation when lifeguards are off duty because the jetty is prone to rip currents (Lt. Matthew Sparling, personal communication, 2015). The danger is compounded during an ebbing tide as the structurally-controlled rip current can take victims into the much faster, adjacent tidal current where speeds can exceed $1 \mathrm{~m} / \mathrm{s}$, which will carry them far offshore (e.g., ebb tidal delta of Haulover Inlet extends more than 1 $\mathrm{km}$ offshore).

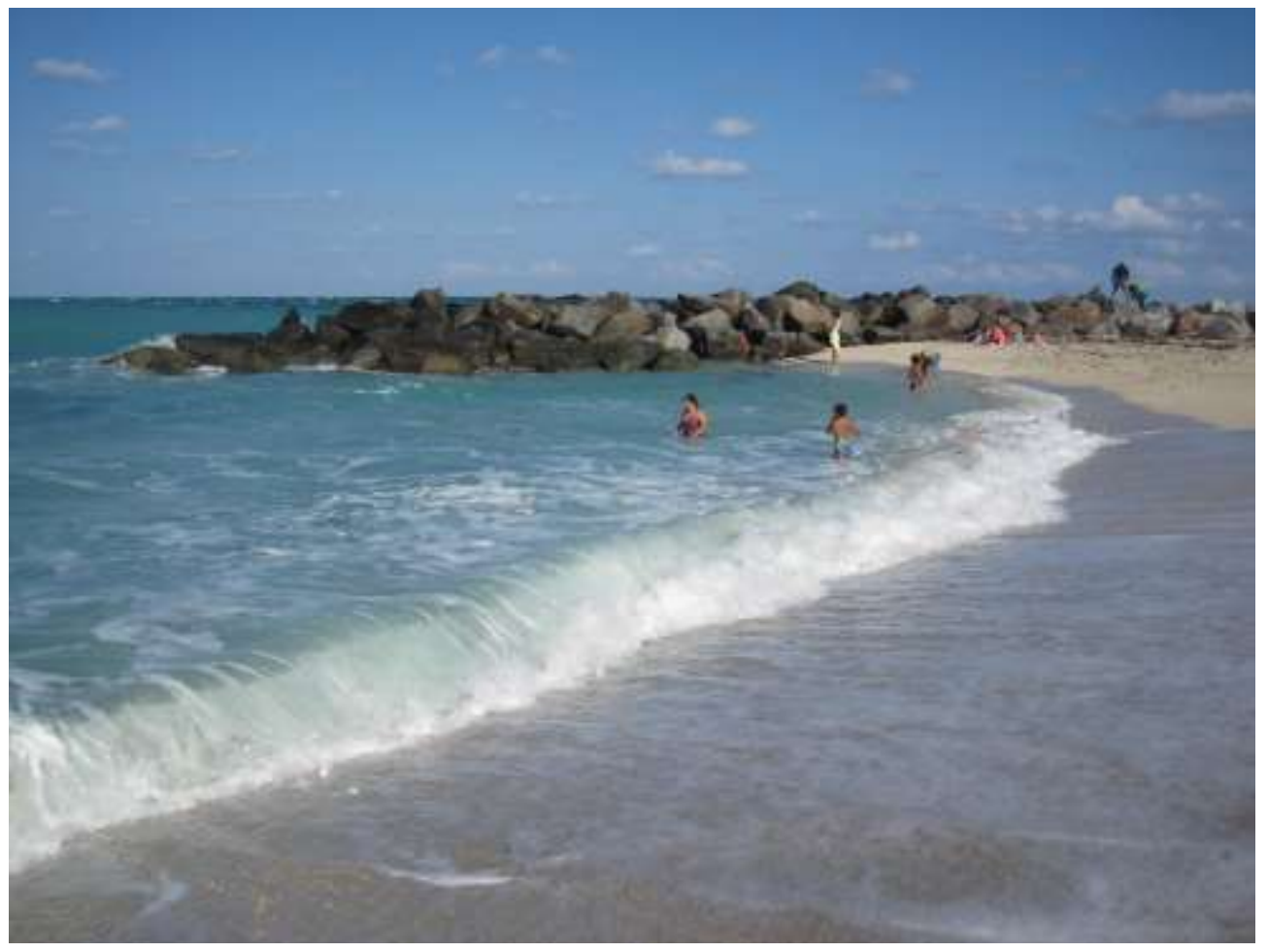

5-2. The breakwater at Haulover Inlet jetty is a popular spot for families to bathe. 
Ocean Reef Park in Riviera Beach is located in Palm Beach County (Figure 5-1). This beach has a structurally-controlled rip current that is formed by an outcropping of the Anastasia formation of coquina limestone rock. The rock outcropping is nearly exposed at low tide. This structurally-controlled rip current is most active during northeast winds at 15-20 kts or higher according to lifeguard Chief Allan Macquen of Ocean Reef Park.

\section{METHODS}

The methodology for measuring rip speeds at Haulover and Miami Beach consisted of a non-differential GPS unit attached to a drifter. The design of the homemade GPS drifters closely resembles that of Sabet and Barani (2011), which consisted of a Garmin etrex $\mathrm{H}$ integrated receiver/antenna shown to have an accuracy of 1 meter. The GPS fits inside a waterproof PVC casing (Figure 5-3). The GPS drifter body is a cylinder of PVC pipe that is $0.15 \mathrm{~m}$ in diameter and is $0.2 \mathrm{~m}$ long. The ends of the cylinder are glued shut with $0.15 \mathrm{~m}$ PVC pipe caps. The drifters are weighted at the bottom with three $1.1 \mathrm{~kg}$ plate weights. The weights act as ballast and allow the drifter to self-right itself when knocked over by waves as aided by the ring of closed-cell foam. On top of the drifter is a water-tight boating box attached by glue. A GPS unit is placed inside of the water-tight box when deployed. 


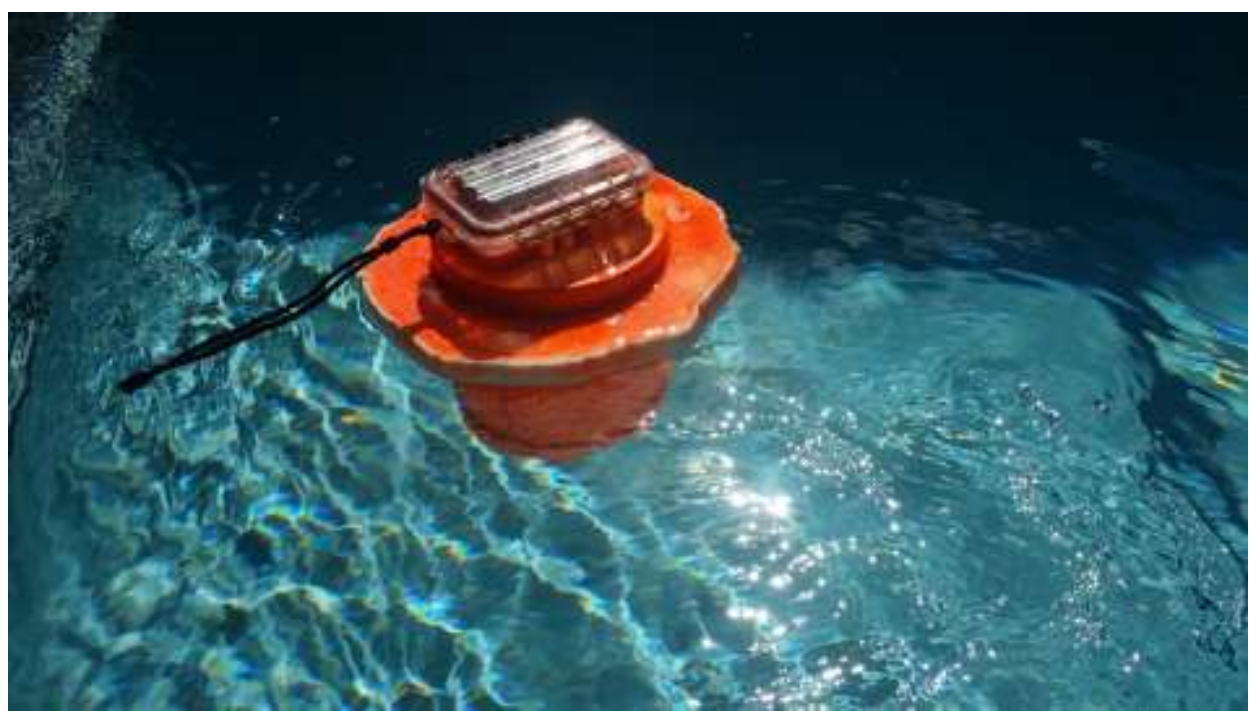

5-3. The GPS drifter is constructed out of a PVC body with a Garmin E Trek H GPS attached on top.

A Nikon Prostaff 7 laser rangefinder was used to determine the GPS drifter position as a check on the GPS measurements. The laser rangefinder is a hand-held, lowcost device that bounces a laser off an object and records the laser travel time to calculate the distance from the object; the Prostaff 7 model has an accuracy of $0.1 \mathrm{~m}$ up to a distance of 540 meters according to the manufacturer. Laser beams were bounced off the GPS drifter as it was pulled offshore in the rip current so that speeds could be calculated by the distance traveled during the time of deployment.

Ocean Reef Park in Riviera Beach is a special case where the rock outcropping made deployment of the GPS drifters impossible at low tide as the shallow water caused the drifter to occasionally hit the bottom. A DJI Phantom 3 Advanced quadcopter equipped with a high definition, gimbal-stabilized video camera was used to trace a plume of fluorescein tracer dye carried seaward by the rip current. This method provides a bird's eye view of the rip in motion as delineated by the dye. Using satellite imagery and geographic information system software, the speed of the rip current was determined 
by calculating the rate that the dye traveled across a known distance (the natural rock outcropping). The distance of the rock outcropping was determined by using ESRI ArcMap GIS software.

\section{RESULTS}

South Beach has an established rip current channel at $10^{\text {th }}$ Street near the lifeguard tower. This bar-gap rip becomes active during certain wind, wave and tidal conditions. During the March 23, 2016 field study, the significant wave height was $0.6 \mathrm{~m}$, and the waves had a period of 5 seconds with spilling breakers. The wind was blowing onshore from the east at $15 \mathrm{kts}$; the wave approach was generally from the east but varied slightly in direction with the confused sea conditions. A weak rip current with an average speed of $0.3 \mathrm{~m} / \mathrm{s}$ was measured in this rip channel based on four deployments of the GPS drifters (Table 5-1).

5-1. Four GPS drifter deployments were undertaken at South Beach on March 23, 2016, which had an average rip speed of $0.3 \mathrm{~m} / \mathrm{sec}$

\begin{tabular}{|l|l|l|}
\hline Deployment & Rip Speed (m/s) & Distance (m) \\
\hline 1 & 0.3 & 60 \\
\hline 2 & 0.3 & 67 \\
\hline 3 & 0.3 & 71 \\
\hline 4 & 0.2 & 75 \\
\hline Average & 0.3 & 68 \\
\hline
\end{tabular}


The weak rip current at South Beach started in waist-deep (e.g., one-meter deep) water. In addition to the GPS drifter, fluorescein dye and a laser rangefinder were used to check the rip speed. One assistant deployed the dye in the rip and flowed with the dyed current while a laser rangefinder was used to take readings off his body; this yielded a similar result of $0.3 \mathrm{~m} / \mathrm{s}$. Interestingly, one teenage girl was caught in the $10^{\text {th }}$ Street rip on March 23, 2016 while the research was underway and had to be rescued by lifeguards via jet ski. While red flags were flying, South Beach had over 50 rescues that day according to Miami Beach lifeguard records as the beach was packed by Spring Breakers. Rip currents measurements were undertaken at South Beach on April 10, 2016 when the beach was very crowded because of an LGBT celebration, and there were many assists and several rescues (Miami Beach lifeguard records) on this red flag day. Field measurements indicated that the wind was blowing from the east-northeast at $15 \mathrm{kts}$ and gusting to $20 \mathrm{kts}$. Significant wave height was $0.6 \mathrm{~m}$ with spilling breakers and a 4 second period. The rip current was apparent in waist-deep water, and rip speed ranged from 0.3 to $0.5 \mathrm{~m} / \mathrm{s}$ (Table 5-2). The rip current was moving southeast because of the longshore current (Figure 5-4). 
5-2. Five GPS drifter deployments were carried out on April 10, 2016 at South Beach; average rip speed was $0.4 \mathrm{~m} / \mathrm{sec}$.

\begin{tabular}{|l|l|l|}
\hline Deployment & $\begin{array}{l}\text { Rip Speed } \\
(\mathrm{m} / \mathrm{s})\end{array}$ & Distance (m) \\
\hline 1 & 0.4 & 70 \\
\hline 2 & 0.4 & 94 \\
\hline 3 & 0.5 & 85 \\
\hline 4 & 0.4 & 82 \\
\hline 5 & 0.3 & 70 \\
\hline Average & 0.4 & 80 \\
\hline
\end{tabular}

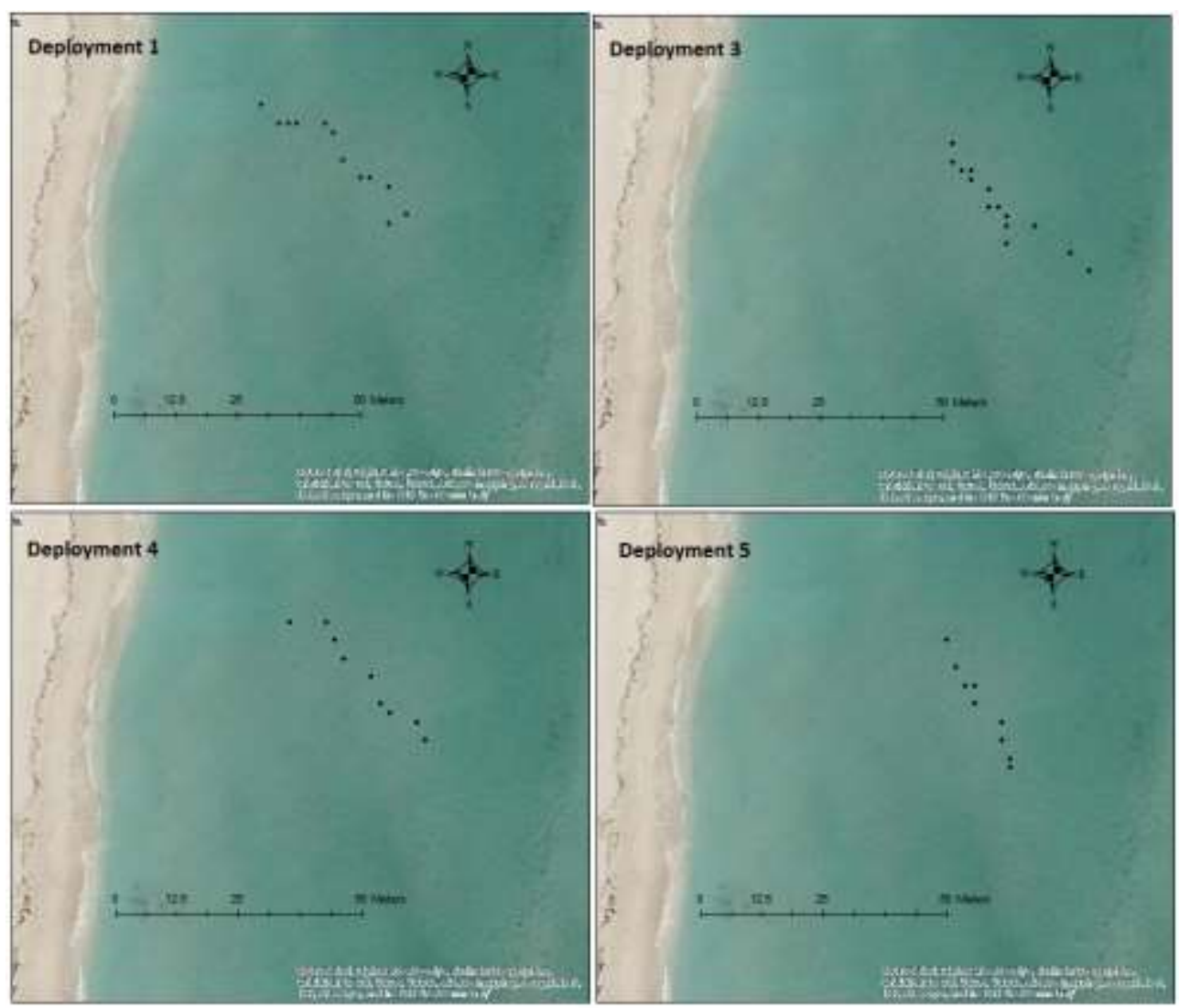

5-4. Rip current paths as determined by GPS drifters on April 10, 2016 at $10^{\text {th }}$ Street in South Beach. The rip current was angled southeast because of the longshore current. The rip was not detected at the shoreline, but instead tens of meters offshore in waist-deep water. 
The rip current was not a steady flow as there was some fluctuation in response to the varying incident waves. The speed only ranged from 0.1 to $0.5 \mathrm{~m} / \mathrm{s}$. The drifter was sometimes hit by a spilling breaker in the rip channel, which pushed it back and made it wobble along its relatively straight pathway with no recurvature (Figure5-4). When a wave passed, the drifter sped up based on an observer who floated in the water with the drifter. During these rip currents, wave heights were small (e.g., $0.6 \mathrm{~m})$ and varied little unlike those areas in the swell-dominated, higher-energy environments. These weak rips did not exhibit the marked pulsing, which can be very dangerous for bathers (MacMahan et al., 2005).

Another set of rip current measurements was acquired on July 18, 2016; the wind varied from 15-20 kts from the east, significant wave height was $1 \mathrm{~m}$ with a 5 second period on this breezy, sunny day. All three GPS drifter deployments yielded a rip speed of $0.4 \mathrm{~m} / \mathrm{s}$ (Table 5-3) so additional measurements were not taken. Red flags were flying, and fewer people were in the water than usual because of the blowing sand on the dry beach and rougher than normal water conditions.

5-3. Three drifter deployments were undertaken on July 18, 2016 at South Beach.

\begin{tabular}{|l|l|l|}
\hline Deployment & Rip Speed (m/s) & Distance (m) \\
\hline 1 & 0.4 & 91 \\
\hline 2 & 0.4 & 101 \\
\hline 3 & 0.4 & 111 \\
\hline Average & 0.4 & 101 \\
\hline
\end{tabular}


Rip current speeds were measured at Haulover Park jetty on April 6, 2016.

Significant wave height was $0.8 \mathrm{~m}$ with spilling breakers and a 6 second period. The wind was $15 \mathrm{kts}$ from the northeast, and red and purple lifeguard flags were flying at the lifeguard stand. This structurally-controlled rip current is created by a breakwater that is attached to the jetty (Figure 5-2). The average rip speed was measured at $0.2 \mathrm{~m} / \mathrm{s}$ (Table $5-4)$.

5-4. Three GPS drifter deployments at Haulover Park Jetty on April 6, 2016 indicated an average rip speed of $0.2 \mathrm{~m} / \mathrm{sec}$. The distance is measured in a northward direction along the breakwater, which is perpendicular to the jetty.

\begin{tabular}{|l|l|l|}
\hline Deployment & $\begin{array}{l}\text { Rip Speed } \\
(\mathrm{m} / \mathrm{s})\end{array}$ & Distance (m) \\
\hline 1 & 0.3 & 10 \\
\hline 2 & 0.2 & 16 \\
\hline 3 & 0.2 & 16 \\
\hline Average & 0.2 & 14 \\
\hline
\end{tabular}

A frontal system on June 20, 2016 generated 15 kts onshore winds, resulting in a significant wave height of $0.9 \mathrm{~m}$ and period of 7 seconds. The rip current speed ranged from $0.1 \mathrm{~m} / \mathrm{s}$ to $0.3 \mathrm{~m} / \mathrm{s}$ based on five deployments of the GPS drifter at the jetty breakwater (Table 5-5). Interestingly, a nearby bar-gap rip at Haulover Park was delineated by a stream of offshore-flowing seaweed. The significant wave height by that afternoon had dropped to $0.6 \mathrm{~m}$, and the rip speed was measured to be only $0.1 \mathrm{~m} / \mathrm{s}$ at low tide. 
5-5. Five GPS drifter deployments at Haulover Park Jetty on June 20, 2016 indicated an average rip speed of $0.2 \mathrm{~m} / \mathrm{s}$. The distance is measured in a northward direction along the breakwater, which is perpendicular to the jetty.

\begin{tabular}{|l|l|l|}
\hline Deployment & Rip Speed (m/s) & Distance (m) \\
\hline 1 & 0.1 & 9 \\
\hline 2 & 0.3 & 8 \\
\hline 3 & 0.3 & 18 \\
\hline 4 & 0.1 & 9 \\
\hline 5 & 0.2 & 7 \\
\hline Average & 0.2 & 10 \\
\hline
\end{tabular}

The structurally-controlled rip current at Ocean Reef Park in Riviera Beach (Palm Beach County) was measured on April 27, 2016. The significant wave height was $0.6 \mathrm{~m}$ from the east-southeast with a period of 10 seconds. Wind speed was only $10 \mathrm{kts}$ from the east. The rip current is controlled by an outcropping of Anastasia formation of coquina limestone rock, making it angle towards the southeast (Figure 5-5). Rip speed could not be measured by the GPS drifter because it would occasionally hit a rock during this low tide field study. Instead, a fluorescein dye plume was released into the rip current and video recorded by the quadcopter. Rip speed was determined by the distance that the dye traveled as recorded on the timed video, which amounted to a distance of 39 meters in 100 seconds — an average of $0.4 \mathrm{~m} / \mathrm{s}$. Several other dye tests yielded similar results. 


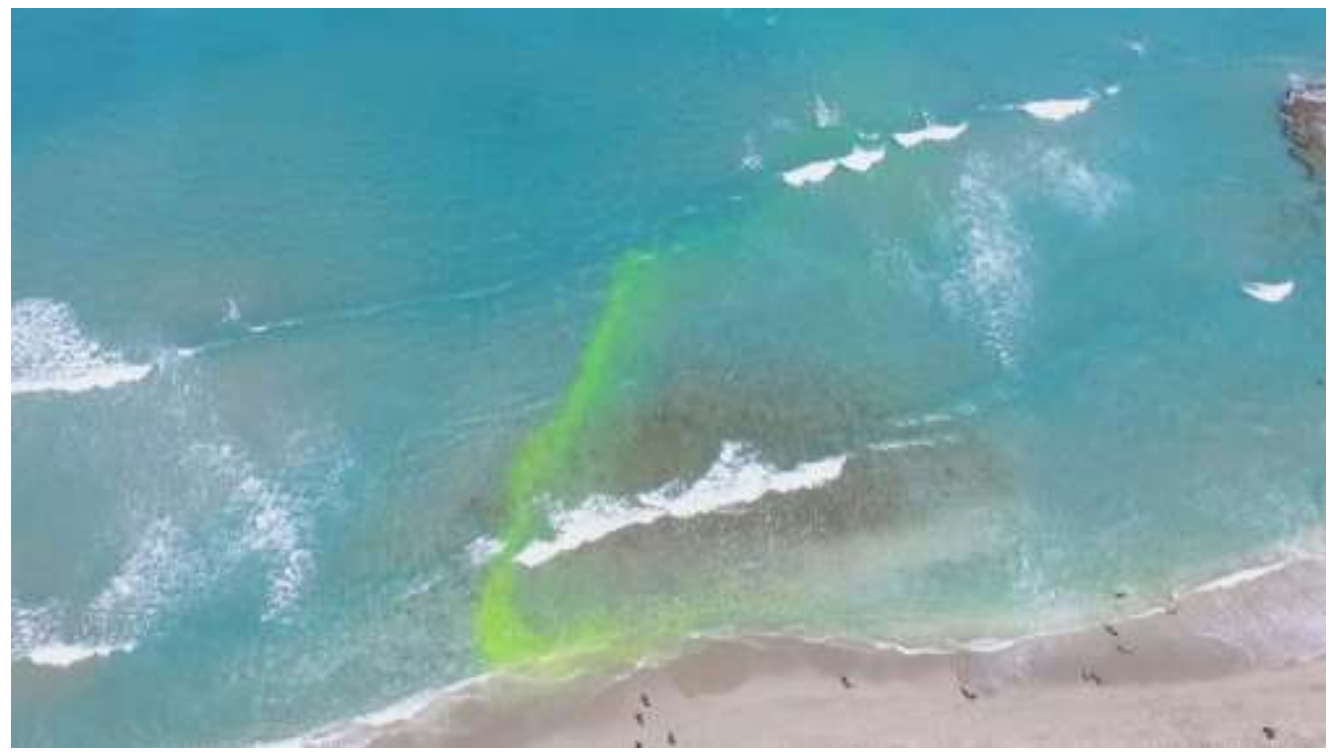

5-5. The freeze-frame from the quadcopter video shows the rip current at Ocean Reef Park as delineated by fluorescent dye; the rip is angled east-southeast as controlled by the rock outcrop.

\section{DISCUSSION}

Rip currents in Miami Beach differ from those at swell-dominated beaches due to the fact that their mean rip speed is similar to their maximum speed. Studies in California (MacMahan et al., 2006) and Australia (Brander, 1999) found a rip speed of 0.3 to $0.4 \mathrm{~m} / \mathrm{s}$, respectively, with a maximum of $2 \mathrm{~m} / \mathrm{s}$. Miami Beach rips never displayed a rip speed greater than $0.5 \mathrm{~m} / \mathrm{s}$, with the average rip speed being $0.3 \mathrm{~m} / \mathrm{s}$. Miami Beach has a gently-sloping nearshore (Leatherman, 2015; also see Chapter 3 in this dissertation) such that beachgoers can venture 15-20 meters offshore at low tide and still be in shallow water (e.g. less than waist-deep), making it safer compared to the steeper-sloping beaches of Monterey, California and Sydney, Australia. Additionally, the waves at Miami Beach were typically short-period (5 second) and low energy ( $0.6 \mathrm{~m}$ in height), which is much lower than those found in Australia and California (MacMahan et 
al., 2006). Therefore, Miami Beach appears to be a safe place to bathe, but it is the third most deadly beach area in the United States (Paxton, 2014). Another difference is that a huge number of people, approximately eight million per year, visit Miami Beach (Houston, 2013). Many of these visitors are tourists from other countries who are weak swimmers (based on an unpublished survey of beachgoers by the author). While the rips at Miami Beach move fairly slowly, they are still dangerous as they can occur during seemingly safe conditions (e.g., low wave heights of 0.6-0.9 m on sunny days) albeit red flags are flying.

Rip currents at Miami Beach are often hard to locate because of the confused sea conditions, which includes some wave-breaking in the rip channel. Fluorescein dye tracer was used to detect the offshore-flowing current and therefore where to place the GPS drifter. The rip was very narrow, being only a few meters wide so one drifter was deployed. Five drifters have been used in much larger and more powerful rips in California (MacMahan et al., 2005). For the weak, narrow rips in South Florida, the pathway was well-defined by one drifter with multiple deployments.

Structurally-controlled rips at Haulover Park were measured using the GPS drifter. The drifter had a thin $(0.5 \mathrm{~cm}$ diameter $)$, floating neoprene line attached to prevent its loss around the breakwater and into the tidal flow at Haulover Inlet. The GPS drifter was placed in knee- deep (approximately 1 meter) water in the protection of the breakwater where bathers often congregate (Figure 5-2). The drifter moved north in response to deflection of the longshore current, which measured $0.6 \mathrm{~m} / \mathrm{s}$. It was carried by the rip current in spurts; larger breaking waves stalled drifter movement, but afterwards it would start moving again. The weak rip current was measured during eight 
deployments with the average speed being $0.2 \mathrm{~m} / \mathrm{s}$ (Tables 5-4 and 5-5). Fluorescein dye was also released simultaneously with the drifter, and this tracer dye showed that the rip fed into the tidal current. This area is particularly dangerous because the relatively quiet water behind the breakwater is perceived to be safe for families and bathers.

Red flags were flying on all days in which rips were measured except for Ocean Reef Park. Red flags mean no swimming is advised, but it does not imply that the beach is closed. There were many people in the water during the field experiments, indicating that beachgoers do not take the flags very seriously. Winds generated by high pressure systems to the north produce breezy beach conditions, and beachgoers that included the research team found it to be refreshing on hot sunny days. The general public does not equate danger with fair-weather conditions in combination with fairly small, spilling breakers. Furthermore, the "tell-tale" signs of rip currents, such as a tongue of turbid water moving offshore, are not present with these clear-water rips. There are no flowing rivers in South Florida, and the only rock type is limestone; therefore, there is no source of fine-grained sediment (e.g., silt and clay) that results in water turbidity. In terms of beach safety, beachgoers do not detect any of the warning signs from the waves or currents here.

Weak, clear-water rips are typical for South Florida, but stronger rips can be generated by swell waves or a more consistent and stronger wind field. Winter nor'easters can generate large swell waves, but they rarely hit Miami Beach because of blockage by The Bahamas and the extensive offshore shoals (Figure 5-1). Typically, these conditions do not pose a major threat because most beachgoers stay out of the water during large waves (e.g., exceeding $1.5 \mathrm{~m}$ ). During the winter of 2015-2016, El Nino 
suppressed winter nor'easters off the Carolina coast which severely limited swellgenerated rip currents in South Florida.

\section{CONCLUSIONS}

South Florida is a low wave energy environment - significant wave heights that generated rip currents averaged $0.6 \mathrm{~m}$ to $0.9 \mathrm{~m}$ during this field study. These conditions resulted in fairly weak rip currents with an average speed of $0.3 \mathrm{~m} / \mathrm{s}$. The rips exhibited nearly straight-line paths that terminated seaward of the sand bar-the GPS drifters and fluorescein tracer dye as imaged by the quadcopter did not travel far beyond the breaker zone. Quadcopters are now being used for field surveying in many areas and are especially useful for studying rip currents adjacent to shore-perpendicular, coastal engineering structures (e.g., groins and jetties) and in high-energy wave environments where large breaking waves cause dangerous conditions.

South Florida rip currents are "clear-water rips" as little to no sediment is entrained in the flow (Figure 5-5). Clear-water rips, even weak ones, are especially dangerous because most beachgoers cannot detect them. It is also difficult to spot rip channels without utilizing polarizing sunglasses because of the glint off the water surface. Therefore, beachgoers do not sense danger and often ignore the red flags, too often resulting in drownings. 


\title{
VI. RIP CURRENT FLOW CHARACTERISTICS AND HAZARDS FOR BEACHGOERS
}

\begin{abstract}
The effect of rip currents on swimmers was analyzed based on the drag force acting on swimmers and the power they generate to overcome the currents when swimming against them. The drag force and power increase quadratically and cubically, respectively, with increase of rip current and swimming speeds. An additional $50 \%$ increase in rip current speed above swimmer's speed results in a $125 \%$ increase in drag force, requiring a $237.5 \%$ increase in power by the swimmer to overcome the additional drag. Hence, even rip currents of low velocity can be dangerous and swimming against the current should be avoided if possible. A hazard rating developed based on rip current speeds generated low, moderate, high, and extreme categories corresponding to speeds $<0.25,0.25-0.60,0.60-1.0$, and $>1.0 \mathrm{~m} / \mathrm{s}$. By directly linking the degree of danger with rip current speeds, this rating system provides an easy-to-understand way to educate the public of the hazardous effect of rip currents on swimmers.

Because swimming against a rip current is difficult in most cases, rip current escape techniques become very important and are a subject of debate among coastal scientists and surf safety practitioners. Field measurements at three South Florida beaches during 2016 showed that rip currents were weak, flowed in a fairly straight path, and terminated just offshore of the breaker zone. Recent studies in California indicated that these much stronger rips exhibited a circulatory pattern, which could bring a floater back to the safety of a shallow sand bar. South Florida bar-gap rips do not exhibit these flow characteristics so that the traditional approach of swimming left or right, parallel to
\end{abstract}


the shore is probably the best escape strategy. Structurally-controlled rips are unique in that the optimal escape strategies are site-specific.

\section{INTRODUCTION}

Rip currents are narrow strips of water flowing away from the shore and across the surf zone, which are mainly induced by longshore variation in breaking waves and bathymetry. Typical rip currents have a width of $50 \mathrm{~m}$, length of $100 \mathrm{~m}$, and speeds of $0.5-1 \mathrm{~m} / \mathrm{s}$, sometimes reaching a maximum of $2.4 \mathrm{~m} / \mathrm{s}$ (Castelle et al., 2016b; MacMahan et al., 2011). Inexperienced swimmers who are trapped by a rip current and transported to deeper water offshore often attempt to swim against the current directly back to shore at the risk of exhaustion, panic, and drowning unless rescued (Miloshis and Stephenson, 2011). In the United States, drowning associated with rip currents causes $80 \%$ of surf rescues and about one hundred death each year, more than the annual death from the combination of tornadoes, sharks, hurricanes and lightning strikes (Gensini and Ashley, 2010; Miloshis and Stephenson, 2011).

Great progress has been made in the past fifteen years to understand the pattern, dynamics, and formation of rip currents (Castelle et al., 2016b; Dalrymple et al., 2011; MacMahan et al., 2006), develop and evaluate escape strategies (MacMahan et al., 2011; McCarroll et al., 2014; Miloshis and Stephenson, 2011), and examine the rip current knowledge of beach visitors and rip survivors (Drozdzewski et al., 2012; Fallon et al., 2018; Sherker et al., 2010). Yet, few studies have quantified or classified the severity of rip current hazards to human beings, which is essential for public education of rip hazards and operational warning of the risk by beach safety practitioners. 
Lushine (1991) proposed a scale to quantify the threat of rip currents based on the relationship between rip current occurrence and wind, tide and swells by analyzing drowning, meteorological, and oceanographic records for Miami-Dade and Broward counties of southeast Florida from 1979 through 1988. The rip current danger was rated by categories from zero to five, with Category Zero constituting no rip current danger and Category Five signifying high danger.

The Lushine scale was calculated mainly from local wind speed and direction since wave data were lacking for southeast Florida. This scale has been refined by Lascody (1998), Engle et al. (2002), Dusek and H. Seim (2013), and Reinhart and Pfaff (2016) by incorporating wave data into the rating. The operational forecast produced by the National Weather Service (NWS) rates the risk of rip current hazards into three categories of low, moderate, and high risks based on these studies. A low risk indicates that rip currents are not developed by winds and waves, while a high risk of rip currents means dangerous and potentially life threatening conditions for swimmers (https://www.weather.gov/safety/ripcurrent-forecasts). The Lushine and NWS scales are essentially measures of the likelihood of weak and strong rip currents, rather than metrics of the degree of danger from rip currents. For example, these scales cannot explicitly assess how much the danger increases if the rip current speed increases from $0.3 \mathrm{~m}$ to 0.5 $\mathrm{m} / \mathrm{s}$, resulting in difficulty in educating beachgoers of the risk of rip currents. Field measurements near Duck, North Carolina, USA, showed that the strongest measured rip current speeds coincided with high hazard likelihoods (Moulton et al., 2017). However, some of the highest likelihoods of rip currents from the forecast corresponded to 
moderate rip speeds. Therefore, the likelihood of rip currents from NWS forecasts did not always match with rip speeds.

In order to rate rip current hazards, McCarroll et al. (2014) employed hazard classes developed for the fresh water flooding based on investigations of loss of human stability in flood flows from indoor experiments (Abt et al., 1989; Jonkman and PenningRowsell, 2008; Wade et al., 2005). The severity of the flood hazard is given by

$$
H R=d(u+0.5)
$$

where HR represents flood hazard rating with a unit of $\mathrm{m}^{2} / \mathrm{s}$, $\mathrm{u}$ is the speed of floodwaters in $\mathrm{m} / \mathrm{s}$, and $\mathrm{d}$ is the depth of the flooding in $\mathrm{m}$. The flood hazard was classified into low, moderate, high, and extreme for HR values of less than $0.75,0.75-1.25,1.25-2.5$, and greater than $2.5 \mathrm{~m}^{2} / \mathrm{s}$, respectively.

The HR was used by Hanes (2016) to analyze human instability (the loss of contact between a beachgoer's feet and the seabed) in surf zones and by Van Leeuwen et al (2016) to define hazard areas based on water depths. Quantification of the loss of stability in the ocean water with rip currents is certainly a way to measure the severity of rip current hazards. Introduction of the water depth into the equation makes HR values more site-specific and difficult to quantify because the water depth changes as tides fluctuate and the bottom topography is modified by erosion and accretion. Also, accurate measurements of bathymetry are rarely available. It is preferred to use a single value representing the strength of rip currents (e.g., speed) to rate hazard at a beach to simplify warning and education from operational perspective. Moreover, according to a survey of rip current survivors (Drozdzewski et al., 2012), the dominant physical response to being caught in rip currents is "swim against rip/toward shore" and emotional responses are 
"panic, anxiousness, nervousness, distress or fear". Drowning may then result from fatigue induced by energy exhaustion through swimming against rip currents. The risk of drowning, i.e., the degree of danger of a rip current, is determined by two factors: (a) the strength of a rip current and (b) the ability of the swimmer to overcome this strength. It follows, then, that rip currents may be rated according to the power that a swimmer has to generate to overcome the drag force induced by the current.

Many studies on the drag force caused by swimmers have been done in the field of biomechanics (Hazrati, 2016; Sacilotto et al., 2014; Toussaint et al., 2002). The drag force produced by swimmers is composed of skin friction drag, form (or pressure) drag associated with the pressure difference between the head and toe of a swimmer, and wave drag caused by the movement of the swimmer through the surface of water (Vorontsov and Rumyantsev, 2000b; Webb et al., 2011). The drag force on a swimmer may also be distinguished as passive drag, that is generated as the swimmer glides through the water without using self-propulsive force, and active drag, that is generated by the swimmer who uses self-propulsive force to propel the body forward (Hazrati, 2016; Vennell et al., 2006). Since the swimmer has to propel himself forward when swimming against rip currents, active drag is the subject of this study, and hereafter is referred to simply as drag. By analyzing the relationship between drag forces, swimming velocities, and rip current velocities, our objectives were to (1) quantify the danger of rip currents by estimating their effect on the drag forces acting on swimmers, and the powers produced by swimmers to overcome drag forces when swimming against rip currents; (2) to classify and rate rip hazards in terms of the powers for overcoming drag forces. 
Rip currents account for approximately 100 drownings in the United States annually and probably more than 500 globally (Brander and MacMahan, 2011). These seaward-flowing currents are deceptively dangerous as they are often seen as calm water between breaking waves, offering an inviting place to swim (Figure 6-1). Rip currents receive far less attention than other coastal hazards because they do not result in economic losses to property and relatively few people are impacted at any one time or location. In fact, rip current drownings are rarely reported in the national news; many people know little about their dangers, yet they are responsible for more deaths annually on average than tornadoes, sharks, hurricanes and lightning strikes and are the major hazard on most surf beaches (Short and Hogan, 1994). There are more rip drownings in Florida than any other state (Figure 6-2).

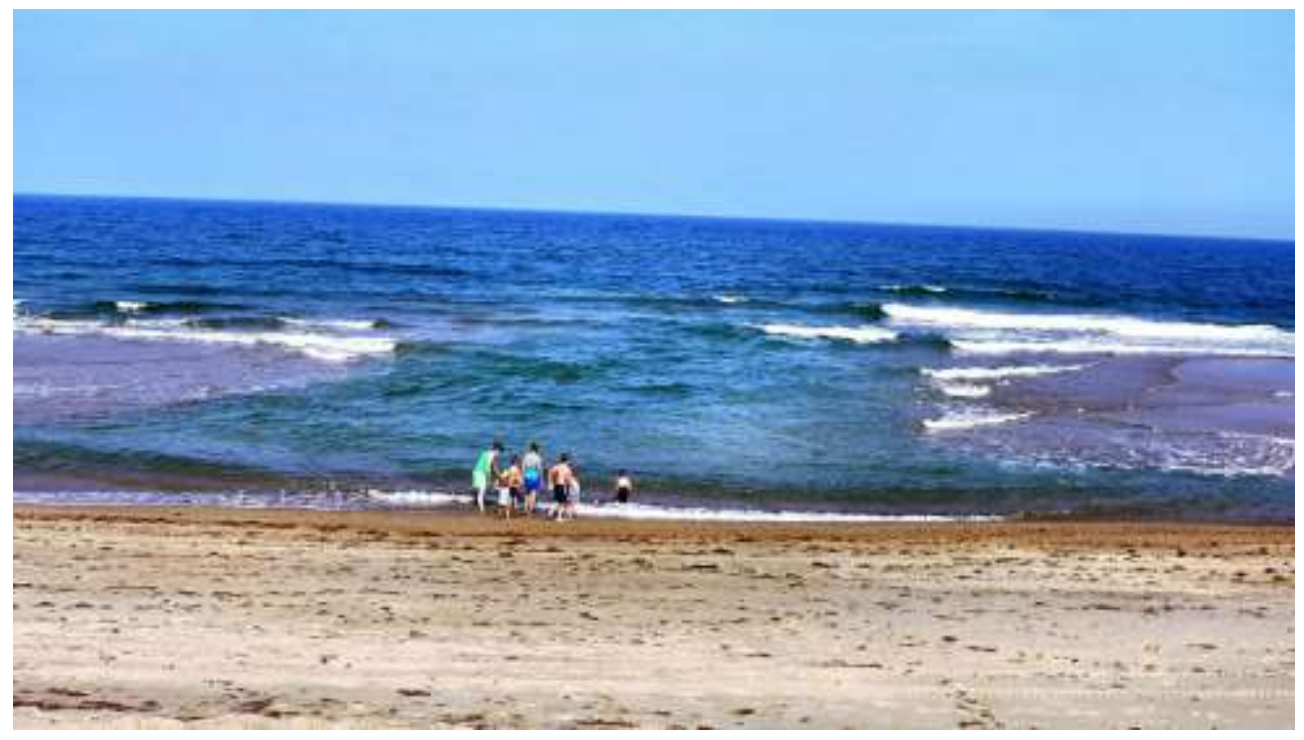

6-1. A family prepares to enter the water at the location of a bar-gap rip current on the Outer Banks of North Carolina (Photo courtesy of David Elder). This "clear-water" rip is deceptively dangerous as the lack of breaking waves appears as an inviting place to swim. 


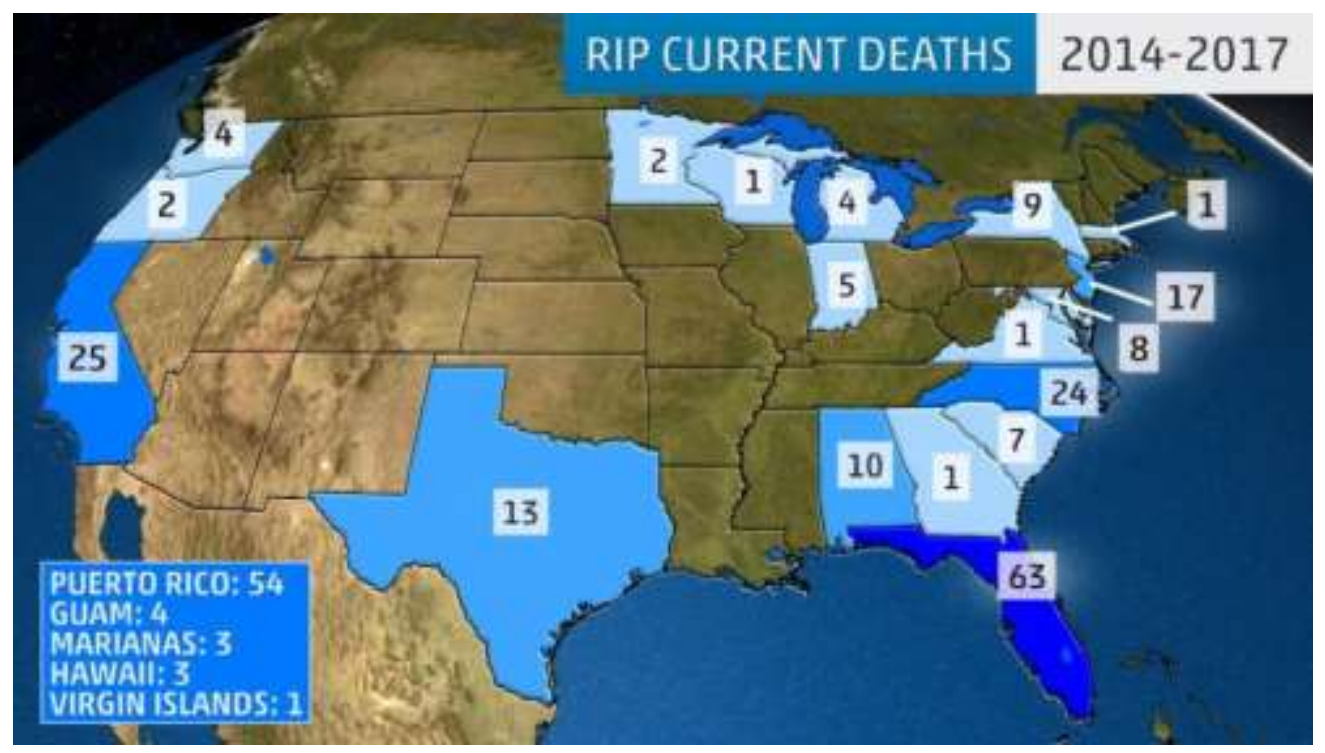

6-2. Rip current deaths in the United States 2014 to 2017 (Dolce, 2017).

Beaches are the number one recreational destination for Americans, and there are more than two billion beach visits per year (Houston, 2013). The United States public is primarily educated about rip currents on site via beach hazard flags, where lifeguards post current beach conditions by using different colored flags to represent danger. Many visitors from inland areas lack experience and knowledge of the ocean, and international tourists may not be able to read beach warning signs or understand the hazard flag system. This lack of public knowledge contributes to the high annual death toll of rip currents.

Shepard (1936) was the first person to coin the term "rip current" in order to distinguish them from undertow and rip tide, which are separate phenomena commonly confused with rip currents. Undertow is a seaward-flowing current produced by the backwash of a breaking wave which extends only as far as the next breaking wave. Calling a rip current "undertow" is a misnomer--rip currents extend beyond the surfzone 
and do not pull bathers under the water as the name "undertow" implies. A rip tide, another misnomer for a rip current, is a strong current produced by tidal constriction at an inlet. Rips are wave-driven, not tidally-generated, and are generally much narrower currents than rip tides.

Rip current research was originally conducted for cross-shore transport and sediment budget calculations, not beach safety. Sonu (1972) was one of the first scientists to describe the flow characteristics of rip currents. He deployed neutral-density balls and used dye to trace rips at Sea Grove, Florida in the Gulf of Mexico. Unlike Shepard's conceptual diagram of a shore-perpendicular pathway, rip currents were sometimes arcuate in shape because of a strong longshore current (Figure 6-3).

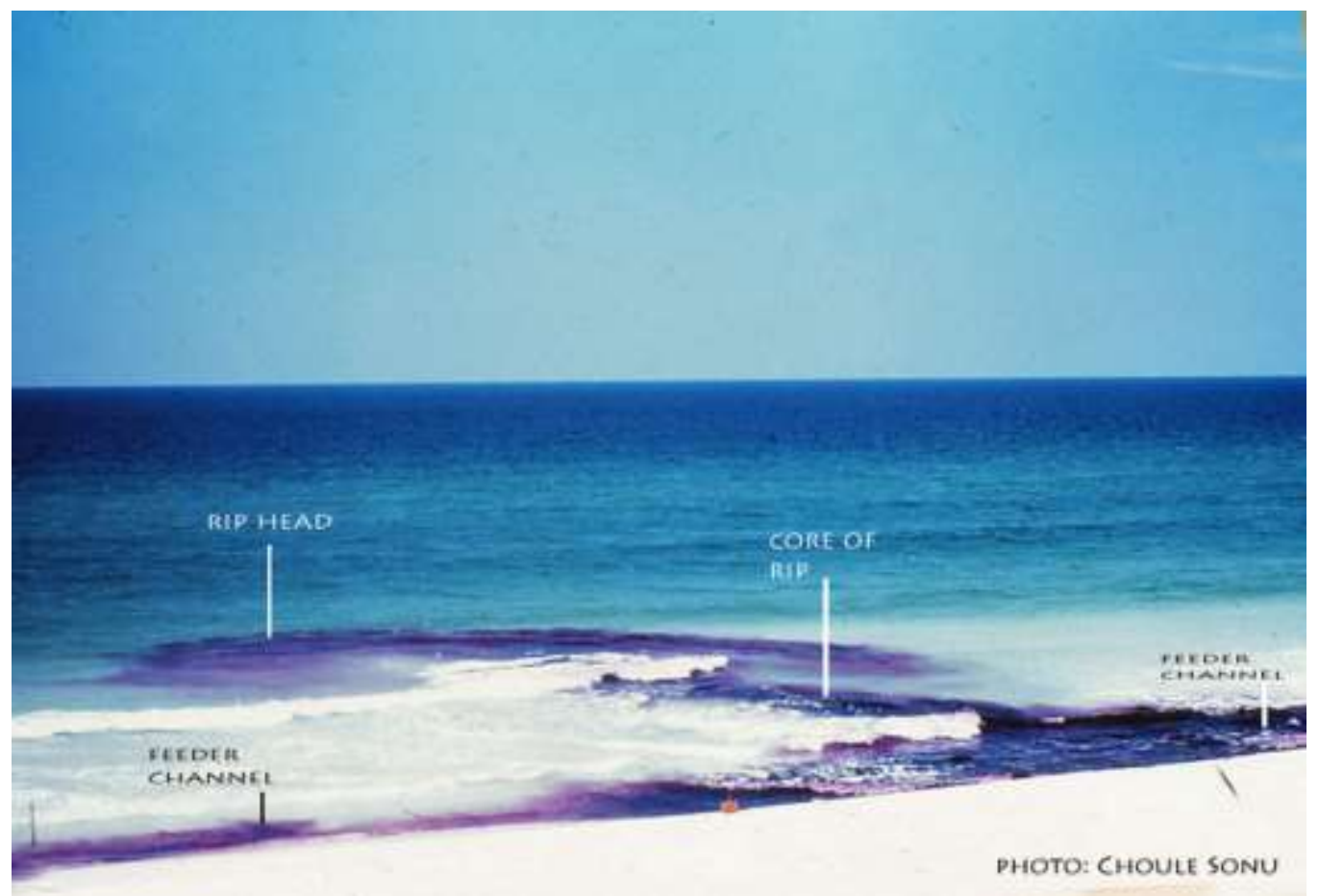

6-3. A Florida panhandle rip current has an arcuate shape due to a strong longshore current (Photo courtesy of Choule Sonu 1972). 
Recent papers (e.g., Brander and MacMahan, 2011; Bradstreet et al., 2014) indicated that rip currents, especially in California, are often characterized by circulatory eddies (Figure 6-4), and hence swimmers might choose to float until the current brings them back to the sand bar. MacMahan et al. (2010) conducted studies at an open-coast beach in Sand City, Monterey, California where GPS surf zone drifters were used to study rip current flow patterns. The circulatory eddies were found to deliver swimmers back to the safety of the bar $80 \%$ of the time, and exit the surf zone the other $20 \%$.

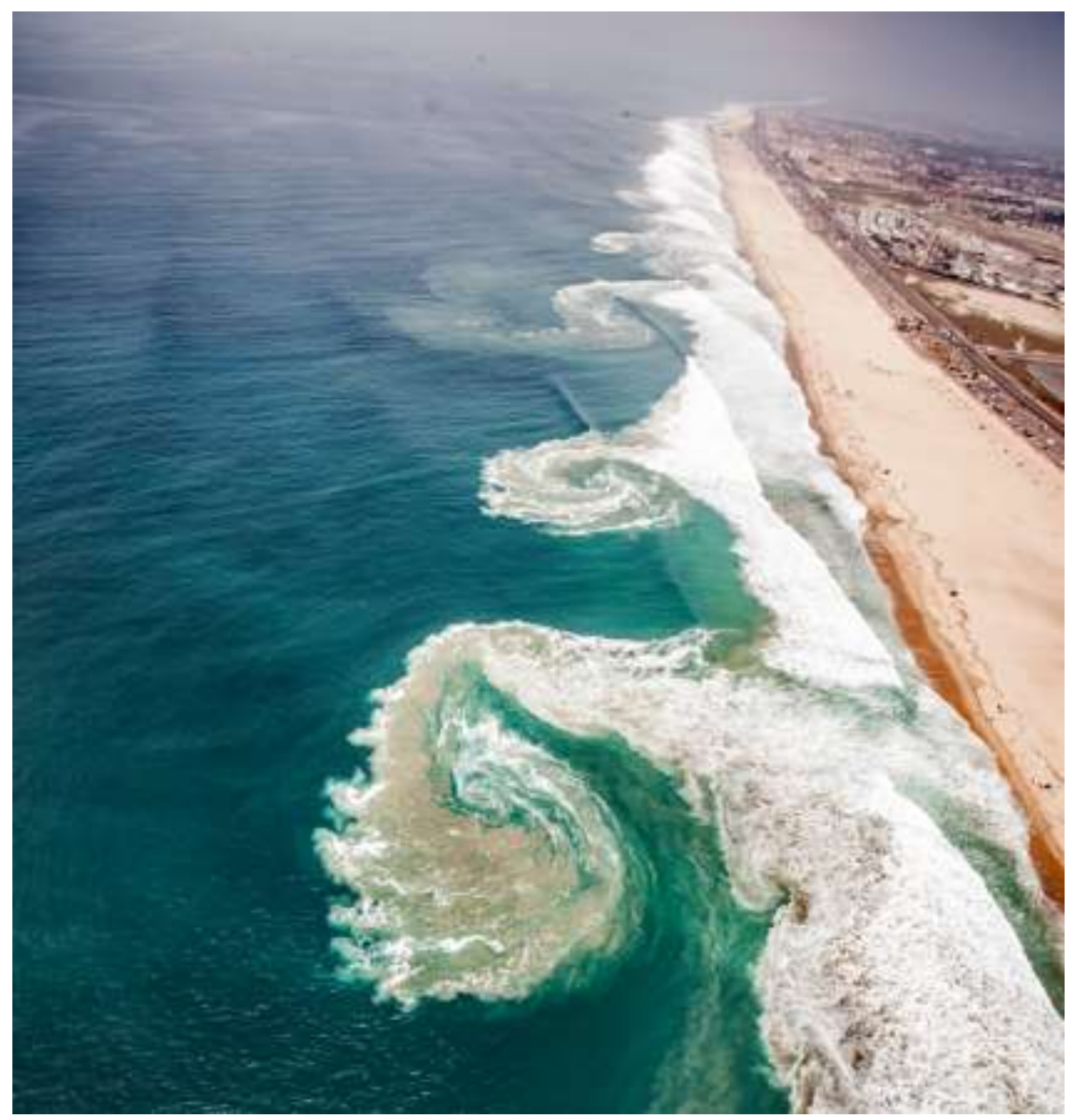

6-4. Rip currents with a circulatory pattern are shown at Newport Beach, California (Photo courtesy of Tom Cozard). 


\section{METHODS}

Research was conducted to determine the flow characteristics of rip currents in South Florida. Presently there is a controversy regarding whether to swim parallel to the shore or to let the current take one offshore with the hope that the rip will recurve landward and deliver the floater to the shallow, nearshore bar (Brander and MacMahan, 2011). This study involved acquiring the first field measurements of rip current in South Florida and was designed to address the question of rip flow characteristics and hence the best escape strategies.

Rip currents were studied at three different coastal settings: Miami Beach, Haulover Park jetty area, and Ocean Reef Park in Riviera Beach (Figure 6-5). GPS drogues were used to measure rip speeds and track. A Garmin Etrex GPS receiver and antenna, similar to those employed by Sabet and Barani (2011), were mounted on a drogue that was neutrally buoyant (Leatherman and Leatherman, 2017). The GPS drogues were deployed multiple times within each rip current, and the average speed was determined. There are no nearshore wave gauges located in the study area so measurements were made directly by researchers in the surf zone. Paxton (2014) showed that the offshore NOAA wave buoy data did not correlate well to rip current occurrence because of wave interference caused by the nearshore coral reefs in South Florida. 


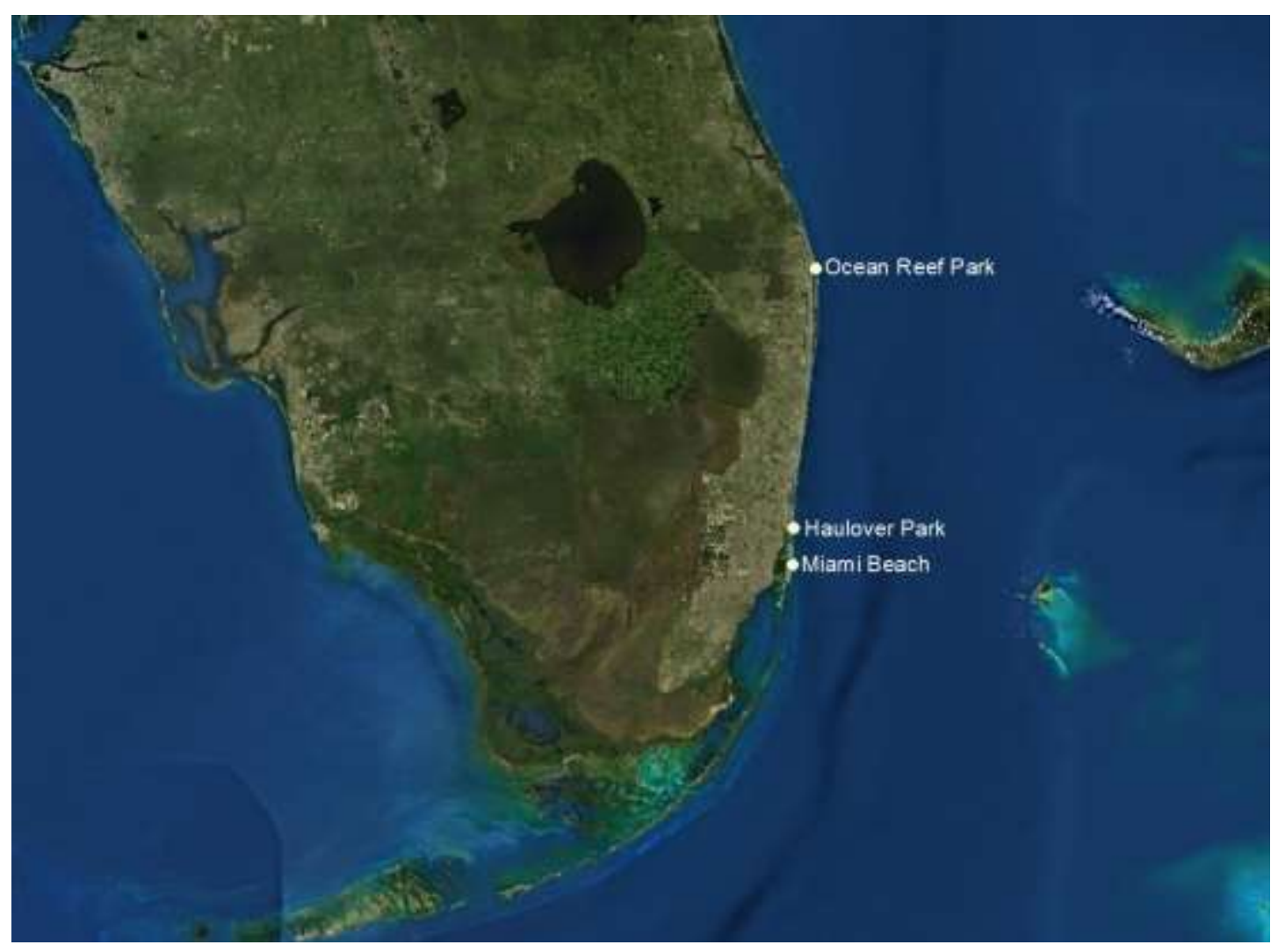

6-5. The three study areas are shown: Ocean Reef Park, Haulover Park and Miami Beach.

Rip current paths were imaged using a DJI Phantom 3 Advanced Quadcopter which has a built-in 1080p hd gimbal-stabilized video camera. Florescence tracer dye was released into the rip current to delineate the path, and the quadcopter was used to video record the dye as it was carried by the rip. The florescence tracer dye is an environmentally-safe disodium salt that degrades in sunlight in a matter of minutes. A freeze-frame from the quadcopter video was used to show the path of the rip currents. These freeze-frames were taken approximately five minutes after release of the tracer dye as to allow the dye to fully encompass the rip current.

Rip current danger to an individual is determined by the strength of a rip current and the ability of the swimmer to overcome this strength. The relationship between drag 
forces, swimming velocities, and rip current velocities were analyzed in order to quantify the danger of rip currents by estimating their effect on the drag forces acting on swimmers and the power produced by swimmers to overcome drag forces when swimming against rip currents. Rip hazards were classified and rated in terms of the powers that a swimmer has to generate for overcoming these drag forces.

Two major variables, the velocity of rip currents $\overrightarrow{u_{r}}$ that indicates the strength of a rip current and the maximum sustainable velocity from steady pace swimming $\overrightarrow{u_{s}}$ that indicates the ability of the swimmer to move at certain distance (e.g., $200 \mathrm{~m}$ ) in an approximately constant speed to get out of rip currents and get back to shore, were employed to estimate the effect of rip currents on swimming. Since the interaction between a swimmer and the ocean with currents, waves, and tides is a complex process, the following assumptions were made to simplify the analysis of the forces acting on the swimmer by the water:

(1) a rip current flowing offshore at a constant speed $u_{r}$ relative to the ground is the only current in the coastal zone and no other currents induced by waves, tides, and winds exist;

(2) a swimmer swims against the rip current at a maximum sustainable constant speed $u_{s}$ relative to the ground and the swimmer only moves horizontally and does not move vertically, in other words, the $\overrightarrow{u_{r}}$ and $\overrightarrow{u_{s}}$ are parallel to each other;

(3) the centers of the volume and the mass of the swimmer's body are coincident, in other words, the buoyant and gravity forces act along the same vertical line (Figure 6-6). 


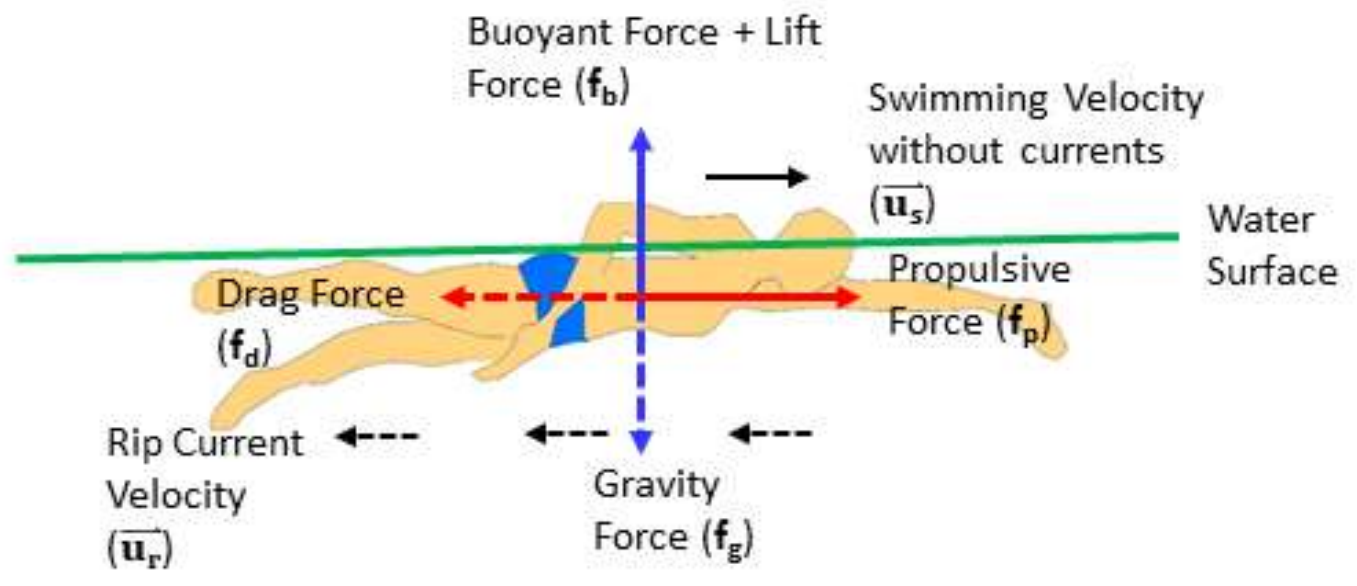

6-6. Diagram of the forces acting on a swimmer modified from the Physics of Swimming (https://www.real-world-physics-problems.com/physics-of-swimming.html).

The forces acting on the human body along vertical and horizontal directions have to be balanced (Serway and Jewett, 2018) because the swimmer moves against the head rip current at a constant horizontal speed (Figure 6-6). Here the head rip current flows in opposition to the movement direction of the swimmer, while the tail rip current flows toward the movement direction of the swimmer, similar to the definition of the head and tail winds to an aircraft. Hence we have

$$
f_{b}=f_{g} \text { and } f_{p}=f_{d}
$$

where $f_{g}$ is the gravity force, and $f_{b}$ is the combination of the buoyant force and possible uplift force caused by the swimmer depending upon the fashion of swimming (Vorontsov and Rumyantsev, 2000a). The propulsive force $f_{p}$ is generated by the swimmer to propel the body forward. The drag force $f_{d}$ is exerted by the water on the swimmer (Alcock and Mason, 2007; Hazrati, 2016). The $\mathrm{f}_{\mathrm{d}}$ is related to the velocity $\mathrm{u}$ of the swimmer through the equation

$$
f_{d}=\frac{1}{2} \rho C_{d} A u^{2}=\frac{1}{2} \rho C_{d} A\left(u_{s}+u_{r}\right)^{2}=\frac{1}{2} \rho C_{d} A u_{s}^{2}
$$


where $\rho$ is the mass density of ocean water, $\mathrm{C}_{\mathrm{d}}$ is drag coefficient, and $\mathrm{A}$ is the crosssection area of the swimmer's body perpendicular to the rip current velocity (Webb et al., 2011).

Equation 3 can be used not only to evaluate the relative contribution of rip currents to the drag force, but also to calculate the drag force given the rip current and swimming speeds. The drag coefficient $C_{d}$ is an important parameter of Equation 3 and difficult to estimate. Since $\rho, \mathrm{C}_{\mathrm{d}}$, and $\mathrm{A}$ in Equation 3 are treated as constants in comparison with $\mathrm{u}$, many researchers have attempted to establish the direct relationship between $f_{d}$ and $u$ through measurements from the laboratory by using various methods (Toussaint et al., 2004). Unfortunately, the measurements of $f_{d}$ were not consistent and scatter considerably versus the same swimming speed (Hazrati, 2016). Here, a simple strategy was employed to estimate $f_{d}$. Given the values of $\rho$ and chest circumference, $c$ (Table 6-1), and ranges of $u_{s}$, and $u_{r}$ (Table 6-2), the value of $C_{d}$ was selected to be 0.65 so that the calculated $\mathrm{f}_{\mathrm{d}}$ values at speeds $0.6 \mathrm{~m} / \mathrm{s}, 1.0 \mathrm{~m} / \mathrm{s}, 1.4 \mathrm{~m} / \mathrm{s}$ and $2.0 \mathrm{~m} / \mathrm{s}$ matched with most of clustered measurements in Hazrati (2016). Given a world record of $21.30 \mathrm{~s}$ for $50 \mathrm{~m}$ freestyle swimming by César Cielo and a maximum measured rip current speed of $2.43 \mathrm{~m} / \mathrm{s}(8 \mathrm{ft} / \mathrm{s})$ (National Oceanic and Atmospheric Administration, 2005), the ranges of $u_{s}$ and $u_{r}$ were set to be $0-2.4 \mathrm{~m} / \mathrm{s}$ and $0-2.6 \mathrm{~m} / \mathrm{s}$, respectively. 
6-1. Parameters for the calculation of drag force $\left(f_{d}\right)$ and power $\left(P_{s}\right)$. The values of $e_{p}$ and $e_{g}$ were taken from Table 1 in Toussaint and Beek (1992).

\begin{tabular}{|l|l|l|}
\hline Parameters & Unit & Value \\
\hline$\rho$ & $\mathrm{kg} / \mathrm{m}^{3}$ & 1027 \\
\hline $\mathrm{C}_{\mathrm{d}}$ & & 0.65 \\
\hline $\mathrm{c}($ chest circumference) $)$ & $\mathrm{m}$ & 1 \\
\hline${\text { Min } \mathrm{u}_{\mathrm{s}}}_{\mathrm{Max} \mathrm{u}_{\mathrm{s}}}$ & $\mathrm{m} / \mathrm{s}$ & 0 \\
\hline${\text { Min } \mathrm{u}_{\mathrm{r}}}_{\mathrm{Min} \mathrm{u}_{\mathrm{r}}}$ & $\mathrm{m} / \mathrm{s}$ & 2.4 \\
\hline $\mathrm{e}_{\mathrm{p}}$ & $\mathrm{m} / \mathrm{s}$ & 0 \\
\hline $\mathrm{e}_{\mathrm{g}}$ & $\mathrm{m} / \mathrm{s}$ & 2.6 \\
\hline
\end{tabular}

6-2. Ranges of $\mathrm{U}_{\mathrm{s}}$ and Drag Force.

\begin{tabular}{|l|l|}
\hline $\begin{array}{l}\text { Swimming Speed } \\
(\mathrm{m} / \mathrm{s})\end{array}$ & Drag Force $(\mathrm{N})$ \\
\hline 0 & 0 \\
\hline 0.2 & 1.1 \\
\hline 0.6 & 9.6 \\
\hline 1.0 & 26.6 \\
\hline 1.4 & 52.0 \\
\hline 1.8 & 86.1 \\
\hline 2.0 & 106.2 \\
\hline 2.4 & 153.0 \\
\hline
\end{tabular}

The swimmer must overcome the drag force by doing work and consuming energy through propulsive efforts. According to Toussaint et al. (1992; 1994), the power $\mathrm{P}_{\mathrm{s}}$, the time rate of energy transfer for the case without rip currents (i.e., $\mathrm{u}_{\mathrm{r}}=0$ ), is defined by

$$
P_{s}=\frac{d W}{d t}=\frac{d\left(f_{d} s\right)}{d t}=f_{d} \frac{d s}{d t}=f_{d} u_{s}
$$

where $\mathrm{W}$ is the work done by overcoming $\mathrm{f}_{\mathrm{d}}$ through swimming a distance $\mathrm{ds}$ in time $\mathrm{dt}$. The part of work done by propelling the water transfers to the energy overcoming the drag force and moving the swimmer forward. The other part is expended in giving water a kinetic energy change. Hence, the propelling efficiency coefficient, $\mathrm{e}_{\mathrm{p}}$, which is about 
50 70\% for a human being (Toussaint et al., 1988) is introduced into Equation 4 to derive effective power $\mathrm{P}_{\mathrm{p}}$

$$
P_{p}=e_{p} P_{s}=\frac{1}{2} \rho C_{d} A u_{s}^{3}
$$

In addition, the metabolic power generated by a human being cannot be converted to one hundred percent mechanical power, thereby an additional efficiency coefficient $\mathrm{e}_{\mathrm{g}}$ (Toussaint and Beek, 1992) is introduced to calculate the effective apportionment power $\mathrm{P}_{\mathrm{g}}$ to overcome the drag.

$$
P_{g}=e_{g} e_{p} P_{s}=\frac{1}{2} \rho C_{d} A u_{s}^{3}
$$

The effective apportionment power $\mathrm{P}_{\mathrm{g}}$ that a swimmer has to generate to overcome the drag force caused by both swimming speed, $\mathrm{u}_{\mathrm{s}}$, and head rip current speed, $\mathrm{u}_{\mathrm{r}}$ by moving a distance relative to water in time $\mathrm{dt}$ is

$$
P_{g}=e_{g} e_{p} P_{s}=e_{g} e_{p} f_{d}\left(u_{s}+u_{r}\right)=\frac{1}{2} e_{g} e_{p} \rho C_{d} A\left(u_{s}+u_{r}\right)^{3}
$$

Therefore, the total power generated by a swimmer to overcome the drag is

$$
P_{s}=\frac{1}{2} \frac{\rho C_{d} A u_{s}^{3}}{e_{g} e_{p}}\left(1+3 \frac{u_{r}}{u_{s}}+3 \frac{u_{r}^{2}}{u_{s}^{2}}+\frac{u_{r}^{3}}{u_{s}^{3}}\right)
$$

The values of power $\mathrm{P}_{\mathrm{s}}$ can be used to categorize the severity of rip current hazards.

First, given an average swimmer with a $1.0 \mathrm{~m} / \mathrm{s}$ speed (MacMahan et al., 2011), the relative increase of the power (p) due to rip currents was calculated based on the following equations

$$
\begin{aligned}
& P_{0}=\frac{1}{2} \frac{\rho C_{d} A}{e_{g} e_{p}} \cdot 1 \\
& p=\frac{P_{s}-P_{0}}{P_{0}}=\left(u_{s}+u_{r}\right)^{3}-1
\end{aligned}
$$


where $\mathrm{P}_{0}$ is the power for the average swimmer moving at a $1.0 \mathrm{~m} / \mathrm{s}$ speed without rip currents. Then, the rip current velocity that requires a power increase of $100 \%, 300 \%$, and $700 \%$ for the average swimmer were computed and generated the values of 0.25 , 0.60 , and $1 \mathrm{~m} / \mathrm{s}$. Finally, the severity of rip current hazards were classified into low, intermediate, high, and extreme based on these boundary values (Table 6-3).

6-3. The rip hazard category based on increased power generated by an average swimmer of speed $1 \mathrm{~m} / \mathrm{s}$ to overcome the drag force by swimming against rip currents.

\begin{tabular}{|l|l|}
\hline Rip Current Speed (m/s) & Rip Hazard Category \\
\hline $\mathrm{u}_{\mathrm{r}} \leq 0.25 \mathrm{~m} / \mathrm{s}$, about 100 (actual 95) \% increase in power & Low \\
\hline $\begin{array}{l}0.25<\mathrm{u}_{\mathrm{r}} \leq 0.60 \mathrm{~m} / \mathrm{s}, \text { about } 300 \text { (actual 310) \% increase } \\
\text { in power }\end{array}$ & Moderate \\
\hline $\begin{array}{l}0.60<\mathrm{u}_{\mathrm{r}} \leq 1.00 \mathrm{~m} / \mathrm{s}, \text { about } 700 \text { (actual 700) \% increase } \\
\text { in power }\end{array}$ & High \\
\hline$>1.00 \mathrm{~m} / \mathrm{s}$ & Extreme \\
\hline
\end{tabular}

\section{RESULTS}

Based on Equation 3, the drag force that the swimmer must overcome increased by 1.25 times the force without rip currents when the speed of head rip currents is half of the speed of the swimmer without rip currents. The drag force increases by 3 times of the force without rip currents when the speed of head rip currents reaches the speed of the swimmer. Therefore, the quadratic relationship between the drag force and rip current speed as well as the swimming speed causes drag forces to increase quickly as speed increases. Figure 6-7 shows the variations of $f_{d}$ as $u_{s}$ and $u_{r}$ change in two and three dimensions. Without rip currents, the drag force that an average swimmer with a speed of $1 \mathrm{~m} / \mathrm{s}$ has to overcome is about $26.6 \mathrm{~N}$. Since average rip current speeds are 0.5 to 1.0 $\mathrm{m} / \mathrm{s}$ (MacMahan, 2011), the drag forces that an average swimmer has to overcome 
become 59.9 and $100.4 \mathrm{~N}$, respectively, corresponding to these two head rip current speeds.
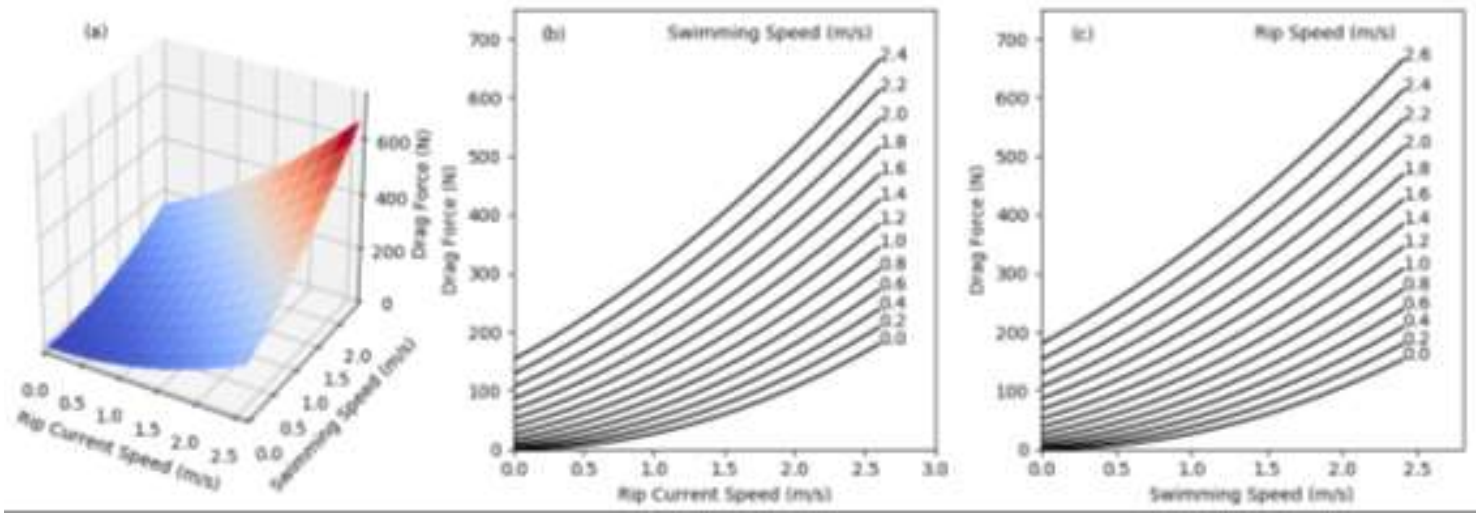

6-7. (a) The relationship between head rip current speeds, swimming speeds and drag forces. (b) The relationship between head rip current speeds and drag forces with various swimming speeds. (c) The relationship between swimming speeds and drag forces with various head rip current speeds.

When the speed of the head rip current is half of the speed of the swimmer, the power produced by the swimmer increases by 2.375 times the power produced without rip currents, based on Equation 8. When the speed of the head rip current reaches the speed of the swimmer, the power produced by the swimmer increases by seven times the power produced without rip currents. This is why it is not suggested for beachgoers to swim against rip currents to get back to the shore when they are caught in strong rip currents. An example of the power $\mathrm{P}_{\mathrm{s}}$ calculated using head rip current and swimming speeds in Table 6-2 is shown in Figure 6-8. It should be emphasized that the calculation of the drag force and power is based on swimming speed data from indoor experiments in freshwater. Swimming conditions in a surf zone with breaking waves, foam, and suspended sediments is more challenging than calm indoor conditions. In addition to 
quick energy consumption by swimming against rip currents, swimming in the surf zone adds extra stress on inexperienced swimmers and could reduce their swimming ability.
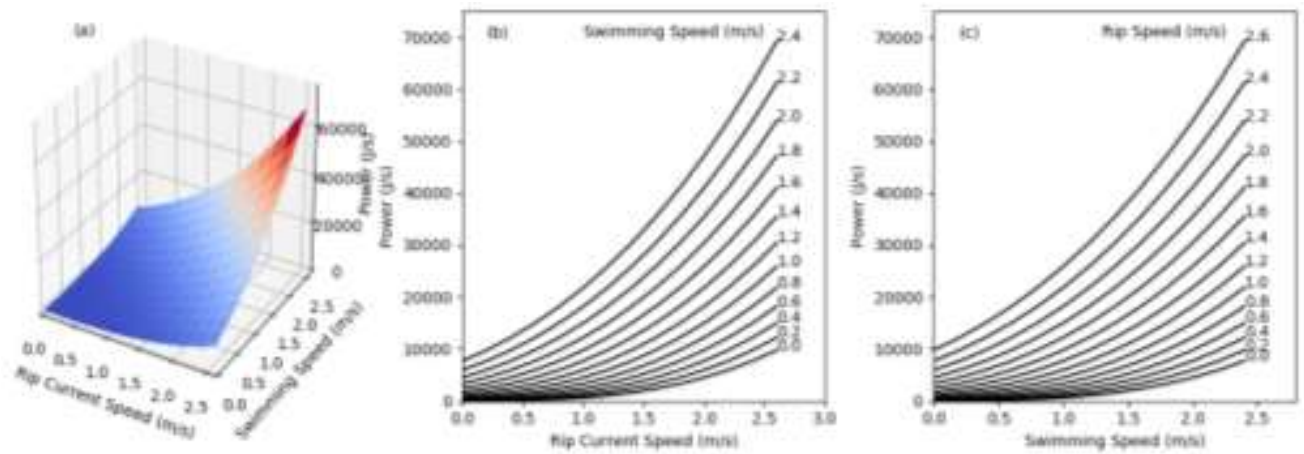

6-8 (a) The relationship between the head rip current speed, swimming speed and power. (b) The relationship between the head rip current speed and power with various swimming speeds. (c) The relationship between the swimming speed and power with various head rip current speeds.

The variation of $f_{d}$ values from various measurement methods results in different estimates of $\mathrm{C}_{\mathrm{d}}$, consequently influencing the calculation of drag forces and power in Figures 6-7 and 6-8. However, this variation does not influence the calculation of $\mathrm{p}$ in Figure 6-9 if all coefficients in Equation 10 do not change as rip current and swimming speeds vary because $\mathrm{p}$ is normalized by $\mathrm{P}_{0}$ in Equation 10 . Hence, the boundary values for rating rip current hazard do not change as they are determined based on $\mathrm{p}$ values. By using the power of an average swimmer moving at a speed of $1 \mathrm{~m} / \mathrm{s}$ as a baseline, the effect of the difference in swimming ability that is represented by maximum sustainable swimming speeds is shown in Figure 6-9. For example, if the power increases by 6, the risk for an average swimmer of a maximum sustainable speed of $1 \mathrm{~m} / \mathrm{s}$ is high, while the risk for a strong swimmer of $2 \mathrm{~m} / \mathrm{s}$ maximum sustainable speed is low. By contrast, the risk is extreme for a weak swimmer of $0.6 \mathrm{~m} / \mathrm{s}$ maximum sustainable speed. The utilization of a single variable-rip current speed to rate the hazard makes the warning and 
education of rip current hazards easier from an operational perspective. Given wave conditions at a beach, a consistent hazard category can be issued for warning, in comparison with the hazard rating by Equation 1 which changes as water depth varies. The boundary values of different hazard categories are empirical in the current rating. Limited evidence from comparing modeled hazard likelihood with observed rip current speeds suggests that rip currents with speeds greater than $0.2 \mathrm{~m} / \mathrm{s}$ may be hazardous (Moulton et al., 2017). More accurate boundaries should be determined through experiments similar to measure the active drag force (Sacilotto et al., 2014).

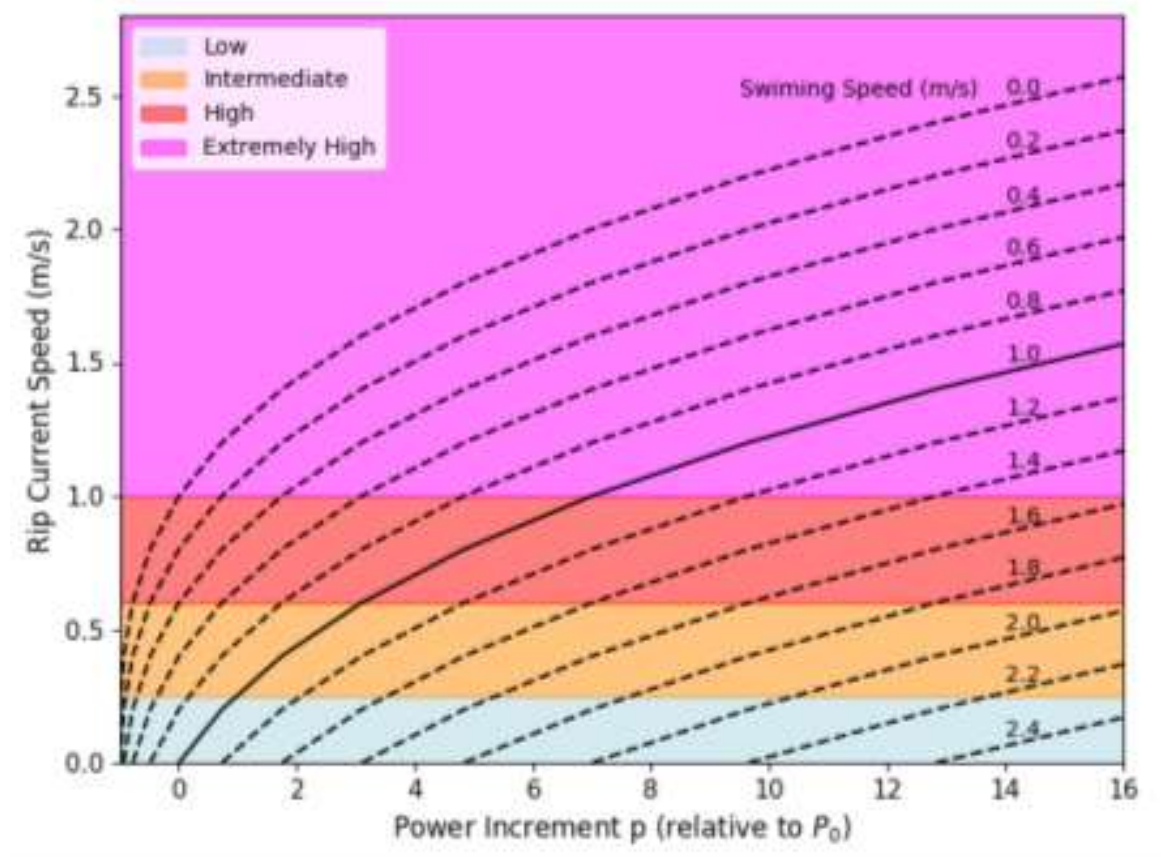

6-9. The zones of low, intermediate, high, and extreme hazards based on rip current speeds. The relative power increment parameter $\mathrm{p}$ was calculated using Equation 10.

A quadratic relationship has been employed to calculate the active drag force in terms of speed in this paper. However, except for the form drag, the skin drag has a linear relationship with speed, and the wave drag has a cubic relationship with speed (Vorontsov and Rumyantsev, 2000b), although the form drag is the dominant component. 
Toussaint et al. (2004) found that an increase of the exponent of the speed in the drag force formula to 2.34 would reduce $10 \%$ of the difference of the active drag forces from various methods. This change in the exponent value of the speed will lead to the change in the calculation of $f_{d}, P_{s}, P_{p}, P_{g}$, and $p$, but the change should not be large because the exponent of the speed does not increase much.

Field studies of bar-gap rip currents, which are the most common type (Leatherman, 2012), were conducted at South Beach, which is the south end of Miami Beach. South Beach is the most popular beach in Florida with more than eight million visitors annually (Houston, 2013). This beach is characterized by a moderately-sloping beach foreshore and moderately low wave energy (Leatherman, 2015).

Tracer dye showed that rips flow relatively straight offshore (Figure 6-10). During this May 2011 dye release, the spilling breakers were $0.6 \mathrm{~m}$ high with a short period (4 second) during onshore east winds of 15 knots; this represents the minimal conditions for rip current generation at South Beach (Table 6-3). 
6-4. Rip current measurements at South Beach and rip hazard assessed for a $1 \mathrm{~m} / \mathrm{s}$ swimmer. Note that all measurements were taken at or near low tide.

\begin{tabular}{|c|c|c|c|c|c|c|}
\hline Date & $\begin{array}{l}\text { Wind } \\
\text { Speed and } \\
\text { Direction }\end{array}$ & $\begin{array}{l}\text { Wave } \\
\text { Height } \\
\text { (m) }\end{array}$ & $\begin{array}{l}\text { Wave } \\
\text { Period } \\
\text { (s) }\end{array}$ & $\begin{array}{l}\text { Rip } \\
\text { Speed } \\
(\mathrm{m} / \mathrm{s})\end{array}$ & $\begin{array}{l}\text { Rip } \\
\text { Offshore } \\
\text { Extent (m) }\end{array}$ & $\begin{array}{l}\text { Rip Hazard } \\
\text { for } 1 \mathrm{~m} / \mathrm{s} \\
\text { swimmer }\end{array}$ \\
\hline $\begin{array}{l}\text { May } \\
2011\end{array}$ & $15 \mathrm{kts} \mathrm{E}$ & 0.6 & 4 & $0.2 *$ & $\begin{array}{l}\text { Not } \\
\text { recorded }\end{array}$ & Low \\
\hline $\begin{array}{l}\text { March } \\
23,2016\end{array}$ & $15 \mathrm{kts} \mathrm{E}$ & 0.6 & 5 & 0.3 & 68 & Intermediate \\
\hline $\begin{array}{l}\text { April 10, } \\
2016\end{array}$ & $\begin{array}{l}15 \mathrm{kts} \\
\text { ENE }\end{array}$ & 0.6 & 4 & 0.4 & 80 & Intermediate \\
\hline $\begin{array}{l}\text { July } 18, \\
2016\end{array}$ & $\begin{array}{l}15-20 \mathrm{kts} \\
\mathrm{E}\end{array}$ & 1 & 5 & 0.4 & 101 & Intermediate \\
\hline $\begin{array}{l}\text { January } \\
12,2017\end{array}$ & $15 \mathrm{kts} \mathrm{E}$ & 0.8 & 5 & $0.1^{*}$ & $\begin{array}{l}\text { Not } \\
\text { recorded }\end{array}$ & Low \\
\hline
\end{tabular}

*Estimated from drifting seaweed and tracer dye. 


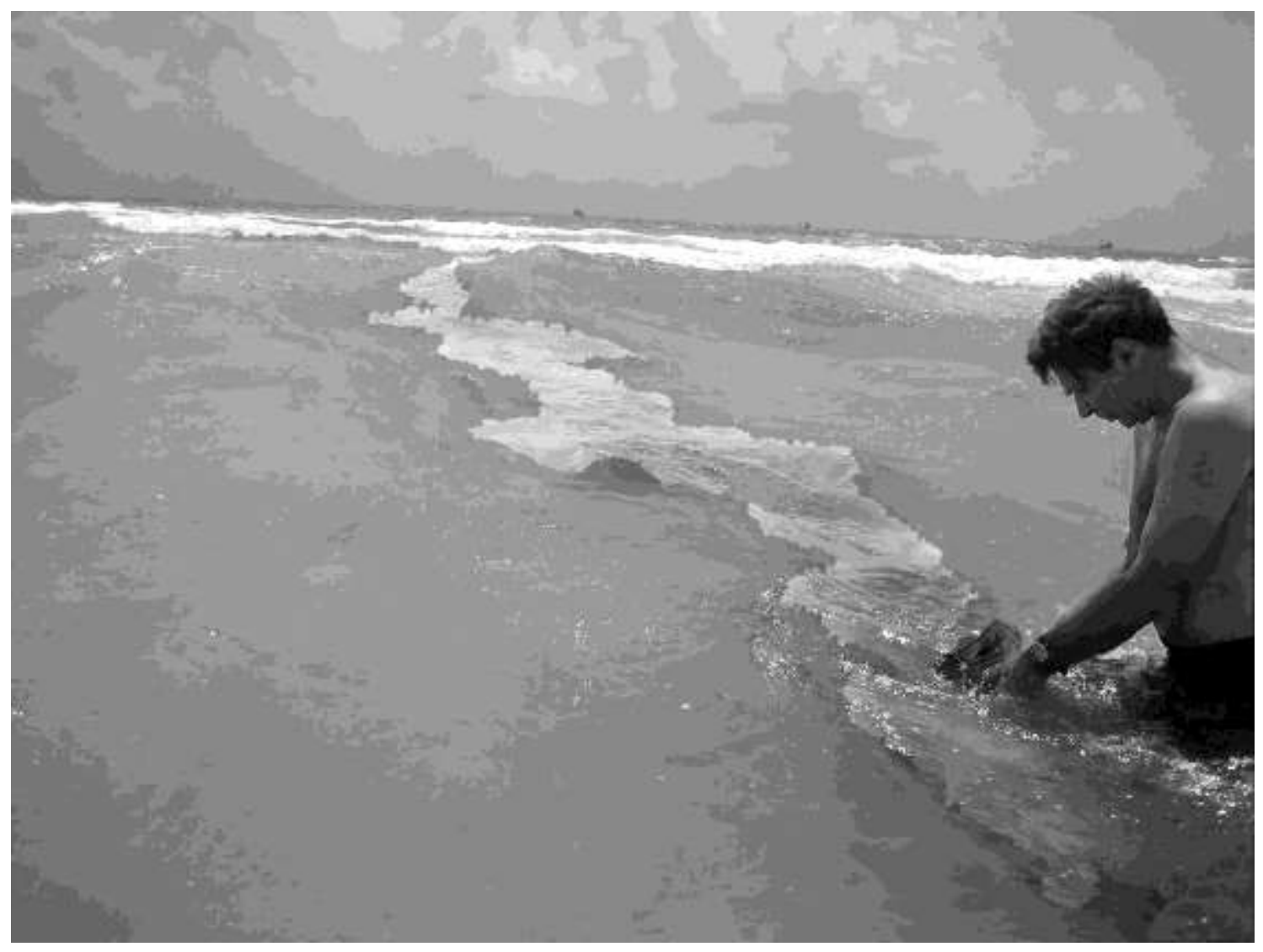

6-10. A weak rip current at South Beach, Florida is marked with fluorescent dye.

Rip current speed averaged $0.3 \mathrm{~m} / \mathrm{s}$ with a maximum of $0.5 \mathrm{~m} / \mathrm{s}$ based on six field deployments with three to five drogue tests undertaken during each deployment (Leatherman, 2017a). By contrast, MacMahan et al (2006) found average rip current velocity at Sand City, Monterey, California to be $0.3 \mathrm{~m} / \mathrm{s}$ with a peak of $2 \mathrm{~m} / \mathrm{s}$, which corresponds to much higher energy conditions. Brander and Short (2001) also reported much higher mean rip speeds of 0.5-1 m/s for "low-energy" rips in Australia.

Structurally-controlled rip currents were studied at Haulover Park, which is located just north of Miami Beach. The jetty at Haulover Park is a unique structure that has a beach-parallel spur (e.g., breakwater) at the end that provides a barrier against the 
waves (Figure 6-11). Rip currents are generated by longshore currents in response to obliquely-approaching waves from the northeast. The southward-flowing longshore current is deflected by the jetty to form a structurally-controlled rip. This spur causes the southward-flowing longshore current to be deflected to the north and then offshore as a rip current. Rips here are especially dangerous for bathers because they can move around the spur and converge with the even stronger tidal flow of Haulover Inlet (Figure 6-11). Beachgoers caught in the rip should not swim against this current. The best method to escape this rip current is to swim straight back onshore (e.g. due west), which is counter to the normal guidance (Figure 6-11). Lifeguards blow the whistle and keep beachgoers out of this area, but are off duty by 5 PM, and this park does not close until sundown.

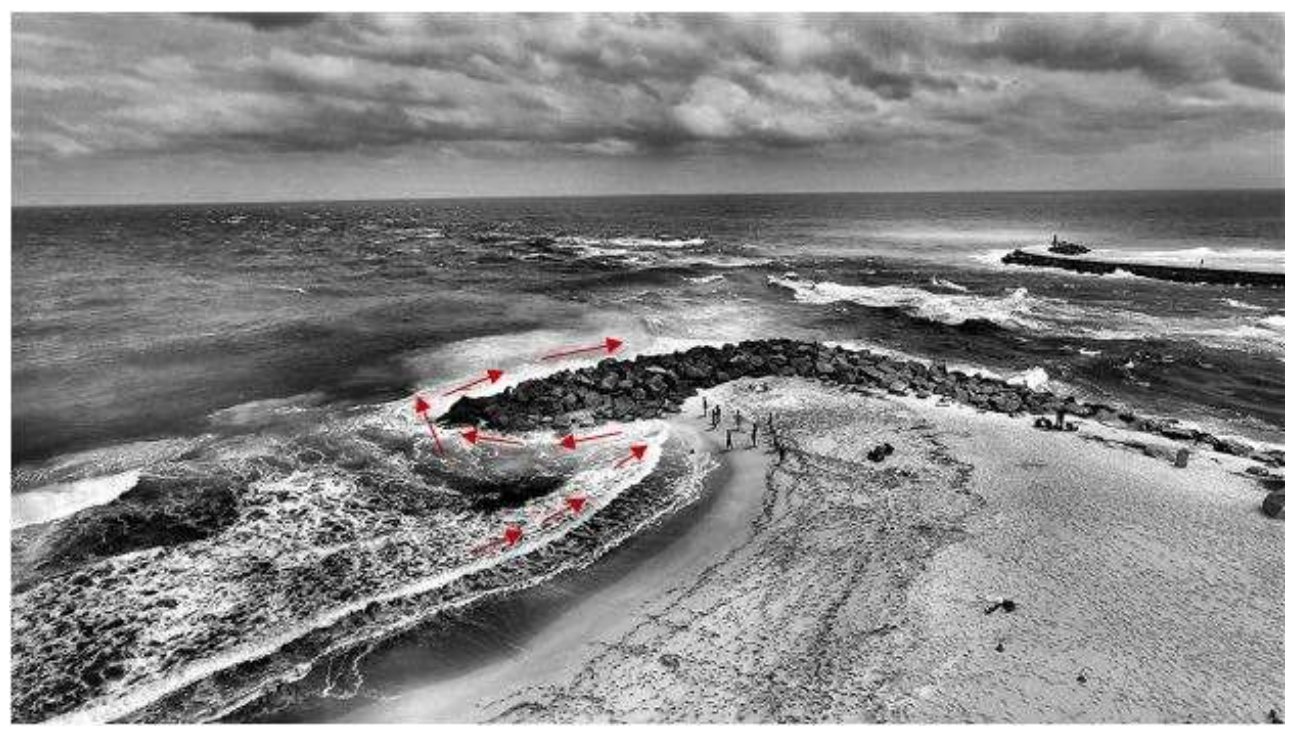

6-11. A freeze-frame from the quadcopter video shows fluorescent dye moving around the jetty and toward the strong tidal current at Haulover Inlet on April 6, 2016. The arrows represent the rip current flow path.

Ocean Reef Park in Riviera Beach is located in Palm Beach County. This beach has a structurally-controlled rip current that is formed by an outcropping of coquina limestone rock, which controls the location of the rip. This rip current was imaged with the quadcopter on April 27, 2016. Significant wave height was $0.6 \mathrm{~m}$ from the east- 
southeast with a period of 10 seconds; wind speed was only 10 kts from the east. The flow characteristics showed the same pattern as the bar-gap rip at South Beach--a relatively straight-flowing rip that terminated at the outer edge of the surf zone (Figure 612).

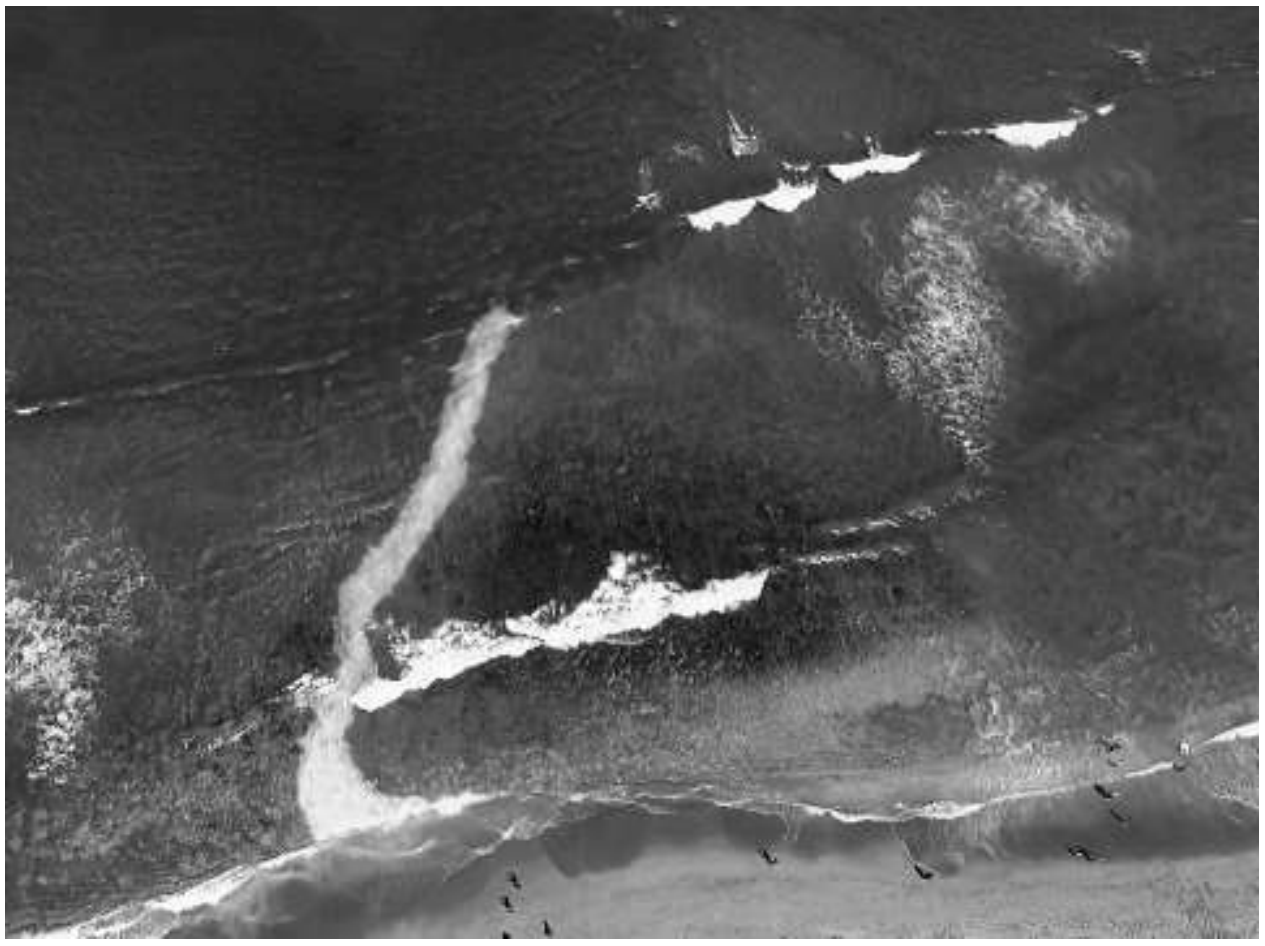

6-12. A freeze-frame from the quadcopter video of fluorescent dye at Ocean Reef Park, Palm Beach County shows that the rip current is fairly linear and terminates at the surf zone on April 27, 2016.

\section{DISCUSSION}

The analysis here represents a simplified picture that captures the first order effect of the drag force on a swimmer by rip currents. The real drag force caused by a swimmer involves a complicated interaction between different parts of the human body with water. The effect of rip currents on the drag force and power have to be derived through numerical simulation of the interaction between rip currents and the human body by combining the models for rip currents (Castelle et al., 2016a) and swimming movements 
(Li and Zhan, 2015; Rouboa et al., 2006), and through expanding indoor experiments (Alcock and Mason, 2007; Hazrati, 2016; Sacilotto et al., 2014) to measure various body resistant forces, energy consumption rates, and fatigue rates in a flowing-water setting.

Rip current velocity is a useful and convenient parameter to represent the strength of a rip current in terms of the analysis in this paper. Unfortunately, it is difficult to measure the velocity in the field, compared to wave heights and periods, because the interaction of breaking waves, tides, and morphology in the surf zone often causes spatial and temporal variation of rip current locations which are difficult to pinpoint (Moulton et al., 2017). Fortunately, there is a site-specific, close relationship between rip current speeds and nearshore wave heights according to field observations (Brander, 1999; Houser et al., 2013; MacMahan et al., 2005) and laboratory studies (Drønen et al., 2002; Haller et al., 2002). Therefore, parameters of nearshore wave measurements can be used as surrogates for rip velocity to quantify the danger of rip currents as long as the relationship between waves and rip currents are established through field observations at a specific beach.

Field measurements of rip current speeds at South Beach, Florida are compared to the hazard rating in Table 6-4. The rip speeds varied from 0.1 to $0.5 \mathrm{~m} / \mathrm{s}$ in response to 15+ knot East winds. The hazard ratings for these rips were based on an average swim speed of $1 \mathrm{~m} / \mathrm{s}$, and hazards varied from low for rip speeds below $0.25 \mathrm{~m} / \mathrm{s}$ to intermediate for speeds between 0.25 to $0.5 \mathrm{~m} / \mathrm{s}$. However, the amount of power required to overcome these rip speeds doubles from low to intermediate ratings (Figure 6-9).

There are pros and cons of the stay-afloat versus swim-parallel escape methods. The stay-float method requires less energy by allowing the current to take the victim to 
safety (Figure 6-13). Additionally, the victim can wave his arm for help while floating in the rip, and this escape method does not require a strong swimmer. The negatives of this method are that the swimmer could be pulled offshore beyond the surf zone roughly $20 \%$ of the time (Brander and MacMahan, 2011), and it is harder to see a victim in trouble when they are farther offshore.

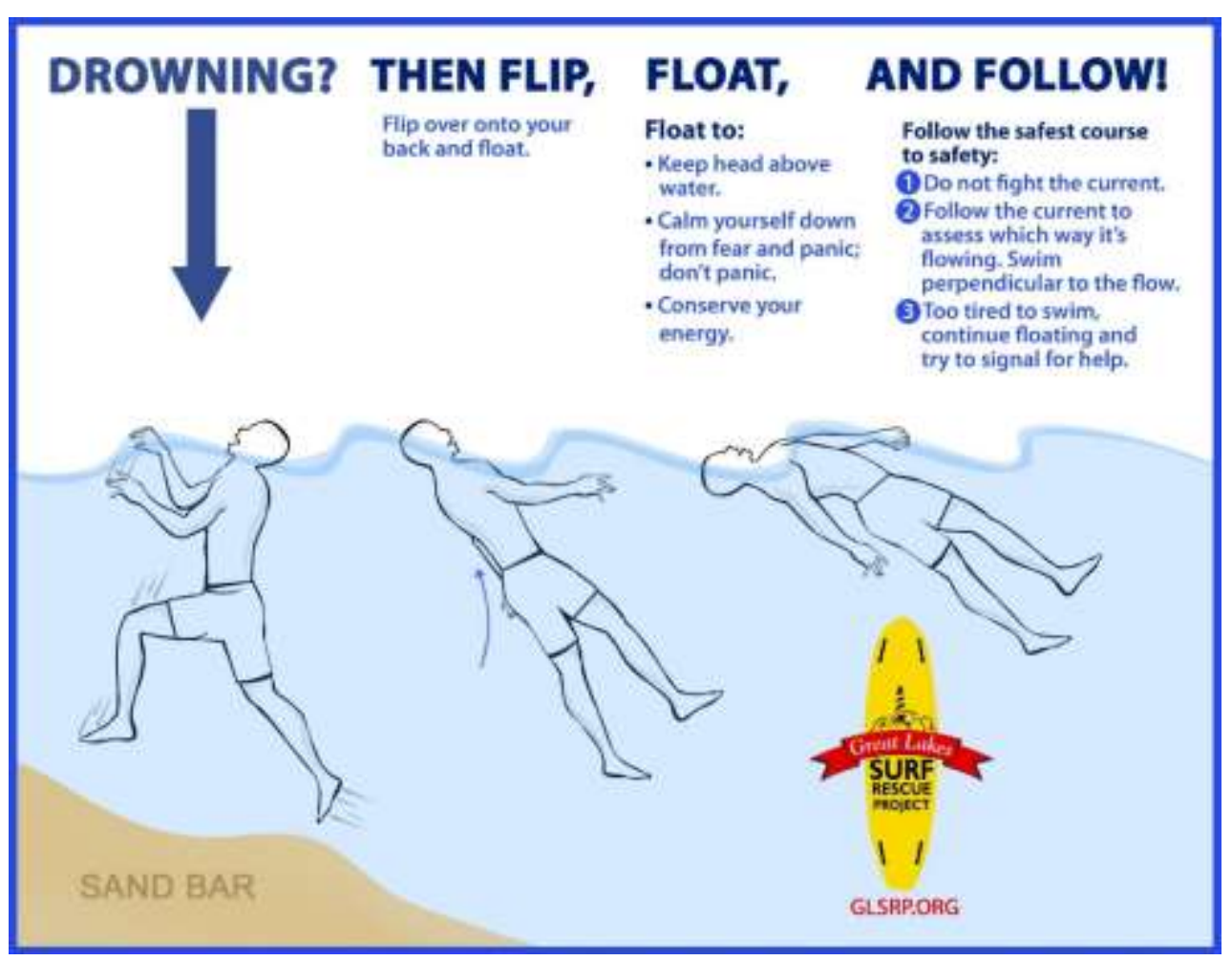

6-13. The flip, float, and follow method of rip escape is now being shown on signage in the Great Lakes.

The swim-parallel method can expedite escape from a rip current (Figure 6-14). However, this can be problematic for beachgoers who are advised to swim left or right because they might be swimming against the longshore current (e.g., $50 \%$ chance if no surf knowledge). Bathers not progressing out of the rip may become fatigued and panic, possibly leading to drowning (Leatherman, 2016). Therefore, swimmers need to be 
informed on how to identify rip and longshore currents so that they can avoid dangerous situations.

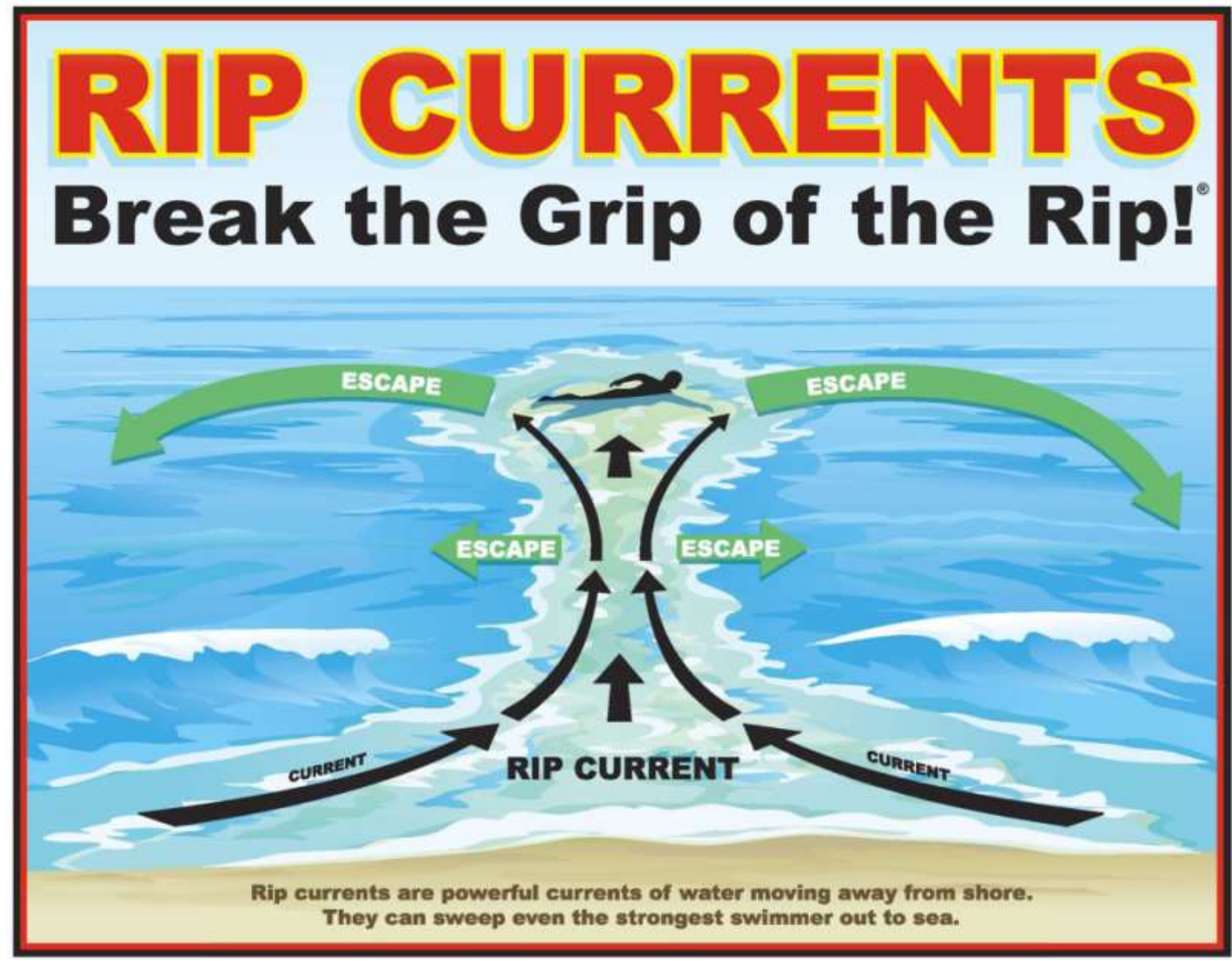

6-14. The traditional rip escape method of swimming parallel to the shore.

California often has relatively high, long-period waves that break as plungers on moderately steep beaches. California rips can extend hundreds of meters offshore (Brander and MacMahan, 2011). By contrast, beaches in South Florida have much lower energy waves with shorter periods and usually spilling breakers on a gently-sloping beach shoreface. Field measurements show that rip currents in South Florida are weaker, have a shorter offshore extent and do not circulate back to the bar. 


\section{CONCLUSIONS}

The intuitive physical reaction of an inexperienced swimmer is to swim against the rip current to get back to the shore when he is trapped by a rip current. Drowning occurs when the swimmer become fatigued by consuming most his energy in attempt to overcome the drag force induced by the head rip current. The effect of rip currents on swimmers was investigated through a simplified analysis of the drag force acting on the swimmer and the power generated to overcome it. The drag force and power have a quadratic and cubic relationships with the rip current speed. The drag force increases by 1.25 times and power increases by 2.375 times of the drag and power produced without rip currents, respectively, when the speed of rip currents is half of the swimmer's speed. When the speed of a rip current reaches the speed of the swimmer, the drag force and power increase by three and seven times the drag and power without rip currents, respectively.

Rip current hazards were rated as low, moderate, high, and extreme in terms of rip current speeds of $0.25,0.60$, and $1.0 \mathrm{~m} / \mathrm{s}$, corresponding to increases of $100 \%, 300 \%$, and $700 \%$ in the power generated by an average swimmer of maximum sustainable speed of $1.0 \mathrm{~m} / \mathrm{s}$. This rating is solely based on the speed of rip currents and does not change as the coefficients in the drag force equation vary. Hence, it provides consistent values for warning of the degree of danger of the rip currents at a beach, given a fixed wave condition. A strong swimmer can generate more power, thus overcome larger drag forces from strong rip currents, resulting in lower risk of drowning compared to a weak swimmer. However, a small increase in rip current speed leads to a large increase in the power generated to overcome the increase in the drag force because of the velocity-cubed 
function of power. Therefore, even rip currents with small velocity are dangerous, especially to weak swimmers, and swimming against rip currents is not recommended. The easy-to-understand quantitative relationships that the drag force is proportional to the square of velocity, and the power to overcome drag is proportional to the cube of velocity can be used to educate the public and help bathers and swimmers avoid the danger of swimming against rip currents.

Most rip currents in South Florida are the bar-gap type, and the best approach is to swim parallel to shore (but not against the longshore current) at these locations. This method is preferred because bar-gap rips here terminate just seaward of the surf zone. South Florida rips have no return flow; therefore, the stay-afloat approach will cause the victim to be pulled further offshore taxing their swimming abilities. In this situation, victims may panic, leading to drowning.

Rip current escape methods vary according to the flow characteristics. For example, at Haulover jetty, which has an unusual rip current flow pattern, the best escape method is to swim straight back to shore (which is counter to all escape advice). The breakwater mitigates wave action, and bathers are allowed to swim in the shallow water near the lifeguards. When the lifeguards are off-duty after 5 PM, some bathers venture into deeper water, which can be dangerous because the rip current can pull them around the breakwater into the strong tidal current. 


\title{
VII. RIP CURRENT GENERATION AND MANAGEMENT IMPLICATIONS IN SOUTH FLORIDA
}

\begin{abstract}
Miami Beach is one of the most dangerous beaches for rip current drownings in the United States. There are three principal wave generators that result in rip currents: onshore winds associated with high pressure cells, swell waves produced by offshore nor'easters, and tropical storms. A logistic regression analysis showed a correlation between rip currents and wave height $(\mathrm{p}=0.0000)$ and period $(\mathrm{p}=0.0000)$. Most rips were found to occur during 15-20 knot onshore winds with 0.6-0.9m significant wave height. Eleven social, physical and safety factors make Miami Beach a rip current hotspot and pose a major coastal management challenge.
\end{abstract}

\section{INTRODUCTION}

South Florida is a tourism destination that is well known for its beaches. Miami Beach is one of the ten most famous beaches in the world and boasts of tens of millions of visitors each year (Houston, 2013). At the same time, Miami Beach is the third most deadly beach in the United States (Paxton, 2014; Table 7-1). Haulover Park, just north of Miami Beach, is the largest public beach in South Florida, and also prone to rip drownings (Leatherman, 2016). 
7-1. Deadliest beach areas in the United States (Paxton, 2014).

\begin{tabular}{|r|l|l|}
\hline \multicolumn{1}{|l|}{ Rank } & Beach & State \\
\hline 1 & Pensacola Beach & Florida \\
\hline 2 & $\begin{array}{l}\text { Panama City } \\
\text { Beach }\end{array}$ & Florida \\
\hline 3 & Miami Beach & Florida \\
\hline 4 & $\begin{array}{l}\text { Ft. Lauderdale } \\
\text { Beach }\end{array}$ & Florida \\
\hline 5 & Gulf Shores & Alabama \\
\hline 6 & South Padre Island & Texas \\
\hline 7 & Myrtle Beach & South \\
\hline 8 & Daytona Beach & Florida \\
\hline 9 & Miramar Beach & Florida \\
\hline 10 & Navarre Beach & Florida \\
\hline
\end{tabular}

National Weather Service rip forecasts have historically been based on a predictive model developed by Lushine (1991, 2011). This deterministic model accounts for wind speed and direction, wave height, and tide level. Lascody (1998) modified the original model to include swell waves generated by offshore storms which has been utilized by Schrader (2004) and Engle (2003) in their studies at Daytona Beach, Florida. The National Weather Service now utilizes a numerical model to predict rip currents in South Florida. The model uses wind and wave data to predict the rip current hazard. The advanced model needs calibration and verification, and field research is needed to provide the necessary data sets.

The overall purpose of this research was to determine the meteorological and nearshore oceanographic conditions under which rips in South Florida are formed and to identify the factors that cause rip currents at Miami area beaches to be hotspots for rip current drownings. Rip current presence and other pertinent data were collected by lifeguards at Miami Beach and Haulover Beach from January 1, 2016 to June 30, 2016. 
The daily observations included rip type, flag color, wave height, wave period, sea or swell waves, wave direction, wave breaker type, wind speed, and wind direction. The lifeguards collecting the data were veterans with decades of experience identifying rip currents and examining surf conditions. Furthermore, the lifeguards were informed on how to measure significant wave height (the highest one third of waves) and wave period to obtain more consistent observations. The dataset was statistically analyzed through a logistic regression using Stata.

\section{RIP GENERATION}

Rip currents in South Florida are primarily generated during fair-weather conditions except for those caused by the passing of tropical storms and hurricanes. Locally-generated winds are produced by the Bermuda high pressure cell positioned offshore the mid-Atlantic coast. A 3-4 mb pressure gradient between Jacksonville and Key West is enough to yield 15 to 20 knot onshore winds (Figure 7-1). Rips are generated by 0.6 to $1.2 \mathrm{~m}$ waves during fair-weather conditions, which seem like perfect beach days, making these rips deceptively dangerous to bathers. 


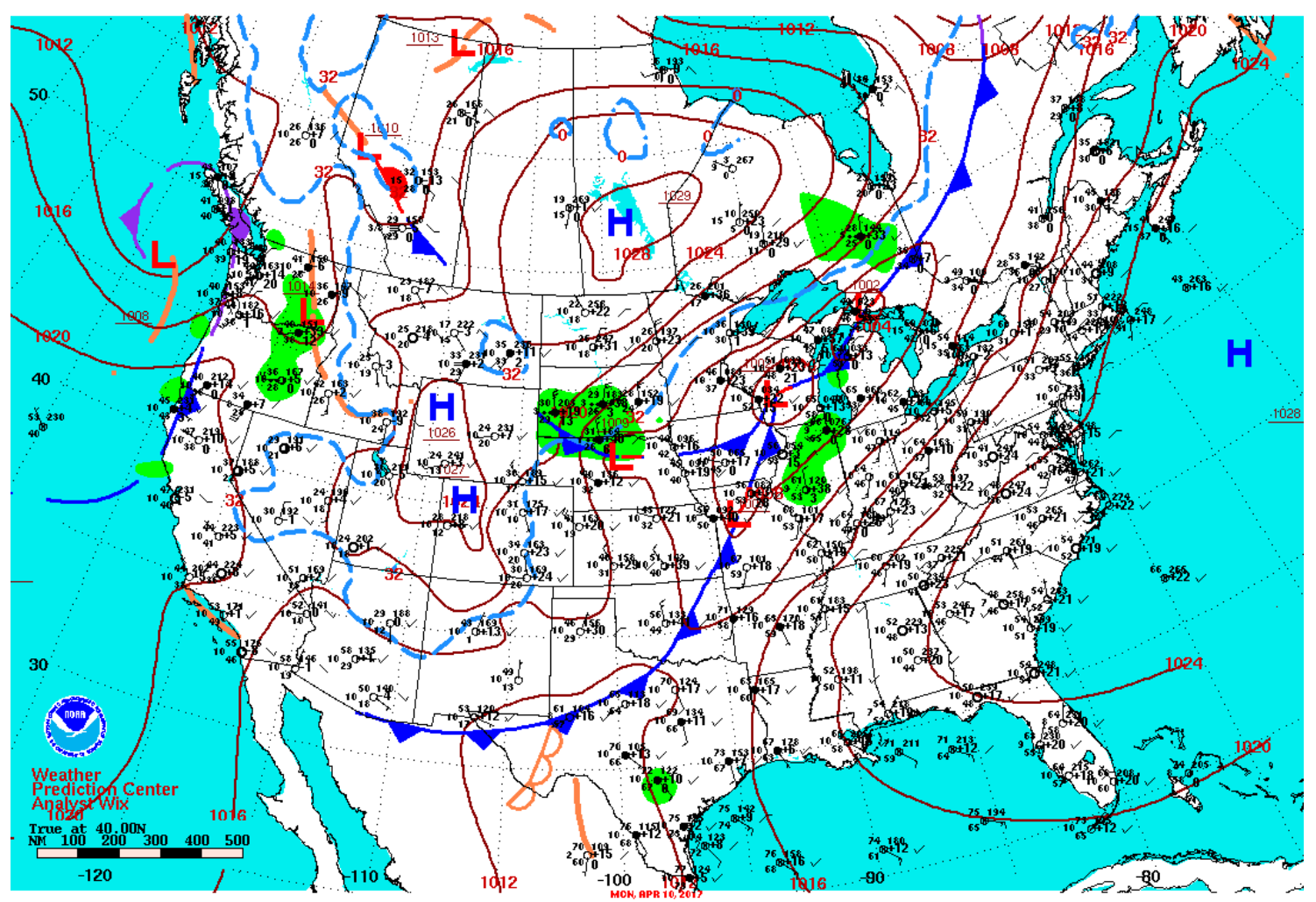

Surface Weather Map and station Weather at 7:00 A.M. E.S.T.

7-1. A Bermuda high pressure cell on April 10, 2016, off the mid-Atlantic coast resulted in a pressure difference of $4 \mathrm{mb}$ between the Florida Keys and Jacksonville, which generated a 15-20 knot East wind.

Another type of rip generator are nor'easters offshore the mid-Atlantic and Northeast coast, which produce large swells (Figure 7-2). These swell waves, while infrequent at Miami Beach, can generate strong rips. Palm Beach is far more impacted by swells than Miami Beach because the Bahamas and continuous, large-scale sand shoals protect Miami Beach from most swell waves. There were few swell waves hitting Miami Beach in 2016 because of El Nino, which caused the nor'easters to track further southward, and hence were not in the right position to generate swells (Robert Molleda, personal communication, 2016). 


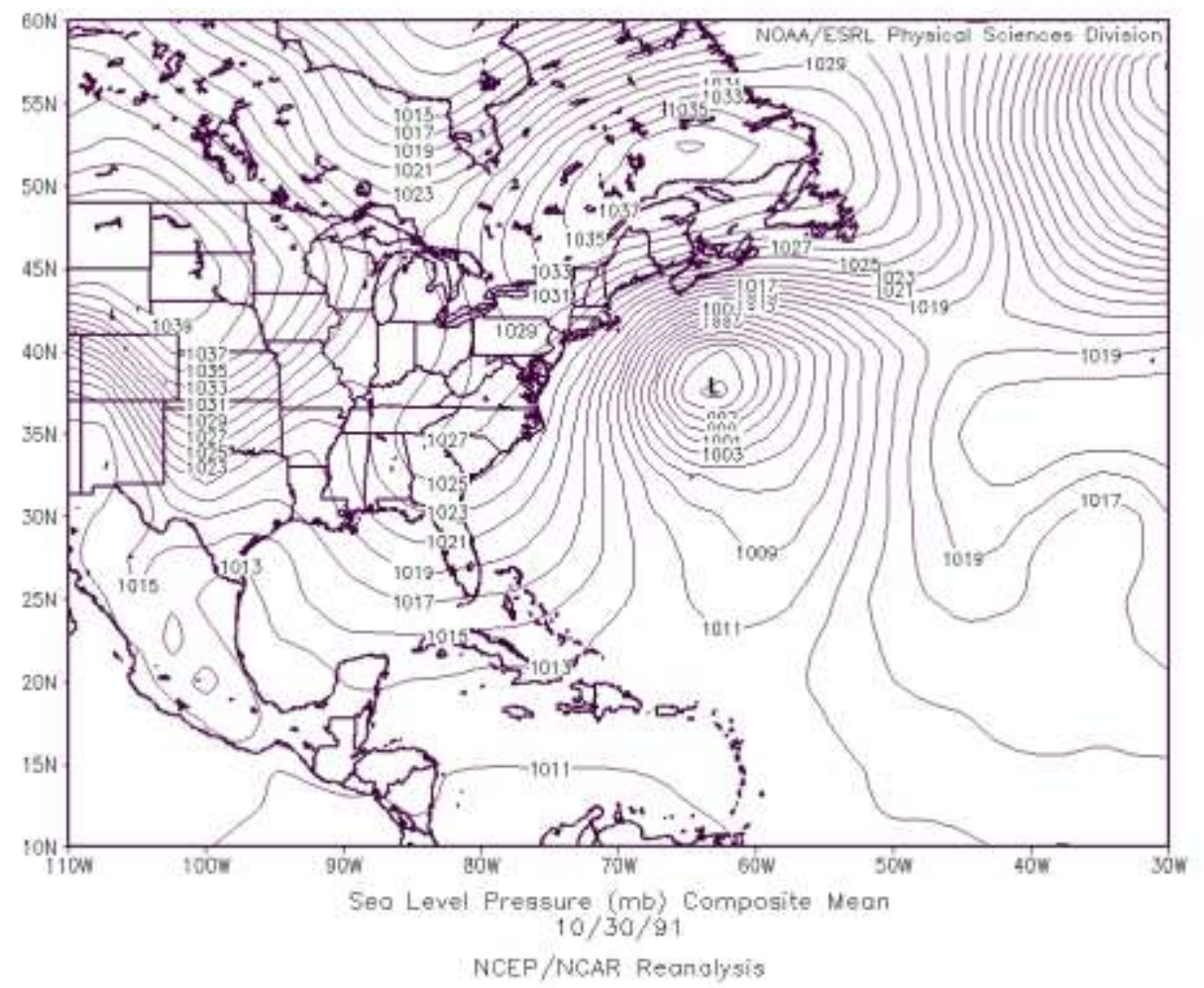

7-2. This nor'easter on October 30, 1991 off the mid-Atlantic coast genereated large swell waves that reached South Florida.

Offshore tropical storms passing between the Florida peninsula and the Bahamas generate rips. Generally, there are no beachgoers in the water during these storms except for a few surfers because the waves reach over $1.5 \mathrm{~m}$ in height. High winds, blowing sand and rain deter bathers. One such event was Hurricane Matthew that paralleled the Florida coastline on October 6-7, 2016. This hurricane produced offshore waves with a significant wave height of $6.4 \mathrm{~m}$ and period of 13 seconds in central Florida (e.g., there are no wave buoys in South Florida but similar wave characteristics would be expected; www.checkthewaves.com). Matthew most certainly generated much stronger rips compared to those measured in this study (Leatherman, 2017a). Governor Rick Scott of 
Florida declared a state of emergency, and Miami Beach was closed with the recommendation that residents evacuate. Therefore, no rip current measurements could be undertaken during this event.

\section{RIP FORECASTING}

The National Weather Service forecasts rip current hazards; this information is available online and reported by TV meteorologists. Lifeguard observations were compared to the National Weather Service rip current daily forecasts for the six-month period when most rips occur (e.g., winter and early spring). The National Weather Service assigns a value of high, moderate, or low risk of rip currents. During the survey period, 43 high-risk days were recorded (Table 7-2). The lifeguard observations showed there were rip currents present in either South Beach or Haulover Beach for 35 of these 43 days or $81 \%$ of the time. Rip currents were present at both locations 21 out of the 43 days, which amounts to $49 \%$ of the time. Furthermore, field measurements of rip currents compare reasonably well with the lifeguard observations and the National Weather Service forecasts based on a limited data set (Table 7-3).

7-2. Rip current presence at Miami Beach and Haulover Park Beach from lif eguard observations during January to June 30, 2016 are compared to the National Weather Service (NWS) high risk days during this time period.

\begin{tabular}{|l|l|l|l|}
\hline Rip Location & Lifeguard Observations & $\begin{array}{l}\text { NWS High Risk } \\
\text { Days }\end{array}$ & Percent of Agreement \\
\hline Rips at either location & 35 & 43 & 81 \\
\hline Rips at both locations & 21 & 43 & 49 \\
\hline
\end{tabular}


7-3. Field deployments for rip presence by the research team (Leatherman, 2017a) are compared to lifeguard observations and the National Weather Service rip forecast.

\begin{tabular}{|c|c|c|c|c|c|}
\hline $\begin{array}{l}\text { Field } \\
\text { Rips }\end{array}$ & Location & $\begin{array}{l}\text { Wind } \\
\text { speed } \\
\text { (kts) }\end{array}$ & $\begin{array}{l}\text { Rip } \\
\text { Presence }\end{array}$ & $\begin{array}{l}\text { Lifeguard } \\
\text { Observations }\end{array}$ & $\begin{array}{l}\text { National Weather } \\
\text { Service Rip Forecast }\end{array}$ \\
\hline $\begin{array}{l}\text { Mar } 23 \\
2016\end{array}$ & $\begin{array}{l}\text { South } \\
\text { Beach }\end{array}$ & 17 & Yes & Rips Present & High Risk \\
\hline $\begin{array}{l}\text { April } 10 \\
2016\end{array}$ & $\begin{array}{l}\text { South } \\
\text { Beach }\end{array}$ & 15 & Yes & Rips Present & High Risk \\
\hline $\begin{array}{l}\text { July } 18 \\
2016\end{array}$ & $\begin{array}{l}\text { South } \\
\text { Beach }\end{array}$ & 15 & Yes & Rips Present & High Risk \\
\hline $\begin{array}{l}\text { Nov } 15 \\
2015\end{array}$ & $\begin{array}{l}\text { Haulover } \\
\text { Park }\end{array}$ & 17 & No & Rips Present & High Risk \\
\hline $\begin{array}{l}\text { April } 6 \\
2016\end{array}$ & $\begin{array}{l}\text { Haulover } \\
\text { Park }\end{array}$ & 15 & Yes & Rips Present & Low Risk \\
\hline $\begin{array}{l}\text { Jun } 20 \\
2016\end{array}$ & $\begin{array}{l}\text { Haulover } \\
\text { Park }\end{array}$ & 15 & Yes & Rips Present & High Risk \\
\hline
\end{tabular}

The lifeguards made a total of 285 observations with 171 at Haulover and 114 at Miami Beach (Table 7-4). Rip currents at Haulover Park Beach were present 47 percent of the time and $30 \%$ of the time at Miami Beach. Haulover tends to have higher wave energy than Miami Beach, which could be caused by wave refraction due to the ebb tidal delta at Haulover Inlet.

7-4. Rip current presence by location.

\begin{tabular}{|l|l|r|}
\hline $\begin{array}{l}\text { Rip by } \\
\text { Location }\end{array}$ & $\begin{array}{l}\text { Rip } \\
\text { Occurrence } \\
(\%)\end{array}$ & $\begin{array}{l}\text { Number of } \\
\text { observations }\end{array}$ \\
\hline Haulover & 47 & 171 \\
\hline South Beach & 30 & 114 \\
\hline Total & 40 & 285 \\
\hline
\end{tabular}

Rip currents were found to start 10 to 15 meters offshore instead of close to the shoreline, and no feeder currents were detected. Beaches in south Florida have a fairly 
gentle slope and a relatively low wave climate (Leatherman, 2015). These offshoreflowing currents are harder to detect because there is little to no suspended sediment in the water column and are slow-moving (Leatherman, 2017a).

Most rip currents occurred during winter months and early spring. The highest months were February, March and April, and then rip occurrence dropped off in May and June (Table 7-5). March is typically when U.S. students have Spring Break, which is also a month with a high probability of rip currents and many rip rescues. During the summer, wave heights decline significantly because there are few wave makers except for tropical storms passing just offshore South Florida, which are infrequent.

7-5. Rip current presence by month.
\begin{tabular}{|l|r|r|} 
Rip by Month & $\begin{array}{l}\text { Rip } \\
\text { Occurrence } \\
(\%)\end{array}$ & $\begin{array}{l}\text { Number of } \\
\text { observations }\end{array}$ \\
\hline January & 40 & 52 \\
\hline February & 47 & 57 \\
\hline March & 42 & 62 \\
\hline April & 49 & 47 \\
\hline May & 28 & 36 \\
\hline June & 25 & 31 \\
\hline Total & 40 & 285 \\
\hline
\end{tabular}

Wind speeds and wave heights were estimated by the lifeguards during this study period. Most rip currents occurred during 15-20 knot winds, with few observations beyond 20 knots (Table 7-6). Rips were also observed during calm and low wind speeds, indicating that these waves were either not locally generated or generated by prior wind speeds (e.g., wind speed can drop while waves are still moving onshore). Wave heights had a positive correlation with rip presence. Rip currents were most commonly generated 
at Miami Beach during wave heights of $0.6 \mathrm{~m}$ to $0.9 \mathrm{~m}$ (Table 7-7). Larger waves, which are less frequent, can generate stronger rips (Leatherman, 2017a).

7-6. Rip current presence by wind speed.

\begin{tabular}{|l|l|r|}
\hline $\begin{array}{l}\text { Rip by Wind } \\
\text { Speed (kts) }\end{array}$ & \begin{tabular}{l} 
Rip $\begin{array}{l}\text { Occurrence } \\
\text { (\%) }\end{array}$ \\
\hline 0 to 3
\end{tabular}$\quad \begin{array}{l}\text { Number of } \\
\text { observations }\end{array}$ \\
\hline 4 to 8 & 25 & 4 \\
\hline 9 to 11 & 14 & 148 \\
\hline 12 to 15 & 73 & 34 \\
\hline 16 to 20 & 91 & 68 \\
\hline
\end{tabular}

7-7. Rip current presence by wave height.

\begin{tabular}{|r|r|r|}
\hline $\begin{array}{l}\text { Rip by Wave } \\
\text { Height }(\mathrm{m})\end{array}$ & \begin{tabular}{l} 
Rip $\begin{array}{l}\text { Occurrence } \\
(\%)\end{array}$ \\
\hline 0.3
\end{tabular} & $\begin{array}{l}\text { Number of } \\
\text { observations }\end{array}$ \\
\hline 0.6 & 52 & 25 \\
\hline 0.9 & 42 & 93 \\
\hline 1.2 & 66 & 53 \\
\hline Total & & 27 \\
\hline
\end{tabular}

A logistic regression analysis was conducted to determine if rip current presence could be predicted by the beach conditions. This analysis predicts a dichotomous outcome of whether a rip current is present (coded as 1) or not present (coded as 0 ). This analysis was conducted using the statsmodels logit function (Seabold et al., 2010) and then the scikit-learn machine learning logisticregression function in Python (Pedregosa et al., 2011). This logistic regression model has the assumptions that only meaningful variables are to be included, and that the model should have little multicollinearity. 
The equation for the logistic regression (McCullagh and Nelder, 1989) is as follows: Where $\mathrm{P}$, the probability that $\mathrm{Y}=1$, is defined as:

$$
P=\frac{e^{\left(B_{0}\right)+\left(B_{1} X_{1}\right)+\left(B_{2} X_{2}\right)+\cdots+\left(B_{k} X_{k}\right)}}{1+e^{\left(B_{0}\right)+\left(B_{1} X_{1}\right)+\left(B_{2} X_{2}\right)+\cdots+\left(B_{k} X_{k}\right)}}
$$

Where $\mathrm{Y}$ is the dependent variable (rips present), $\mathrm{X}$ are the independent variables such as wave height, wind speed, etc. and B are the regression coefficients. Therefore, the outcome is the expected $\log$ odds that $\mathrm{Y}$ is present, such that:

$$
\operatorname{Ln}\left(\frac{P}{1-P}\right)=B_{0}+B_{1} X_{1}+B_{2} X_{2}+\cdots+B_{k} X_{k}
$$

Before building the logistic regression model, the data was first cleaned to drop unimportant categories and missing values. The categories day, month, guard and flag were dropped in order to focus on the wind and wave parameters only. It was found that Haulover Beach was missing a large amount data, specifically rip presence, and South Beach was missing wave height and period data (Table 7-8). The logistic regression model calculates the effect each variable has on rip current presence, and tries to predict the presence of rips based on the beach conditions. Due to the missing rip presence data of Haulover Park, it could not be used in the logistic regression model. Instead, only South Beach was used in the logistic regression model. 
7-8. The summary of missing data by variable for both locations.

\begin{tabular}{|l|l|l|}
\hline Category & Miami Beach & Haulover Park \\
\hline Rip & 10 & 66 \\
\hline Height & 90 & 61 \\
\hline Period & 61 & 14 \\
\hline Direction & 35 & 14 \\
\hline Wind Speed & 9 & 14 \\
\hline Wind Direction & 3 & 14 \\
\hline
\end{tabular}

A heatmap of the different categories was constructed using the seaborn python package from Waskom et al., 2017 (Figure 7-3). The heatmap shows that wave height (height) had the largest correlation to rip current presence (rip1), followed by wind speed (wspeed). Wave period (period) and wave direction (direction) have the least significance on rip presence, and wave breaker type (breaker) had a moderate effect. 


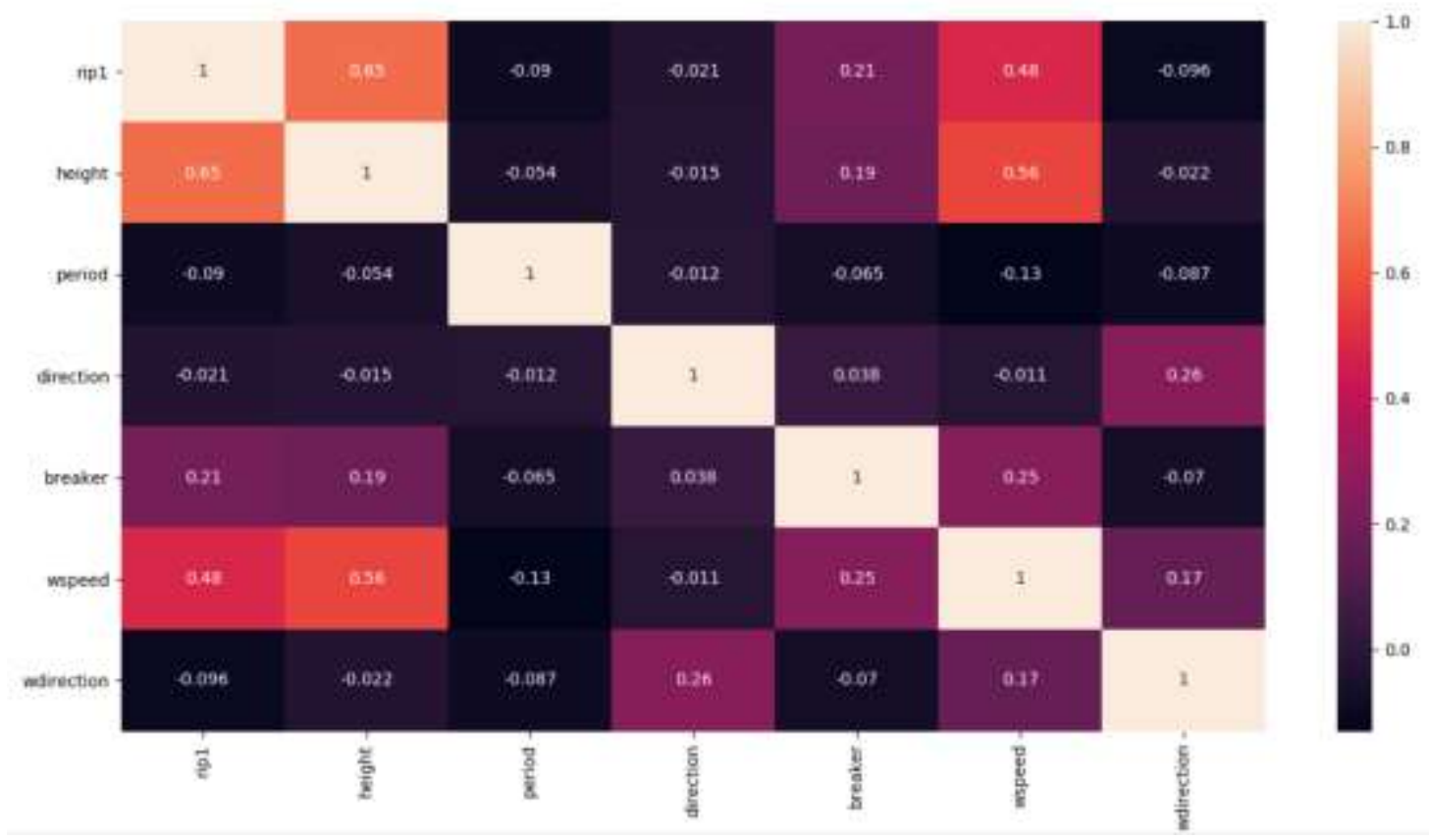

7-3. A heatmap of features shows wave height (height) corresponds well with rip presence (rip1).

The initial model was performed using the statsmodels python module logit (Seabold et al., 2010) and the results are shown in Table 7-9 below. The pseudo Rsquared value was 0.513 with $n=134$. This model shows that wave height, period, and wind speed have $\mathrm{P}$ values of less than 0.05 and are statistically significant. Wave direction, breaker type and wind direction all have $\mathrm{P}$ values of greater than 0.05 and are not statistically significant. Recursive Feature Elimination (RFE) was conducted with cross validation equal to 10 . RFE is a cross-validation model that examines the best or worst performing features, which then drops that feature and repeats the process until all features are exhausted. The RFE model used was from the scikit-learn machine learning package developed by Pedregosa et al. (2011). The results of the RFE show that the first four features: height, period, direction and breaker are optimal (Figure 7-4). 
7-9. The initial logistic regression results.

$\begin{array}{lrrrrrr} & \text { Coef. } & \text { Std.Err. } & \text { z } & \text { P }>|z| & {[0.025} & 0.975] \\ \text { height } & 2.5262 & 0.5650 & 4.4707 & 0.0000 & 1.4187 & 3.6337 \\ \text { period } & -1.8848 & 0.3736 & -5.0455 & 0.0000 & -2.6169 & -1.1526 \\ \text { direction } & -0.2223 & 0.2666 & -0.8337 & 0.4044 & -0.7449 & 0.3003 \\ \text { breaker } & 0.7150 & 0.7576 & 0.9438 & 0.3453 & -0.7699 & 2.1999 \\ \text { wspeed } & 0.1751 & 0.0813 & 2.1537 & 0.0313 & 0.0157 & 0.3344 \\ \text { wdirection } & -0.2034 & 0.1923 & -1.0581 & 0.2900 & -0.5802 & 0.1734\end{array}$

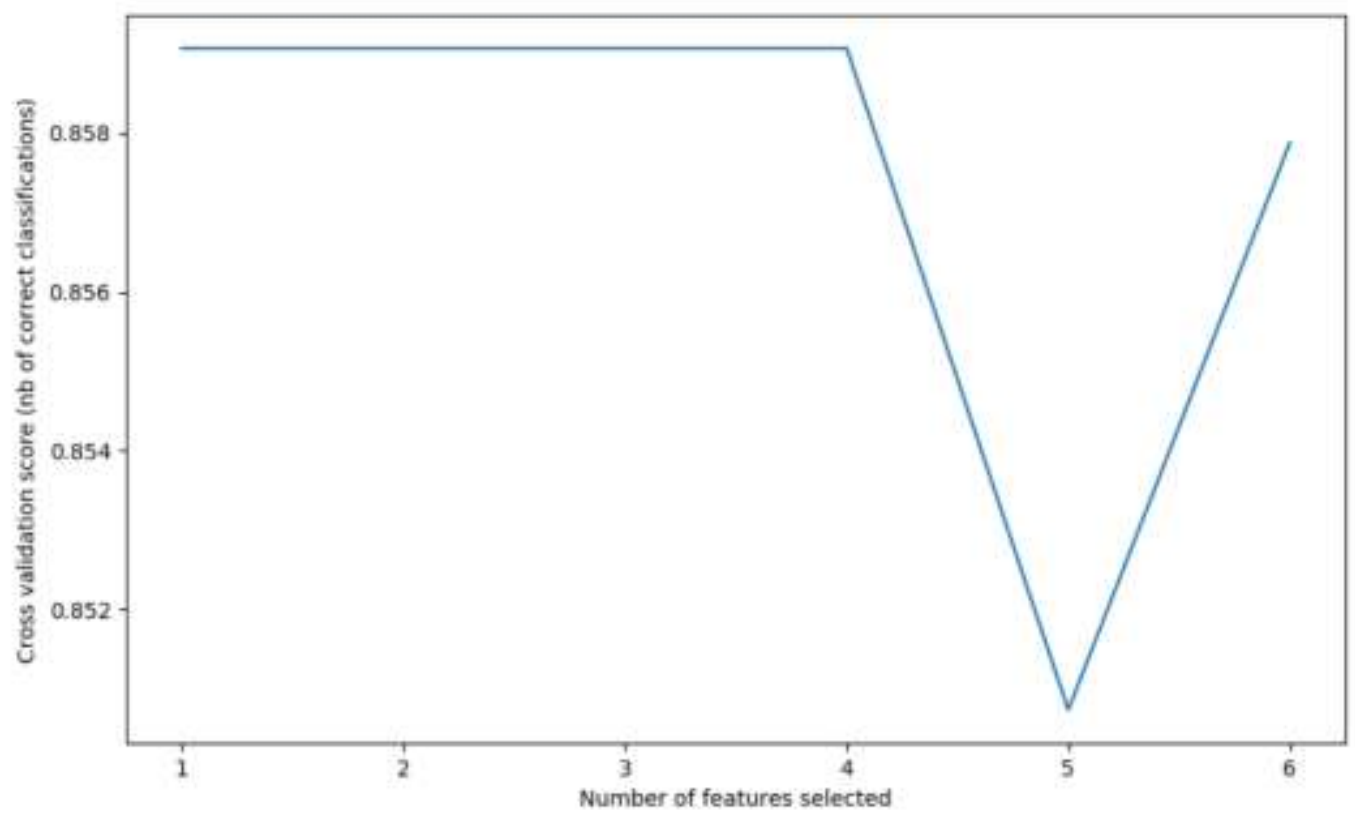

7-4. The RFE cross-validation model shows the first four features are optimal.

The logistic regression was reconducted with the LogisticRegression python module from scikit-learn (Pedregosa et al., 2011) using only the optimal features selected by the RFE. The dataset was split into a training dataset and a testing dataset using the scikit-learn python module, which chooses data from the dataset at random. The pseudo R-squared value was 0.474 and $n=134$. 
7-10. The reconstructed logistic regression model with the four optimal features.

\begin{tabular}{|c|c|c|c|c|c|c|}
\hline & Coef. & Std.Err. & z & $\mathrm{P}>|\mathrm{z}|$ & {$[0.025$} & $0.975]$ \\
\hline height & 2.7756 & 0.5245 & 5.2918 & 0.0000 & 1.7476 & 3.8037 \\
\hline period & -1.7610 & 0.3304 & -5.3308 & 0.0000 & -2.4085 & -1.1136 \\
\hline breaker & 0.9069 & 0.7271 & 1.2473 & 0.2123 & -0.5182 & 2.3319 \\
\hline wdirection & -0.1912 & 0.1994 & -0.9586 & 0.3378 & -0.5820 & 0.1997 \\
\hline
\end{tabular}

The trained model was tested using the test dataset, and the accuracy of the logistic regression classifier on the test set was 0.86 . A confusion matrix was computed using the scikit-learn machine learning package (Pedregosa et al., 2011), which shows the ratio of correct to incorrect predicitions. The results of the confusion matrix show that there were $21+4$ correct predicitions and $1+3$ incorrect decisions (Table 7-11). There were 25 correct predicitions out of 29 total predicitions, leading to an accuracy of $86 \%$.

\begin{tabular}{r|l|l|}
$\begin{array}{r}\text { 7-11. Confusion Matrix } \\
\text { Predicted: } \\
\text { Yes }\end{array}$ & $\begin{array}{l}\text { Predicted: } \\
\text { No }\end{array}$ \\
\hline $\begin{array}{r}\text { Actual: } \\
\text { Yes }\end{array}$ & 21 & 1 \\
Actual: & 3 & \\
No & & \\
\cline { 2 - 3 } & &
\end{tabular}

A classification report is listed below (Table 7-12), as calculated from the scikitlearn module (Pedregosa et al., 2011). The precision is the degree to which the classifier correctly labels a sample as positive.

Precision is defined as:

$\mathrm{tp} /(\mathrm{tp}+\mathrm{fp})$

where, $\mathrm{tp}$ is the total positives and $\mathrm{fp}$ is false positives. 
The recall is defined as :

$\mathrm{tp} /(\mathrm{tp}+\mathrm{fn})$

where $\mathrm{fn}$ is the number of false negatives.

The F1-score is a weighted harmonic mean of the recall and precision ( 1 being optimal and 0 being worst), and the support is the number of occurrences of each class.

7-12. Classification Report.

\begin{tabular}{|l|l|l|l|l|}
\hline Rip Value & Precision & Recall & F1-score & Support \\
\hline 0.0 & 0.88 & 0.95 & 0.91 & 22 \\
\hline 1.0 & 0.80 & 0.57 & 0.67 & 7 \\
\hline Average/ Total & 0.86 & 0.86 & 0.85 & 29 \\
\hline
\end{tabular}

A receiver operating characteristic (ROC) curve was used to display the accuracy of the logistic regression versus the true and false positive rates (Figure 7-5). The ROC curve was computed using the scikit-learn machine learning model (Pedregosa et al., 2011). The closer to the top left of the graph, the better and more accurate the logistic regression model. The accuracy of the model is poorer the closer it gets to the dotted line in the middle of the graph. Figure 7-5 shows that the logistic regression model is very close to the upper left of the graph and therefore is accurate. The logistic regression area under the curve (auc) is 0.981 , where values close to 1 are optimal and values close to 0.5 are poor. 


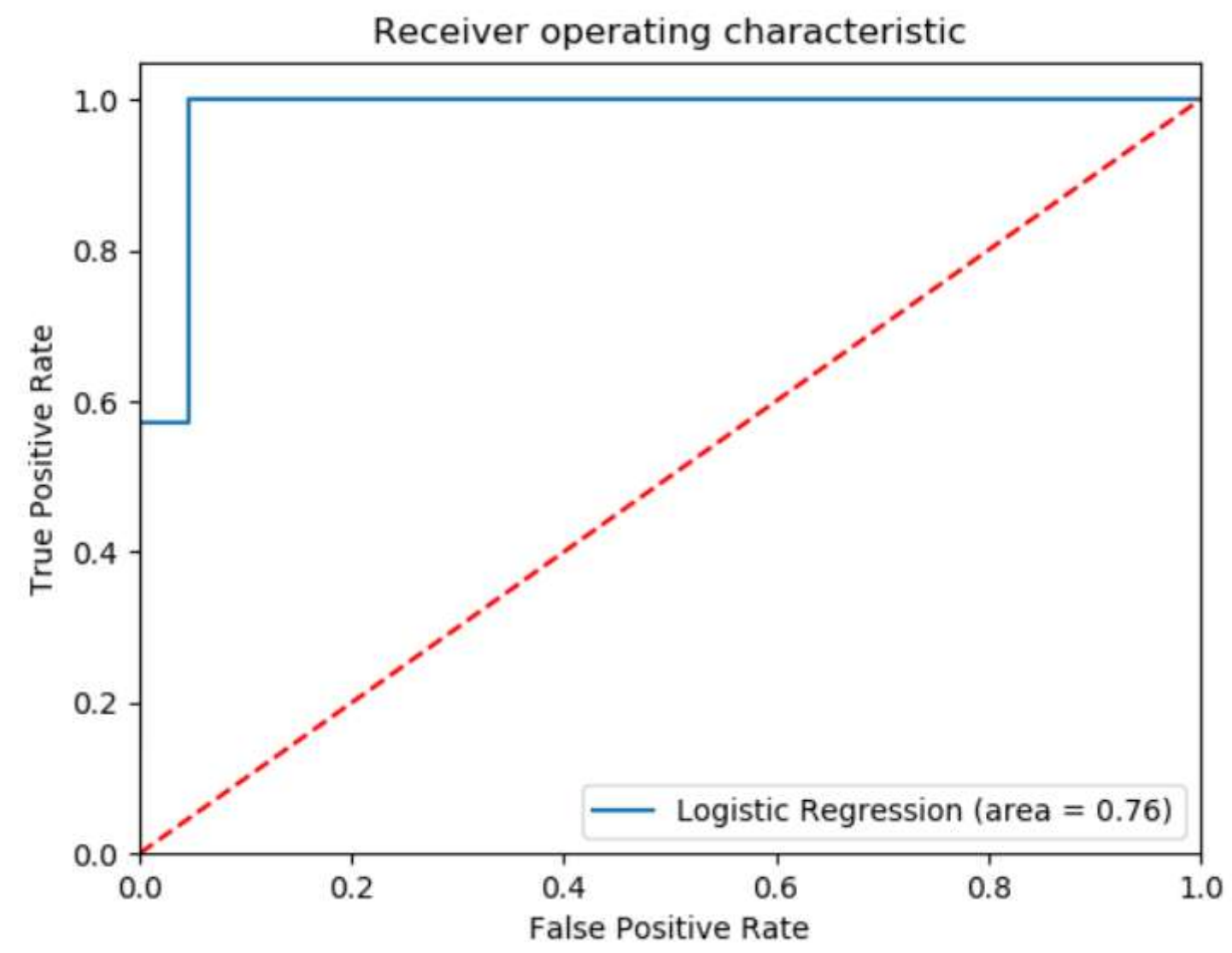

7-5. The receiver operating characteristic shows that the reconstructed logistic regression model is located near the top left corner of the chart, which represents that the model is accurate for the true positive rate.

The results of the logistical regression showed positive correlations between rip presence and wave height and period. South Florida is a relatively low wave energy environment, where little field research has been conducted compared to the high wave energy coasts of California and Australia (Leatherman, 2017b; Brander and MacMahan, 2011). 


\section{MANAGEMENT IMPLICATIONS}

Miami Beach attracts tens of millions of visitors annually and is the number three beach for rip current drownings in the United States (Paxton, 2014). This popular tourist destination has a number of deceptively dangerous factors that make Miami Beach rips so dangerous, which has important management implications (Table 7-13).

7-13. Physical, safety and social factors that have important implications for management at Miami Beach.

\section{Social Factors}

High population in South Florida

10 s of millions of visitors annually

Some people do not understand or heed warning flags

Abundance of bars and night clubs leading to drinking and bathing

Bathers are typically inexperienced swimmers

\section{Physical Factors}

Rips can occur during sunny, fair-weather conditions

Rips generated by moderate onshore winds and non-threatening waves

"Clear-water" rips are nearly invisible

\section{Safety Factors}

Sections of Miami Beach have no lifeguards

Signage is only in English

Lifeguards off duty at 5PM, while many people stay until sunset

Beaches are the number one recreational destination for Americans, and there are more than two billion beach visits per year (Houston, 2013). The United States public is primarily informed about rip currents on site via beach hazard flags, where lifeguards post current beach conditions by using different colored flags to represent danger. Many visitors from inland areas lack experience and knowledge of the ocean, and international tourists may not be able to read beach warning signs which are only in English or 
understand the hazard flag system (Brannstrom et al., 2015; Table 7-13). This lack of public knowledge contributes to the high annual death toll of rip currents (Brander and MacMahan, 2011).

Rip currents at Miami area beaches often occur during sunny, fair-weather conditions with relatively small waves (0.6-0.9m) and a refreshing 15-20 knot onshore breeze (Table7-13). This idyllic weather in combination with South Florida's “clearwater" rips leads to a deceptively dangerous place for bathers (Leatherman, 2017a). Many bathers associate rip currents with large waves or stormy weather and do not realize that rip currents can occur under blue sky conditions. As the clear-water rips here contain little to no sediment, these offshore-flowing currents are practically invisible to the casual beachgoer. This is a serious management problem--how do you educate beachgoers about rip currents when they are almost impossible to spot?

Lifeguards at Miami Beach rescue many bathers annually and are a great asset to beach safety. However, lifeguards are not present along the entire $13 \mathrm{~km}$ coastline of Miami Beach. Furthermore, lifeguards are off-duty at 5 PM, but the beach does not close until sunset (Table 7-13). Many visitors will come to Miami Beach at $4 \mathrm{pm}$ and leave at sunset to avoid the intense UV radiation of the subtropics, but this puts them at risk of rip currents with no lifeguards present for the majority of their beach visit.

\section{DISCUSSION}

During El Nino years, storm systems travel farther south so there are more westerly winds in Florida compared to La Nina years. During El Nino years, the wind can shift from west to south and back again very quickly, so the wind does not have a 
chance to establish an onshore wave field and generate rips. In January, wind direction is much more variable. March is typically when there are stronger east winds. Starting around March to April, high pressure systems off the Atlantic Ocean produce more steady east winds, and this combination of east winds and Spring Break crowds result in many rip rescues and unfortunately some deaths.

Bathers should stay close to the shoreline in the shallower water because rip currents typically do not start until 10 to 15 meters offshore unless much larger waves than were observed during this study are encountered, such as during a passing hurricane or large swell generated by a mid-Atlantic nor'easter. The "clear-water" rips of South Florida are very difficult to detect even for lifeguards. It was often necessary for the research team to wade into the ocean and release fluorescein tracer dye to detect an offshore-flowing current. Lifeguards look for floating Sargasso seaweed as the best natural indicator of rip current presence.

The lifeguard dataset is useful but more and better-documented data using diagnostic tests for rip currents are necessary. Not all of the data collected in this six month survey was used in the logistic regression analysis due to missing values. As explained earlier, the Haulover Park dataset was missing 66 days of rip observations. It would have been useful to use the Haulover Park dataset in the logistic regression analysis to compare how the rip currents change by location. Instrumented measurements are needed daily, particularly by deployment of nearshore wave buoys and/or pressure-transducer wave gauges at the Miami area beaches as has been undertaken at Haeundae Beach in Busan, South Korea (Figure 7-6). 


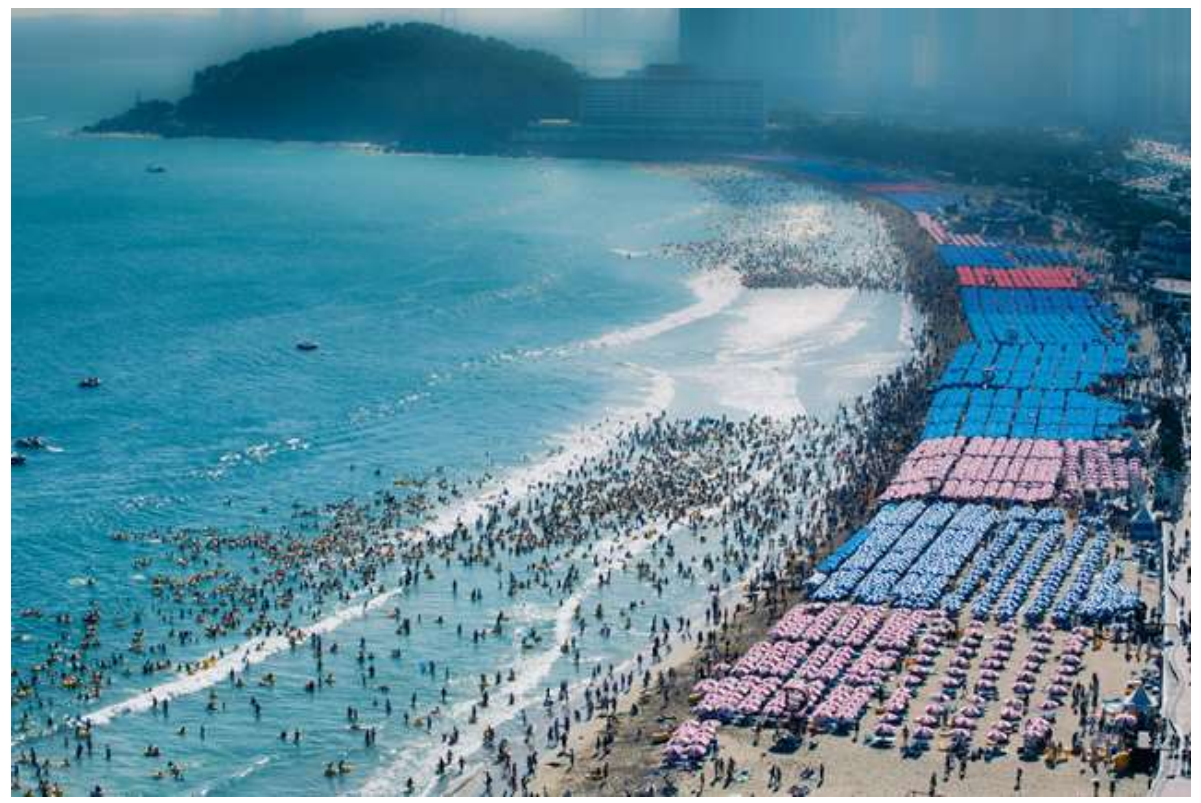

7-6. Beachgoers at Haeundae Beach in Busan, South Korea are prohibited from entering the water at the location of a rip current.

It will also be beneficial to place gauges just beyond the series of coral reefs to determine how offshore waves are transformed and attenuated. Lifeguards should employ a proof-positive method of determining rip presence (e.g., tracer dye, watersaturated coconuts as drogues, etc.). A beach field station is needed to safeguard the instrumentation and provide for better and more frequent field measurements such as was undertaken for the dissertation research at Tamarama Beach, Sydney, Australia by Brander (1997).

Instrumented, continuous wave measurements are necessary to verify and calibrate the National Weather Service numerical model to confirm their rip current forecasts. This data set would also be important for studying beach erosion and to evaluate beach nourishment projects, which are vital to maintaining this very popular, world-famous beach (Leatherman, 2015). 


\section{CONCLUSIONS}

Rip currents at Miami Beach were found to be correlated with wave height and period using a logistic regression analysis. The prevailing thought of many beachgoers is that rip currents occur during stormy conditions, but rips at Miami area beaches are generally "fair-weather killers." Rip currents, which can occur during 15 kt winds (e.g., a moderate onshore breeze) and on warm, sunny days, can be very dangerous even though they are fairly weak. Rips were found to be most commonly generated by relatively small, non-threatening waves (e.g., 0.6 to $0.9 \mathrm{~m}$ in height). Additionally, the "clearwater" rips of South Florida are practically invisible to beachgoers. These physical factors, along with social and safety considerations, pose a significant problem for coastal management. 


\section{CONCLUSIONS}

All surf beaches, including the Great Lakes, are subject to rip current drownings. The public does not have sufficient understanding of rip currents to prevent these all-toocommon tragedies. The prevailing thought is that rip currents only occur during stormy conditions. But dangerous rip currents can occur at $15 \mathrm{kts}$ (a moderate breeze) on a sunny, warm day. Once the wind reaches $25 \mathrm{kts}$, beachgoers start avoiding the beach. The combination of persistent onshore winds and Spring Break crowds often leads to drownings and numerous rescues in South Florida.

Rip currents are present more often and/or stronger during low tide because there is a thinner layer of water over the nearshore bar and hence less depth for water draining the beach to escape offshore; this fact has been recognized by many rip current researchers. Interestingly, sand bar height has not been considered as a factor prior to this study, even though a high sand bar has a similar effect of lowering the water discharge over the bar in a seaward direction, hence concentrating the flow in bar gaps as rip currents. Some beaches have no or extremely small sand bars while others have quite high sand bars so that the presence and strength of rip currents will vary geographically.

South Florida rip currents are "clear-water" rips as little to no sediment is entrained in the flow. With fair-weather conditions and undetectable clear-water rips, even weak ones, beachgoers do not sense danger and often ignore the red flags, resulting in far too many rescues and fatalities.

South Florida is a relatively low wave energy environment--significant wave heights that generated rip currents averaged 0.6 to $0.9 \mathrm{~m}$ during this field study. These conditions 
resulted in fairly weak currents with an average speed of $0.3 \mathrm{~m} / \mathrm{s}$. The rips exhibited nearly straight-line paths that terminated seaward of the sand bar not far beyond the breaker zone. In spite of this, South Florida is \#3 in rip drownings in the nation.

The effect of rip currents on swimmers was investigated through a simplified analysis of the drag force acting on the swimmer and the power generated to overcome it. The drag force and power have a quadratic and cubic relationships with the rip current speed. The drag force increases by 1.25 times and power increases by 2.375 times of the drag and power produced without rip currents, respectively, when the speed of rip currents is half of the swimmer's speed. When the speed of a rip current reaches the speed of the swimmer, the drag force and power increase by 3 and 7 times the drag and power without rip currents, respectively. A small increase in rip current speed leads to a large increase in the power generated to overcome the increase in the drag force because of the velocity-cubed function of power. Therefore, even rip currents with small velocity are dangerous, especially to weak swimmers, and swimming against rip currents is not recommended.

Rip currents at Miami Beach were found to be correlated with wave height and period using a logistic regression analysis. The prevailing thought of many beachgoers is that rip currents occur during stormy conditions, but rips at Miami area beaches are generally "fair-weather killers." Rip currents, which can occur during 15 kt winds (e.g., a moderate onshore breeze) and on warm, sunny days, can be very dangerous even though they are fairly weak. Rips were found to be most commonly generated by relatively small, non-threatening waves (e.g., 0.6 to $0.9 \mathrm{~m}$ in height). Additionally, the "clearwater" rips of South Florida are practically invisible to beachgoers. These physical 
factors, along with social and safety considerations, pose a significant problem for coastal management.

Beachgoers need to heed all warnings (e.g. signage and red flags), know how to swim and learn to read the surf. It is important to know the most successful rip current escape strategy for your area. Most rip currents in South Florida are the bar-gap type, and the best approach is to swim parallel to shore (but not against the longshore current when present). Rip current escape methods vary according to the flow characteristics. For example, at Haulover Park jetty, which has an unusual rip current flow pattern, the best escape method is to swim straight back to shore.

A major limitation of this study is the lack of nearshore wave gauge data and an on-site field station. Rip currents are driven primarily by nearshore breaking waves. As seen in the results of the logistic regression analysis, wave height is a very important parameter in predicting rip presence. However, available offshore wave gauge data does not accurately represent nearshore breaker heights and nearshore wave heights are needed (Paxton, 2014). A wave gauge placed in the surf zone would be very useful in future studies. Additionally, an on-site field station will be of much use logistically for data collection. There were many "dry runs" wherein the wave action had subsided or no rips were found by the time the researchers reached the field site. 


\section{REFERENCES}

Aagaard, T., Greenwood, B. and Nielsen, J. (1997). Mean currents and sediment transport in a rip channel. Marine Geology, 140:25-45.

Abt, S., Wittier, R., Taylor, A., and Love, D. (1989). Human stability in a high flood hazard zone. JAWRA Journal of the American Water Resources Association, 25, 881890.

Alcock, A., and Mason, B. (2007). Biomechanical analysis of active drag in swimming. In: ISBS-Conference Proceedings Archive.

Barrett, G. and Houser, C. (2012). Identifying hot spots of rip current activity using wavelet analysis at Pensacola Beach, Florida, Physical Geography, 33:32-49.

Bowen, A.J. (1969). Rip Currents: Theoretical Investigations. Oceans and Atmospheres, 74:5467-5478.

Bradstreet, A.J., Brander, R.W., McCarroll, J.R., Brighton, B., Howes, D.D., Drozdzewski, D., Sherker, S., Turner, I., Roberts, A. and MacMahan, J. (2014). Rip Current Survival Principles: Towards Consistency. Journal of Coastal Research, 72: 8592.

Brander, R.W. (1997). Field observations on the morphodynamics of rip currents. Unpublished Ph.D. thesis, Department of Geography, University of Sydney, 240pp.

Brander, R.W. (1999). Field observations on the morphodynamic evolution of low wave energy rip current system. Marine Geology, 157:199-217.

Brander R.W. and MacMahan, J. (2011). Future challenges for rip current research and outreach. In: Leatherman, S.P., Fletemeyer, J. (eds). Rip currents: Beach Safety, Physical Oceanography and Wave Modeling. Boca Raton, FL: CRC Press, 1-29

Brander, R.W. and Short, A.D. (2000). Morphodynamics of a large-scale rip current system at Muriwai Beach, New Zealand. Marine Geology, 165(1-4):27-39. 
Brander, R.W. and Short, A.D. (2001). Flow kinematics of low energy rip current systems. Journal of Coastal Research, 17:468-481.

Brander, R.W., Dominey-Howes, D., Champion, C., Del Vecchio, O., and Brighton, B. (2013). Brief communication: A new perspective on the Australian rip current hazard. Natural Hazards and Earth Systems Sciences, 13:1687-1690.

Brannstrom, C., Brown, H.L., Houser, C., Trimble, S., and Santos, A. (2015). "You can't see them sitting here": Evaluating beach user understanding of a rip current warning sign, Applied Geography, 56:61-70.

Callaghan, D.P., Baldock, T.E., Nielsen, P., Hanes, D.M., Hass, K., MacMahan, J.H. (2004). Pulsing and circulation of a rip current system. Proceedings of the $29^{\text {th }}$ International Conference on Coastal Engineering. American Society of Civil Engineers, Portugal, pp. 1493-1505.

Castelle, B., McCarroll, R.J., Brander, R.W., Scott, T., and Dubarbier, B. (2016a). Modelling the alongshore variability of optimum rip current escape strategies on a multiple rip-channelled beach. Natural hazards, 81: 663-686.

Castelle, B., Scott, T., Brander, R., and McCarroll, R. (2016b). Rip current types, circulation and hazard. Earth-Science Reviews, 163: 1-21.

Dalrymple, R.A. (1975). A mechanism for rip current generation on an open coast. Journal of Geophysical Research, 80:3485-3487.

Dalrymple, R.A., MacMahan, J.H., Reniers, A.J., and Nelko, V. (2011). Rip currents. Annual Review of Fluid Mechanics, 43: 551-581.

Davis, R.J., and Paxton, C.H. (2005). How the swells of Hurricane Isabel impacted Southeast Florida. American Meteorological Society, 1065-1068.

Dean, R. G. (2010). Conditions at Sea Camp Beach on Cumberland Island, GA on June 24, 2006 and the likelihood of the presence of rip currents. A consulting report for the U.S. Department of Justice, 1-19. 
Dean, R.G. and Thieke, R.J. (2011). Surf zone hazards: rip current hazards at Pensacola Beach, Florida. In: Rip currents: beach safety, physical oceanography and wave modeling (editors Stephen P. Leatherman and John Fletemeyer), 107-123.

Dolce, C. (2017). Rip currents, an underrated danger, have been more deadly than tornadoes and lightning this year. Retrieved from: https://weather.com/safety/news/201805-07-underrated-dangers-rip-currents-deadly/.

Drønen, N., Karunarathna, H., Fredsøe, J., Sumer, B.M., and Deigaard, R. (2002). An experimental study of rip channel flow. Coastal Engineering: 45: 223-238.

Drozdzewski, D., Shaw, W., Dominey-Howes, D., Brander, R., Walton, T., Gero, A., Sherker, S., Goff, J., and Edwick, B. (2012). Surveying rip current survivors: preliminary insights into the experiences of being caught in rip currents. Natural Hazards and Earth System Sciences: 12: 1201-1211.

Dusek, G., and Seim, H. (2013). A probabilistic rip current forecast model. Journal of Coastal Research. 29: 909-925.

Engle, J. A. (2003). Formulation of a rip current forecasting technique through statistical analysis of rip current-related rescues. M. S. thesis, Univeristy of Florida, 81 pp.

Engle, J., MacMahan, J., Thieke, R. J. and Hanes, D. M. (2002). Formulation of a rip current predictive index using rescue data. National Conference on Beach Preservation Technology, FSBPA (p. 285): Citeseer.

Fallon, K.M., Rip Current Formation and Beach Safety Implications for Several U.S. Atlantic Coast Beach Areas (2017). FIU Electronic Theses and Dissertations, 3382.

Fallon, K.M., Lai, Q., and Leatherman, S.P. (2018). Beachgoer's recognition of rip current hazard at Miami Beach, Florida. Ocean \& Coastal Management, 165: 63-70.

Florida Department of Environmental Protection (2014). Regional Coastal Monitoring Data <http://www.dep.state.fl.us/beaches/data/coastmon.htm\#ProfileSurveyData> 
Genisi, V. A., and Ashley, W.S. (2010). An examination of rip current fatalities in the United States. Natural Hazards, 54:159-175.

Haller, M.C., Dalrymple, R.A., and Svendsen, I.A. (2002). Experimental study of nearshore dynamics on a barred beach with rip currents. Journal of Geohpysical Research, 107:1-21.

Hanes, D.M. (2016). Human instability related to drowning risk in surf zones for novice beachgoers or weak swimmers. Natural hazards, 83, 761-766.

Hazrati, P. (2016). Active drag of front crawl swimmers: estimation, measurement and analysis, doctoral dissertation. University of Sydney, 280pp.

Holland K.T., Puleo, J.A., and Kooney, T.N. (2001). Quantification of swash flows using videobased particle image velocimetry. Coastal Engineering, 44:65-77.

Holman, R.A. and Stanley, J. (2007). The history and technical capabilities of ARGUS. Coastal Engineering, 54(6-7): 477-491.

Houser, C., Arnott, R., Ulzhöfer, S., and Barrett, G. (2013). Nearshore circulation over transverse bar and rip morphology with oblique wave forcing. Earth surface processes and landforms, 38: 1269-1279.

Houser, C., Barrett, G. and Labude, D. (2011). Alongshore variation in the rip current hazard at Pensacola Beach, Florida. Natural Hazards, 57:501-523.

Houston, J. (2013). The economic value of beaches--a 2013 update. Shore and Beach, 81(1): 3-11.

Inman, D., Zampol, J., White, T., Hanes, D., Waldorf, B., and Kastens, K., (1980). Field measurements of sand motion in the surf zone. Coastal Engineering Proceedings, 1(17):1215-1234. 
Jackson, N.L., Nordstrom, K.F., Eliot, I., and Masselink, G. (2002). 'Low energy' sandy beaches in marine and estuarine environments: a review. Geomorphology, 48: 147-162.

Johnson, D., Stocker, R., Head, R., Imberger, J., and Pattiaratchi, C. (2003). A compact, low-cost GPS drifter for use in the oceanic nearshore zone, lakes, and estuaries. Journal of Atmospheric and Oceanic Technology, 20(12):1880-1884.

Jonkman, S., and Penning-Rowsell, E. (2008). Human Instability in Flood Flows 1. JAWRA Journal of the American Water Resources Association, 44: 1208-1218.

Lascody, R.L. (1998). East central Florida rip current program. National Weather Digest, 22: $25-30$.

Leatherman, S.B. (2015). Rip current hazard on Florida and South Georgia Beaches. Shore \& Beach, 83(1):63-66.

Leatherman, S. B. (2016). Rip Currents in South Florida: A Major Coastal Hazard and Management Challenge, Journal of Coastal Zone Management, V. 19:431, Doi: $10.4172 / 2473-3350.1000431$.

Leatherman, S. B. (2017a). Rip Current Measurements at Three South Florida Beaches, Journal of Coastal Research, V. 33:1228-1234.

Leatherman, S. B. (2017b). Rip Flow Characteristics and Escape Strategies in South Florida, Shore and Beach, V. 85:30-34.

Leatherman, S. B., Leatherman, S. P., and Haus, B. K. (2013). Bar height and rip current presence and strength. Shore and Beach, 81:19-22.

Leatherman, S.B., and Leatherman, S.P. (2017). Techniques for Detecting and Measuring Rip Currents. International Journal of Earth Science and Geophysics, 3:014.

Leatherman, S.P. (2012). Rip currents: Types and identification. Shore \& Beach, 80(3):5-10. 
Leatherman, S.P. and Fletemeyer, J. (2011). Rip Currents: Beach Safety, Physical Oceanography and Wave Modeling, CRC Press, Boca Raton, FL, 277pp.

Li, T.-Z., and Zhan, J.-M. (2015). Hydrodynamic body shape analysis and their impact on swimming performance. Acta of bioengineering and biomechanics, 17.

Lushine, J.B. (1991). A study of rip current drownings and related weather factors. National Weather Digest, 16: 13-18.

Lushine, J. B. (2011). Florida rip current deaths forecasts and statistics. In: Rip currents: beach safety, physical oceanography and wave modeling (editors Stephen P. Leatherman and John Fletemeyer), pp. 125-131.

MacMahan, J.H., Brown, J., Thornton, E.B., Reniers, A.J.H.M., Stanton T.P., Henriquez, M., Gallagher, E., Morrison, J., Austin, M., Scott, T., and Senechal, N. (2010). Mean lagrangian flow behavior on an open coast rip-channeled beaches: new perspectives. Marine Geology, doi: 10.1016/j.margeo.2009.09.011.

MacMahan, J.H., Reniers, A.J.H.M., Brown, J., Brander, R., Thornton, E., Stanton, T., and Carey, W. (2011). An introduction to rip currents based on field observations, Journal of Coastal Research, 27:783-786.

MacMahan, J.H., Reniers, A.J.H.M., Thornton, E.B., and Stanton, T. (2004). Surf zone eddies coupled with rip current morphology. Journal of Geophyiscal Research, 109, C07004, doi:10.1029/2003JC002083.

MacMahan, J.H., Thornton, E.B., and. Reniers, A.J.H.M. (2006). Rip current review. Coastal Engineering, 53:191-208.

MacMahan, J.H., Thornton, E.B., Stanton, T.P., and Reniers, A.J.H.M. ( 2005). RIPEX: Observations of a rip current system. Marine Geology, 218:113-134.

McCarroll, R.J., Brander, R.W., MacMahan, J.H., Turner, I.L., Reniers, A.J., Brown, J.A., Bradstreet, A., and Sherker, S. (2014). Evaluation of swimmer-based rip current escape strategies. Natural hazards, 71: 1821-1846. 
McCullagh, P., and Nelder, J. A., (1989). Generalized linear models. Vol. 37. CRC press., $532 \mathrm{pp}$.

Miloshis, M., and Stephenson, W. (2011). Rip current escape strategies: lessons for swimmers and coastal rescue authorities. Natural hazards, 59: 823-832.

Moulton, M., Dusek, G., Elgar, S., and Raubenheimer, B. (2017). Comparison of rip current hazard likelihood forecasts with observed rip current speeds. Weather and Forecasting, 32: 1659-1666.

National Climatic Data Center storm data. (2012), (NCDC)

http://www.ncdc.noaa.gov/stormevents/listevents.jsp?beginDate mm=01\&beginDate_dd $=01$ \&beginDate $\_$y y $=2000$ \&endDate $\mathrm{mm}=12$ \&endDate $\mathrm{dd}=31$ \&endDate yy $\mathrm{y}=2012$ \&eventType $=\% 28 Z \% 29+$ Rip + Current \&county $=$ ALL\&zone $=$ ALL\&submitbutton=Search \&statefips $=12 \% 2$ CFLORIDA\#

National Oceanic and Atmospheric Administration (2005). Rip Current Safety, http://www.ripcurrents.noaa.gov.

Paxton, C.H. (2014). Atmospheric and Ocean Conditions and Social Aspects Associated with Rip Current Drownings in the United States. Doctoral dissertation. University of South Florida, $254 \mathrm{pp}$.

Paxton, C.H. and Collins, J.M. (2014). Weather, ocean, and social aspects associated with rip current deaths in the United States. In: Lee, J. L, Leatherman, S. P. and Lee, J. (eds.), The $3^{\text {rd }}$ International Rip Current Symposium. Journal of Coastal Research Special Issue No. 72:50-55.

Pensacola Beach Visitation Numbers. (2009). Pensacola Professional Reports <http://www.visitpensacola.com/professional/reports>

public safety and implications for coastal management. Journal of Coastal Research, 12: 197-209.

Pedregosa, F., Varoquax, G., Gramfort, A., Michel, V., Thirion, B., Grisel, O., Blondel, M., Prettenhofer, P., Weiss, R., Dubourg, V., Vanderplas, J., Passos, A., Cournapeau, D., 
Brucher, M., Perrot, M., and Duchesnay, E. (2011). Scikit-learn: Machine Learning in Python, Journal of Machine Learning Research, 12: 2825-2830.

Reinhart, B. J. and Pfaff, S. (2016). Wave analysis for rip current forecasting in Southeast North Carolina. Eastern Region Technical Attachment No. 2016-01, 17 pp.

Rouboa, A., Silva, A., Leal, L., Rocha, J., and Alves, F. (2006). The effect of swimmer's hand/forearm acceleration on propulsive forces generation using computational fluid dynamics. Journal of biomechanics, 39: 1239-1248.

Sabet, B. S., and Barani, G. A. (2011). Design of small GPS drifters for current measurements in the coastal zone. Ocean and Coastal Management, 54:158-163.

Sacilotto, G.B., Ball, N., and Mason, B.R. (2014). A biomechanical review of the techniques used to estimate or measure resistive forces in swimming. Journal of applied biomechanics, 30: 119-127.

Schmidt, W.E., Woodward, B.T., Millikan, K.S., Guza, R.T., Raubenheimer, B., and Elgar, S. (2003). A GPS-tracked surf zone drifter. Journal of Atmospheric and Oceanic Technology, 20(7):1069-1075.

Schrader, M. (2004). Evaluation of the modified ECFL LURCS rip current forecasting scale and conditions of selected rip current events in Florida. Thesis, University of Florida, $77 \mathrm{pp}$.

Seabold, Skipper, and Perktold, J. (2010). Statsmodels: Econometric and statistical modeling with python. Proceedings of the $9^{\text {th }}$ Python in Science Conference.

Serway, R.A., and Jewett, J.W. (2018). Physics for Scientists and Engineers, $10^{\text {th }}$ Edition, Cengage Learning, Boston, 1296pp.

Shepard, F. P. (1936). Undertow, rip tide, or rip current. Science, 84:181-182. 
Shepard, F.P., and Inman, D.L. (1950). Longshore current observations in southern California, Tech. Memorandum No. 13, Beach Erosion Board, Corps of Engineers, Washington, D.C.

Sherker, S., Williamson, A., Hatfield, J., Brander, R., and Hayen, A. (2010). Beachgoers' beliefs and behaviours in relation to beach flags and rip currents. Accident Analysis \& Prevention, 42: 1785-1804.

Sherman, D.J., Short, A.D. and Takeda, I. (1993). Sediment mixing depth and bedform migration in rip channels. Journal of Coastal Research, 15: 39-48.

Short, A.D., and Hogan, C.L. (1994). Rip currents and beach hazards: their impact on public safety and implications for coastal management. Journal of Coastal Research, 10(12): 197-209.

Smith, J.A. and Largier, J.L. (1995). Observations of nearshore circulation: rip currents. Journal of Geophysical Research, 100: 10967-10975.

Sonu, C. J. (1972). Field observations of nearshore circulation and meandering currents, Journal of Geophysical Research, 77: 3232-3247.

Toussaint, H.M., and Beek, P.J. (1992). Biomechanics of competitive front crawl swimming. Sports Medicine, 13: 8-24.

Toussaint, H.M., Beelen, A., Rodenburg, A., Sargeant, A.J., de Groot, G., Hollander, A.P., and van Ingen Schenau, G.J. (1988). Propelling efficiency of front-crawl swimming. Journal of applied physiology, 65: 2506-2512.

Toussaint, H.M., and Hollander, A.P. (1994). Energetics of competitive swimming. Sports Medicine, 18: 384-405.

Toussaint, H.M., Roos, P.E., and Kolmogorov, S. (2004). The determination of drag in front crawl swimming. Journal of biomechanics, 37: 1655-1663. 
Toussaint, H.M., van Stralen, M., and Stevens, E. (2002). Wave drag in front crawl swimming. In: ISBS-Conference Proceedings Archive.

United States Lifesaving Association. (2013). National Lifesaving Statistics http://www.usla.org/statistics/public.asp

Van Leeuwen, B.R., McCarroll, R.J., Brander, R.W., Turner, I.L., Power, H.E., and Bradstreet, A.J. (2016). Examining rip current escape strategies in non-traditional beach morphologies. Natural hazards, 81: 145-165.

Vennell, R., Pease, D., and Wilson, B. (2006). Wave drag on human swimmers. Journal of biomechanics, 39: 664-671.

Vorontsov, A., and Rumyantsev, V. (2000a). Propulsive forces in swimming. Biomechanics in sport:Performance, enhancement and injury prevention. 205-231.

Vorontsov, A., and Rumyantsev, V. (2000b). Resistive Forces in Swimming \& Propulsive Forces in Swimming. Biomechanics in Sport:Performance, enhancement and injury prevention, 184-204.

Wade, S., Ramsbottom, D., Floyd, P., Penning-Rowsell, E., and Surendran, S. (2005). Risks to people: developing new approaches for flood hazard and vulnerability mapping, Proceedings of the $40^{\text {th }}$ Defra Flood and Coastal Management Conference, 14pp.

Waskom, M., Botvinnik, O., O'Kane, D., Hobson, P., Lukauskas, S., Gemperline, D. C., Augspurger, T., Halchenko, Y., Cole, J. B., Warmenhoven, J., de Ruiter, J., Pye, C., Hoyer, S., Vanderplas, J., Villalba, S., Kunter, G., Quintero, E., Bachant, P., Martin, M., Meyer, K., Miles, A., Ram, Y., Yarkoni, T., Williams, M. L., Evans, C., Fitzgerald, C., Fonnesbeck, C., Lee, A., Qalieh, A. (2017) Zenodo(Version v0.8.1). http://doi.org/10.5281/zenodo.883859

Webb, A., Banks, J., Phillips, C., Hudson, D., Taunton, D., and Turnock, S. (2011). Prediction of passive and active drag in swimming. Procedia Engineering, 13: 133-140.

Wright, L.D. and Short, A.D. (1984). Morphodynamic variability of surf zone and beaches. Marine Geology, 56: 93-118. 


\section{APPENDIX}

The following dataset are the wind, wave, and rip observations made by lifeguards from January to July 2016, as used in the logistic regression analysis in Chapter 7 of this dissertation.

\begin{tabular}{|l|l|l|l|l|l|l|}
\hline rip1 & height & period & direction & breaker & wspeed & wdirection \\
\hline $\begin{array}{l}\text { Rip } \\
\text { presence }\end{array}$ & $\begin{array}{l}\text { Wave } \\
\text { height }\end{array}$ & $\begin{array}{l}\text { Wave } \\
\text { Period }\end{array}$ & $\begin{array}{l}\text { Wave } \\
\text { direction }\end{array}$ & $\begin{array}{l}\text { Wave breaker } \\
\text { type }\end{array}$ & Wind speed & $\begin{array}{l}\text { Wind } \\
\text { direction }\end{array}$ \\
\hline Yes $=1$ & Average & Average & $\mathrm{N}=0$ & Spilling $=0$ & Average & $\mathrm{N}=0$ \\
No=0 & (ft) & (s) & $\mathrm{Ne}=1$ & Plunging $=1$ & (kts) & $\mathrm{Ne}=1$ \\
& & & $\mathrm{E}=2$ & & & $\mathrm{E}=2$ \\
& & $\mathrm{Se}=3$ & & $\mathrm{Se}=3$ \\
& & $\mathrm{~S}=4$ & & $\mathrm{~S}=4$ \\
& & & & $\mathrm{Sw}=5$ \\
& & & & $\mathrm{~W}=6$ \\
& & & & & $\mathrm{Nw}=7$ \\
\hline
\end{tabular}

\begin{tabular}{|c|c|c|c|c|c|c|c|c|}
\hline month & day & rip1 & height & period & direction & breaker & wspeed & wdirection \\
\hline 1 & 1 & & & & & & 8 & 3 \\
\hline 1 & 2 & & & & & & 8 & 3 \\
\hline 1 & 3 & & & & & & 8 & 6 \\
\hline 1 & 4 & 1 & 3 & 8 & 1 & 0 & 8 & 7 \\
\hline 1 & 5 & 1 & 5 & 7 & 1 & 0 & 23 & 1 \\
\hline 1 & 6 & 1 & 5 & 7 & 1 & 0 & 23 & 1 \\
\hline 1 & 7 & 1 & 3 & 7 & 1 & 0 & & 1 \\
\hline 1 & 8 & & & 1 & & & 13 & 3 \\
\hline 1 & 9 & & & 1 & & & 13 & 3 \\
\hline 1 & 10 & & & 10 & & & 13 & 5 \\
\hline 1 & 11 & & & 7 & 0 & & 15 & 7 \\
\hline 1 & 12 & 1 & 2 & 7 & 0 & 0 & 8 & 7 \\
\hline 1 & 13 & & & 4 & 0 & & 8 & 1 \\
\hline 1 & 14 & 1 & 2 & 7 & 3 & 0 & 8 & 3 \\
\hline 1 & 15 & 0 & & & & & 0 & 5 \\
\hline 1 & 16 & 0 & & & & & 5 & 5 \\
\hline 1 & 17 & 1 & 3 & 3 & & 0 & 20 & 5 \\
\hline 1 & 18 & 1 & 1 & 4 & 0 & 0 & 15 & 7 \\
\hline 1 & 19 & 1 & 2 & 8 & 0 & 0 & 15 & 1 \\
\hline 1 & 20 & & & & 0 & & 10 & 1 \\
\hline 1 & 21 & 1 & 2 & 8 & 5 & 0 & 8 & 5 \\
\hline
\end{tabular}




\begin{tabular}{rrrrrrrrr}
1 & 22 & 1 & 2 & 8 & 5 & 0 & 8 & 5 \\
\hline 1 & 23 & & & & 6 & & 8 & 6 \\
\hline 1 & 24 & 1 & 4 & 8 & 0 & 0 & 8 & 7 \\
\hline 1 & 25 & 1 & 2 & 8 & 6 & 0 & 5 & 0 \\
\hline 1 & 26 & 1 & 2 & 12 & 4 & 0 & 13 & 3 \\
\hline 1 & 27 & 1 & 4 & 6 & 4 & 0 & 2 & 3 \\
\hline 1 & 28 & 0 & & & & & 8 & 5 \\
\hline 1 & 29 & 1 & 2 & 8 & 0 & 0 & 8 & 7 \\
\hline 1 & 30 & 0 & & & & & 8 & 1 \\
\hline 1 & 31 & 0 & 0 & 7 & 3 & & 8 & 3 \\
\hline 2 & 32 & 0 & & 4 & 4 & & 8 & 3 \\
\hline 2 & 33 & 0 & & 6 & 4 & & 8 & 3 \\
\hline 2 & 34 & 1 & 2 & 6 & 4 & 0 & 15 & 3 \\
\hline 2 & 35 & 1 & 2 & & 2 & 0 & 18 & 2 \\
\hline 2 & 36 & 1 & 2 & & 0 & 0 & 23 & 0 \\
\hline 2 & 37 & 1 & 2 & & 4 & 0 & 15 & \\
\hline 2 & 38 & 0 & 1 & 5 & 0 & & 15 & 7 \\
\hline 2 & 39 & 1 & 6 & 10 & 0 & 1 & 5 & 6 \\
\hline 2 & 40 & 1 & 3 & 5 & 0 & 0 & 10 & 6 \\
\hline 2 & 41 & 0 & 1 & 5 & 0 & & 10 & 7 \\
\hline 2 & 42 & 1 & 1 & 6 & 0 & 0 & 10 & 0 \\
\hline 2 & 43 & 1 & 1 & 6 & 0 & 0 & 10 & 0 \\
\hline 2 & 44 & 0 & & & & & 5 & 0 \\
\hline 2 & 45 & 1 & 2 & 6 & 0 & 0 & 18 & 1 \\
\hline 2 & 46 & 1 & 4 & 6 & 0 & 0 & 18 & 2 \\
\hline 2 & 47 & 1 & 2 & 6 & 4 & 0 & 15 & 6 \\
\hline 2 & 48 & 0 & & & & & 5 & 6 \\
\hline 2 & 49 & 0 & & & & & 5 & 7 \\
\hline 2 & 50 & 1 & 2 & 6 & 2 & 0 & 18 & 2 \\
\hline 2 & 51 & 1 & 2 & 7 & 2 & 0 & 18 & 2 \\
\hline 2 & 52 & 0 & & 5 & 3 & & 5 & 3 \\
\hline 2 & 53 & 1 & 1 & 11 & 3 & 0 & 15 & 3 \\
\hline 2 & 54 & 1 & 3 & 6 & 3 & 0 & 15 & 3 \\
\hline 2 & 55 & 1 & 3 & 6 & 4 & 0 & 10 & 4 \\
\hline 2 & 56 & 1 & 1 & & 0 & 0 & 8 & 7 \\
\hline 2 & 57 & 1 & 2 & & 0 & 0 & 15 & 7 \\
\hline 2 & 58 & 1 & 2 & & 0 & 0 & 13 & 7 \\
\hline & 60 & 0 & & & & 0 & 8 & 2 \\
\hline & & & & & 2 & & 5 & 2 \\
\hline 21 & 0 & & & & & & \\
\hline 2 & & & & & & & \\
\hline
\end{tabular}




\begin{tabular}{|c|c|c|c|c|c|c|c|c|}
\hline 3 & 62 & 0 & & & 2 & & 5 & \\
\hline 3 & 63 & 0 & & & 2 & & 5 & 1 \\
\hline 3 & 64 & 0 & & & 2 & & 11 & 5 \\
\hline 3 & 65 & 1 & 2 & 6 & 2 & 0 & 10 & 1 \\
\hline 3 & 66 & 0 & & & 0 & & 8 & 7 \\
\hline 3 & 67 & 1 & 2 & 7 & 1 & 0 & 18 & 1 \\
\hline 3 & 68 & 1 & 5 & 7 & 3 & 0 & 15 & 3 \\
\hline 3 & 69 & 1 & 4 & 6 & 3 & 0 & 20 & 3 \\
\hline 3 & 70 & 1 & 4 & 6 & 3 & 0 & 18 & 3 \\
\hline 3 & 71 & 1 & 4 & 6 & 3 & 0 & 15 & 3 \\
\hline 3 & 72 & 1 & 3 & 6 & 3 & 0 & 11 & 3 \\
\hline 3 & 73 & 1 & 2 & 6 & 3 & 0 & 13 & 3 \\
\hline 3 & 74 & 0 & & & 4 & & 8 & 3 \\
\hline 3 & 75 & 0 & & & 4 & & 5 & 5 \\
\hline 3 & 76 & 0 & & & 4 & & 5 & 5 \\
\hline 3 & 77 & 0 & & & 4 & & 5 & 4 \\
\hline 3 & 78 & 0 & & & 4 & & 5 & 4 \\
\hline 3 & 79 & 1 & 1 & 7 & 3 & 0 & 13 & 3 \\
\hline 3 & 80 & 0 & 2 & 1 & & & 8 & 5 \\
\hline 3 & 81 & 0 & 1 & & & & 10 & 7 \\
\hline 3 & 82 & 1 & 2 & 6 & 1 & 0 & 8 & 1 \\
\hline 3 & 83 & 1 & 3 & 0 & 3 & 0 & 8 & 3 \\
\hline 3 & 84 & 1 & 2 & 6 & 2 & 0 & 15 & 2 \\
\hline 3 & 85 & 1 & 2 & 6 & 2 & 0 & 10 & 2 \\
\hline 3 & 86 & 1 & 1 & 7 & 2 & 0 & 10 & 2 \\
\hline 3 & 87 & 1 & 1 & 6 & 3 & 0 & 15 & 3 \\
\hline 3 & 88 & 0 & & & 4 & 0 & 5 & 5 \\
\hline 3 & 89 & 0 & & & 4 & & 5 & 5 \\
\hline 3 & 90 & 1 & 1 & 6 & 3 & 0 & 13 & 3 \\
\hline 3 & 91 & 1 & 2 & 7 & 3 & 0 & 18 & 3 \\
\hline 4 & 92 & 1 & 2 & 6 & 2 & 0 & 10 & 2 \\
\hline 4 & 93 & 1 & 3 & 6 & 3 & 0 & 20 & 4 \\
\hline 4 & 94 & 0 & & & 1 & & 5 & 7 \\
\hline 4 & 95 & 0 & & 4 & 1 & & 5 & 1 \\
\hline 4 & 96 & 0 & & 3 & 1 & & 8 & 1 \\
\hline 4 & 97 & 1 & 3 & 6 & 1 & 0 & 15 & 1 \\
\hline 4 & 98 & 1 & 2 & 10 & 1 & 0 & 5 & 6 \\
\hline 4 & 99 & 0 & & & & & 5 & 6 \\
\hline 4 & 100 & 1 & 1 & 6 & 1 & 0 & 10 & 1 \\
\hline 4 & 101 & 1 & 2 & 7 & 1 & 0 & 15 & 1 \\
\hline
\end{tabular}




\begin{tabular}{rrrrrrrrr}
4 & 102 & 1 & 3 & 7 & 2 & 0 & 15 & 2 \\
\hline 4 & 103 & 0 & 1 & 6 & 2 & 0 & 10 & 2 \\
\hline 4 & 104 & 0 & & & 2 & & 5 & 2 \\
\hline 4 & 105 & 0 & & & 3 & & 5 & 3 \\
\hline 4 & 106 & 0 & & & 3 & & 10 & 3 \\
\hline 4 & 107 & 1 & & 7 & 1 & 0 & 15 & 1 \\
\hline 4 & 108 & 1 & 2 & 6 & 1 & 0 & 10 & 1 \\
\hline 4 & 109 & 1 & 3 & 6 & 1 & 0 & 15 & 1 \\
\hline 4 & 110 & 1 & 2 & 7 & 0 & 0 & 8 & 0 \\
\hline 4 & 111 & 1 & 2 & 6 & 2 & 0 & 15 & 2 \\
\hline 4 & 112 & 1 & 3 & 6 & 2 & 0 & 20 & 2 \\
\hline 4 & 113 & 1 & 3 & 7 & 3 & 0 & 15 & 2 \\
\hline 4 & 114 & 0 & & & 6 & & 10 & 6 \\
\hline 4 & 115 & 0 & & & 3 & & 5 & 3 \\
\hline 4 & 116 & 0 & 1 & 7 & 2 & 0 & 10 & 2 \\
\hline 4 & 117 & 0 & 1 & 8 & 2 & 0 & 10 & 2 \\
\hline 4 & 118 & 0 & & & 2 & & 5 & 3 \\
\hline 4 & 119 & 0 & & & 3 & & 5 & 3 \\
\hline 4 & 120 & 0 & & & 2 & & 10 & 3 \\
\hline 4 & 121 & 0 & & & 2 & & 5 & 3 \\
\hline 5 & 122 & 1 & 2 & 8 & 3 & 0 & 15 & 3 \\
\hline 5 & 123 & 1 & 2 & 7 & 3 & 0 & 15 & 3 \\
\hline 5 & 124 & 0 & & 7 & 3 & 0 & 8 & 3 \\
\hline 5 & 125 & 0 & & & & & 5 & 6 \\
\hline 5 & 126 & 1 & 2 & 10 & 1 & 1 & 15 & 7 \\
\hline 5 & 127 & 0 & & & 1 & & & 1 \\
\hline 5 & 128 & 0 & & & & & 5 & 5 \\
\hline 5 & 129 & 0 & & & 3 & & 2 & 5 \\
\hline 5 & 130 & 1 & 2 & 8 & 3 & 0 & 15 & 3 \\
\hline 5 & 131 & 0 & 1 & 8 & 3 & 0 & 8 & 5 \\
\hline 5 & 132 & 0 & & & 2 & 0 & 8 & 5 \\
\hline 5 & 133 & 0 & & & 4 & & 8 & 3 \\
\hline 5 & 134 & 0 & & & 4 & & 5 & 3 \\
\hline 5 & 135 & 0 & & & 4 & & 5 & 3 \\
\hline 5 & 136 & 0 & & & 4 & 0 & 5 & 4 \\
\hline 5 & 137 & 0 & & & 4 & 0 & 5 & 4 \\
\hline 5 & 138 & 1 & 3 & 7 & 3 & 0 & 13 & 3 \\
\hline 5 & 139 & 0 & 1 & 6 & 3 & 0 & 15 & 3 \\
\hline 5 & 140 & 0 & & & 4 & & 8 & 4 \\
\hline 5 & 141 & 0 & & 6 & 1 & & 5 & 1 \\
\hline & & & & & & & & \\
\hline & & & & & & \\
\hline
\end{tabular}




\begin{tabular}{|c|c|c|c|c|c|c|c|c|}
\hline 5 & 142 & 1 & 1 & 7 & 3 & 0 & 5 & 3 \\
\hline 5 & 143 & 0 & & 10 & 4 & & 10 & 4 \\
\hline 5 & 144 & 0 & & 10 & 2 & & 10 & 5 \\
\hline 5 & 145 & 0 & & 3 & 1 & & 10 & 7 \\
\hline 5 & 146 & 1 & 2 & 5 & 2 & 0 & 15 & 1 \\
\hline 5 & 147 & 0 & 1 & 5 & 1 & & & 1 \\
\hline 5 & 148 & 0 & & 5 & 1 & & & 1 \\
\hline 5 & 149 & 0 & & 4 & 1 & & & 1 \\
\hline 5 & 150 & 0 & & & 2 & & & 2 \\
\hline 5 & 151 & 0 & & 6 & 2 & & & 2 \\
\hline 5 & 152 & 0 & & 7 & 3 & & & 3 \\
\hline 6 & 153 & 0 & & & & & 5 & 5 \\
\hline 6 & 154 & 0 & & & & & 5 & 3 \\
\hline 6 & 155 & 0 & & 4 & 3 & & 10 & 3 \\
\hline 6 & 156 & 0 & & & & & 5 & 3 \\
\hline 6 & 157 & 0 & & 3 & 3 & & 5 & 3 \\
\hline 6 & 158 & 1 & 1 & 4 & 3 & 0 & 10 & 3 \\
\hline 6 & 159 & 1 & 3 & 4 & 3 & 1 & 20 & 3 \\
\hline 6 & 160 & 1 & 2 & 5 & 3 & 0 & 25 & 5 \\
\hline 6 & 161 & 0 & 1 & 5 & 4 & & 13 & 5 \\
\hline 6 & 162 & 0 & & & & & 5 & 3 \\
\hline 6 & 163 & 0 & & & & & 5 & 3 \\
\hline 6 & 164 & 0 & & 3 & & & 5 & 0 \\
\hline 6 & 165 & 0 & & 3 & & & & 6 \\
\hline 6 & 166 & 0 & & 4 & & & 5 & 0 \\
\hline 6 & 167 & 0 & & 4 & & & 8 & 4 \\
\hline 6 & 168 & 0 & & 4 & & & 5 & 5 \\
\hline 6 & 169 & 0 & & 3 & & & 5 & 5 \\
\hline 6 & 170 & 0 & & 3 & & & 5 & 5 \\
\hline 6 & 171 & 0 & & 4 & & & 5 & 1 \\
\hline 6 & 172 & 1 & 3 & 8 & 1 & 0 & 18 & 1 \\
\hline 6 & 173 & 1 & 2 & 7 & 1 & 0 & 13 & 1 \\
\hline 6 & 174 & 0 & & 4 & 2 & & 5 & 2 \\
\hline 6 & 175 & 0 & & 3 & 2 & & 5 & 2 \\
\hline 6 & 176 & 0 & & 4 & 3 & & 8 & 3 \\
\hline 6 & 177 & 1 & 1 & 7 & 3 & 0 & 13 & 3 \\
\hline 6 & 178 & 0 & & 3 & 3 & & 5 & 4 \\
\hline 6 & 179 & 0 & & 3 & 3 & & 5 & 4 \\
\hline 6 & 180 & 0 & & 4 & & & 5 & 4 \\
\hline 6 & 181 & 0 & & 3 & & & 5 & 2 \\
\hline
\end{tabular}




\begin{tabular}{|c|c|c|c|c|c|c|c|c|}
\hline 1 & 1 & 0 & 2 & 5 & 3 & 0 & 8 & 3 \\
\hline 1 & 2 & 0 & & & & 0 & & 7 \\
\hline 1 & 3 & 0 & 2 & 5 & 3 & 0 & 5 & 3 \\
\hline 1 & 4 & 0 & 3 & 10 & 1 & 0 & 5 & 7 \\
\hline 1 & 5 & 1 & 4 & 5 & 1 & 0 & 13 & 1 \\
\hline 1 & 6 & 1 & 4 & 5 & 1 & 0 & 15 & 1 \\
\hline 1 & 7 & 0 & 2 & 10 & 0 & 0 & 5 & 0 \\
\hline 1 & 8 & 0 & 2 & 5 & 3 & 0 & 5 & 3 \\
\hline 1 & 9 & 0 & 1 & 5 & 5 & 0 & 3 & 5 \\
\hline 1 & 10 & 0 & 2 & 5 & 5 & 0 & 8 & 5 \\
\hline 1 & 11 & 0 & 4 & 5 & 0 & 0 & 5 & 0 \\
\hline 1 & 12 & 0 & 2 & 5 & 0 & 0 & 5 & 7 \\
\hline 1 & 13 & 0 & 2 & 5 & 0 & 0 & 5 & 7 \\
\hline 1 & 14 & 0 & 2 & 5 & 1 & 0 & 5 & 1 \\
\hline 1 & 15 & 1 & 4 & 5 & 3 & 1 & 10 & 3 \\
\hline 1 & 16 & 0 & 2 & 5 & 0 & 0 & 7 & 6 \\
\hline 1 & 17 & 0 & 4 & 5 & 5 & 0 & 13 & 5 \\
\hline 1 & 18 & 0 & 3 & 5 & 0 & 0 & 13 & 6 \\
\hline 1 & 19 & 0 & 2 & 5 & 0 & 0 & 5 & 0 \\
\hline 1 & 20 & 0 & 2 & 5 & 0 & 0 & 5 & 0 \\
\hline 1 & 21 & 0 & 2 & 5 & 2 & 0 & 5 & 2 \\
\hline 1 & 22 & 0 & 2 & 5 & 0 & 0 & 5 & 7 \\
\hline 1 & 23 & 0 & 2 & 5 & 0 & 0 & 15 & 7 \\
\hline 1 & 24 & 0 & 2 & 5 & 0 & 0 & 20 & 7 \\
\hline 1 & 25 & 0 & 4 & 5 & 3 & 0 & 10 & 3 \\
\hline 1 & 26 & 1 & 4 & 5 & 3 & 0 & 10 & 3 \\
\hline 1 & 27 & 1 & 4 & 5 & 3 & 0 & 15 & 3 \\
\hline 1 & 28 & 0 & 2 & 10 & 7 & 0 & 5 & 0 \\
\hline 1 & 29 & 0 & 2 & 5 & 0 & 0 & 8 & 7 \\
\hline 1 & 30 & 0 & 2 & 5 & 0 & 0 & 5 & 0 \\
\hline 1 & 31 & 0 & 2 & 5 & 0 & 0 & 5 & 0 \\
\hline
\end{tabular}


VITA

STEPHEN B. LEATHERMAN

2008

2009

2010

2010

2012

2013

2013

$2013-2016$

$2016-2018$
Eagle Scout, Boy Scouts of America

Cliff Stability Analysis in Peconic Bay on Long Island, NY for Belvedere Management Company, New York City

Forest Density Investigation in the Amazon River, Peru through New College of Florida

Hurricanes in Belize-- Implications for Aerial Distribution of Papaya Crops for Brooks Tropical, Homestead, Florida

Erosion Hotspot Identification Using Geographic Information Systems on the Outer Banks of North Carolina

B. S. Environmental Science, New College of Florida

Public Survey of Beachgoer's Knowledge of Rip Currents at Cooper's Beach for Eastern Long Island Coastal Conservation Alliance, Inc., Southampton, New York

Presidential Fellowship, Geosciences

Florida International University

Miami, Florida

Teaching Assistant

Florida International University

\section{PUBLICATIONS AND PRESENTATIONS}

Leatherman, S. B., Leatherman, S. P. and Haus, B. (2013). Bar Height and Rip Current Presence and Strength, Shore and Beach, V. 81:19-22.

Leatherman, S. B. (April, 2014). Rip Current Hazard on Florida and South Georgia Beaches. Paper presented to American Association of Geographers annual meeting, Tampa, Florida.

Leatherman, S. B. (July, 2014). Rip Current Activity in Florida. Paper presented at rip current workshop, Jaco Beach, Costa Rica. 
Leatherman, S. B. (2015). Rip Current Hazard on Florida and South Georgia Beaches. Shore and Beach V.83:63-66.

Leatherman, S. B. (2016). Rip Currents in South Florida: A Major Coastal Hazard and Management Challenge. Journal of Coastal Zone Management, V. 19:431, Doi:10.4172/2473-3350.1000431.

Leatherman, S. B. and Leatherman, S.P. (2017). Techniques for Rip Current Detection and Measurement. International Journal of Earth Science and Geophysics. 3:014.

Leatherman, S. B. (2017). Rip Flow Characteristics and Escape Strategies in South Florida. Shore and Beach. V. 85:30-34.

Leatherman, S. B. (2017). Rip Current Measurements at Three South Florida Beaches. Journal of Coastal Research. V. 33:1228-1234.

Leatherman, S. P. and Leatherman, S. B. (2017). Sea Level Change International Encyclopedia of Geography, People, the Earth, Environment and Technology, WileyBlackwell Publishers. p. 6084-6093.

Leatherman, S. B. (October, 2017). Rip Current Detection and Measurement in South Florida. Seminar Series, New College of Florida, Sarasota, FL.

Leatherman, S. B. (February, 2018). Rip Current Generation, Flow Characteristics, and Implications for Beach Safety in South Florida. Paper presented at Florida Society of Geographers annual meeting, Melbourne, Florida.

Leatherman, S. B. (December, 2018). Rip Current Measurement Techniques and Recent Results in South Florida. Abstract accepted, American Geophysical Union fall meeting, Washington, D. C. 